\title{
Effects of the Janani Suraksha Yojana on maternal and newborn care practices: Women's experiences in Rajasthan
}

\author{
K.G. Santhya \\ Population Council \\ Shireen J. Jejeebhoy \\ Population Council \\ Rajib Acharya \\ Population Council \\ A.J. Francis Zavier \\ Population Council
}

Follow this and additional works at: https://knowledgecommons.popcouncil.org/departments_sbsr-pgy

Part of the International Public Health Commons, Maternal and Child Health Commons, Social and Behavioral Sciences Commons, and the Women's Health Commons How does access to this work benefit you? Let us know!

\section{Recommended Citation}

Santhya, K.G., Shireen J. Jejeebhoy, Rajib Acharya, and A.J. Francis Zavier. 2011. "Effects of the Janani Suraksha Yojana on maternal and newborn care practices: Women's experiences in Rajasthan." New Delhi: Population Council. 


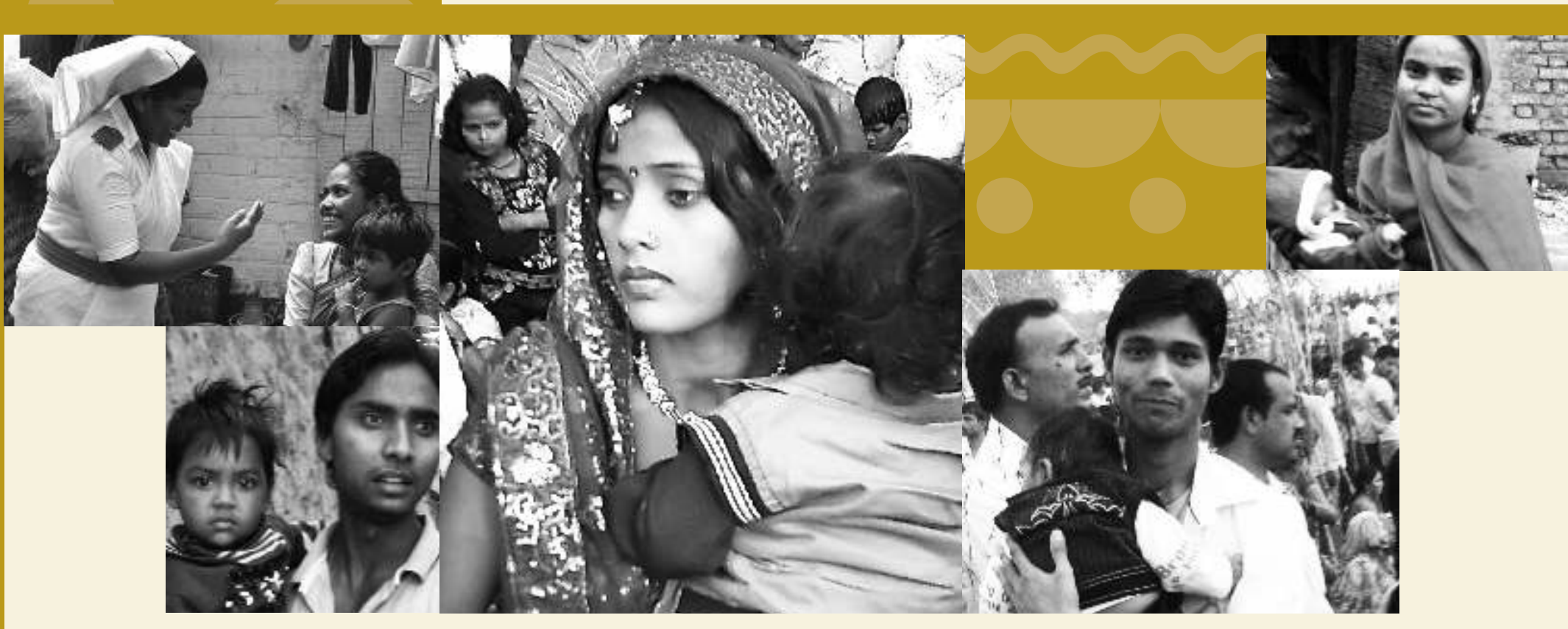

Effects of the Janani Suraksha Yojana on maternal and newborn care practices: Women's experiences in Rajasthan 
This report is the result of a large-scale evaluation of the Janani Suraksha Yojana in rural and urban settings of the north-western state of Rajasthan, India. The study explored recently delivered women's awareness and perceptions of the JSY, the reach of the scheme among the most vulnerable women, and the effects of the scheme on the utilisation of maternal health services, the adoption of best practices in newborn care and the quality of maternal health services.

For additional copies of this report, please contact:

Population Council

Zone 5-A, Ground Floor

India Habitat Centre

Lodi Road

New Delhi -110003

Phone: 011-2464 2901/02

Email: info-india@popcouncil.org

Web site: http://www.popcouncil.org/asia/india/html

The Population Council is an international, non-profit, non-governmental organisation that seeks to improve the well-being and reproductive health of current and future generations around the world and to help achieve a humane, equitable and sustainable balance between people and resources. The Council conducts biomedical, social science and public health research, and helps build research capacities in developing countries.

Copyright (C) 2011 Population Council

Suggested citation: Santhya, K. G., S. J. Jejeebhoy, R. Acharya and A. J. Francis Zavier. 2011. Effects of the Janani Suraksha Yojana on maternal and newborn care practices: Women's experiences in Rajasthan. New Delhi: Population Council. 


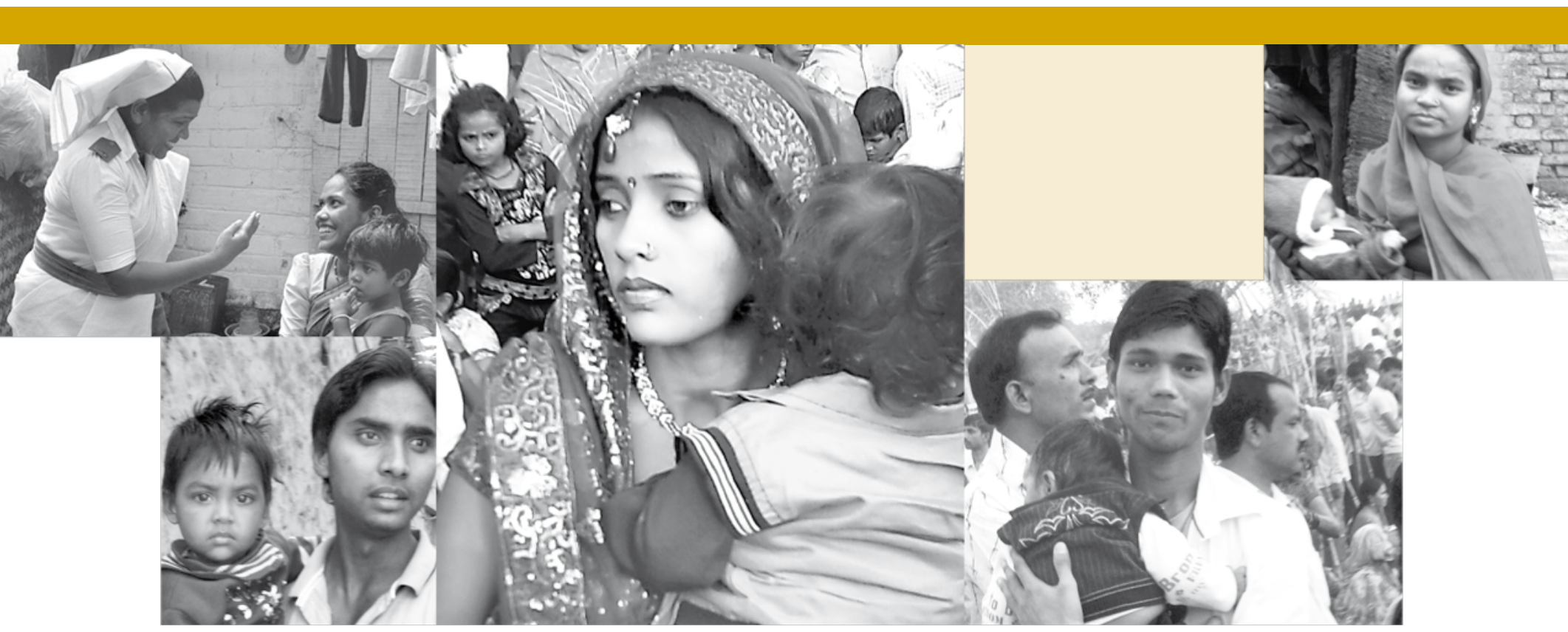

\section{Effects of the Janani Suraksha Yojana on maternal and newborn care practices: Women's experiences in Rajasthan}

K.G. Santhya

Shireen J. Jejeebhoy

Rajib Acharya

A.J. Francis Zavier 



\section{Contents}

Acknowledgements

ix

Executive summary

Recommendations $\quad$ xvi

$\begin{array}{ll}\text { Chapter 1: Introduction } & 1\end{array}$

Background 1

$\begin{array}{ll}\text { Study objectives } & 4\end{array}$

Study setting $\quad 4$

$\begin{array}{ll}\text { Study design } & 6\end{array}$

$\begin{array}{ll}\text { Analytic approaches } & 7\end{array}$

Characteristics of respondents' households 10

Characteristics of respondents $\quad 12$

Structure of the report $\quad 13$

Chapter 2: Awareness of the Janani Suraksha Yojana 14

Awareness of the JSY $\quad 14$

Awareness of the ASHA and her responsibilities 18

Awareness of schemes other than the JSY 20

$\begin{array}{ll}\text { Summary } & 21\end{array}$

Chapter 3: Women's experiences in accessing JSY benefits and their perceptions about the JSY 22

Reach of the JSY $\quad 22$

Experiences of accessing JSY cash assistance $\quad 25$

Reasons for not availing of JSY cash assistance 28

$\begin{array}{ll}\text { Support received from the ASHA } & 31\end{array}$

Reach of schemes other than the JSY

Perceptions about the JSY $\quad 35$

$\begin{array}{ll}\text { Summary } & 37\end{array}$

Chapter 4: Association between JSY beneficiary status and awareness of maternal and $\begin{array}{ll}\text { child health care practices } & 38\end{array}$

Association between JSY beneficiary status and awareness of antenatal care practices 38

Association between JSY beneficiary status and awareness of key elements of birth preparedness $\quad 40$ 
Association between JSY beneficiary status and awareness of postpartum care practices 40

Association between JSY beneficiary status and awareness of newborn care practices 42

Awareness of best practices in immediate newborn care $\quad 42$

Awareness of best practices in breastfeeding 43

Awareness of the immunisation schedule for infants 44

Association between JSY beneficiary status and awareness of maternal and newborn complications 45

$\begin{array}{lr}\text { Summary } & 48\end{array}$

\section{Chapter 5: Effects of the JSY on the utilisation of maternal health services and adoption of} best practices in newborn care

$\begin{array}{ll}\text { Utilisation of antenatal care services } & 50\end{array}$

Association between JSY beneficiary status and utilisation of antenatal care services $\quad 50$

Effect of the JSY on the utilisation of antenatal care services $\quad 51$

Utilisation of delivery care services

Association between JSY beneficiary status and utilisation of delivery care services $\quad 54$

Effect of the JSY on the utilisation of delivery care services

Utilisation of postpartum care services $\quad 56$

Association between JSY beneficiary status and utilisation of postpartum care services $\quad 57$

Effect of the JSY on the utilisation of postpartum care services $\quad 58$

Adoption of best practices in newborn care $\quad 58$

Adoption of best practices in immediate care of the newborn $\quad 58$

Association between JSY beneficiary status and the adoption of best practices in $\begin{array}{ll}\text { immediate newborn care } & 58\end{array}$

Effect of the JSY on the adoption of best practices in immediate newborn care $\quad 61$

$\begin{array}{ll}\text { Breastfeeding practices } & 63\end{array}$

Association between JSY beneficiary status and adoption of best practices in breastfeeding 63

Effect of the JSY on adoption of best practices in breastfeeding 66

$\begin{array}{ll}\text { Immunisation of infants } & 67\end{array}$

Association between JSY beneficiary status and full immunisation of infants $\quad 67$

$\begin{array}{ll}\text { Effect of the JSY on full immunisation of infants } & 67\end{array}$

$\begin{array}{ll}\text { Summary } & 68\end{array}$

$\begin{array}{ll}\text { Chapter 6: Effect of the JSY on the quality of maternal health services } & 70\end{array}$

Effect of the JSY on the quality of antenatal care services $\quad 70$

Effect of the JSY on the quality of delivery care services $\quad 74$

Effects of the JSY on healthy and harmful practices followed during labour and delivery $\quad 74$

Effect of the JSY on access to client-friendly facilities $\quad 76$

Effect of the JSY on the quality of postpartum care services

$\begin{array}{ll}\text { Summary } & 79\end{array}$ 
Chapter 7: Associations between JSY beneficiary status and women's experiences of maternal and newborn complications

Associations between JSY beneficiary status and women's experiences of pregnancy-related complications

Associations between JSY beneficiary status and women's experiences of complications in the newborn

Summary

Chapter 8: Summary and recommendations

Recommendations

Annexure 1: Summary of sample size and analytic approaches used in the study

Annexure 2: Percentage distribution of the matched sample of JSY beneficiaries and non-beneficiaries by selected background characteristics

Annexure 3: Calculation of the wealth index 


\section{List of tables}

Table 1.1 Profile of the study districts and Rajasthan state 5

$\begin{array}{lll}\text { Table } 1.2 & \text { Coverage of the study } & 7\end{array}$

Table 1.3 Selected characteristics of respondents' households, according to residence 11

Table $1.4 \quad$ Selected socio-demographic characteristics and reproductive experiences of $\begin{array}{ll}\text { respondents, according to residence } & 12\end{array}$

Table 2.1 Percentage of women reporting awareness of the JSY, according to residence 15

Table 2.2 Percentage of women reporting correct awareness of eligibility conditions for availing of the JSY, according to residence 16

Table 2.3 Percentage of women reporting awareness of the ASHA and her responsibilities, $\begin{array}{ll}\text { according to residence } & 19\end{array}$

Table 3.1 Percentage of women who received JSY benefits by selected background $\begin{array}{ll}\text { characteristics, according to residence } & 23\end{array}$

Table 3.2 Percentage of women who received JSY benefits by their experiences of accessing cash $\begin{array}{ll}\text { assistance, according to residence } & 26\end{array}$

Table 3.3 Percentage of women by reasons for not availing of JSY cash assistance, according to residence

Table 3.4 Percentage of women by type of assistance received from the ASHA during pregnancy, delivery and the postpartum period, according to residence

Table 3.5 Of those not escorted by an ASHA to a health facility for delivery, percentage of women who had approached the ASHA to escort them, and of those who had not approached the ASHA, percentage reporting reasons for not doing so, according to residence

Table 4.1 Percentage of women reporting awareness of key elements of birth preparedness by JSY beneficiary status, according to residence

Table 4.2 Percentage of women reporting awareness of the immunisation schedule for infants by JSY beneficiary status, according to residence

Table 4.3 Percentage of women reporting awareness of maternal and newborn complications by JSY beneficiary status, according to residence

Table 5.1a Association between JSY beneficiary status and utilisation of antenatal care services by women, according to residence: logistic regression results

Table 5.1b Effect of the JSY on the utilisation of antenatal care services: panel comparison of women's experiences before and after introduction of the JSY, according to residence

Table 5.2 Effect of the JSY on the utilisation of delivery care services: panel comparison of women's experiences before and after introduction of the JSY, according to residence

Table 5.3a Association between JSY beneficiary status and utilisation of postpartum care services by women according to residence: logistic regression results 
Table 5.3b Effect of the JSY on women's utilisation of postpartum care services: panel comparison of women's experiences before and after introduction of the JSY, according to residence

Table 5.4a Association between JSY beneficiary status and the adoption of best practices in immediate newborn care: cross-sectional comparison of women's experiences during the most recent birth, according to residence

Table 5.4b Effect of the JSY on the adoption of best practices in immediate newborn care: panel comparison of women's experiences before and after introduction of the JSY, according to residence

Table 5.5a Association between JSY beneficiary status and adoption of best practices in breastfeeding: cross-sectional comparison of women's experiences during the most recent birth, according to residence

Table 5.5b Effect of the JSY on adoption of best practices in breastfeeding: panel comparison of women's experiences before and after introduction of the JSY, according to residence

Table 5.6 Effect of the JSY on full immunisation of infants : panel comparison of women's experiences before and after introduction of the JSY, according to residence

Table 6.1 Effect of the JSY on the quality of antenatal care services: panel comparison of women's experiences before and after introduction of the JSY, according to residence

Table 6.2 Effects of the JSY on healthy and harmful practices followed during labour and delivery: panel comparison of women's experiences before and after introduction of the JSY

Table 6.3 Effect of the JSY on access to client-friendly facilities: panel comparison of women's experiences before and after introduction of the JSY

Table 6.4 Effect of the JSY on the quality of postpartum care services: panel comparison of women's experiences before and after introduction of the JSY

Table 7.1 Associations between JSY beneficiary status and pregnancy-related complications: cross-sectional comparison of women's experiences during the most recent birth, according to residence

Table 7.2 Associations between JSY beneficiary status and complications in the newborn: cross-sectional comparison of women's experiences during the most recent birth, according to residence 


\section{List of figures}

Figure 2.1 Awareness of schemes other than the JSY among women, according to residence

Figure 3.1 Major reasons given by women for not availing of JSY cash assistance, according to residence

Figure 3.2 Reach of schemes other than the JSY: percentage of women who had availed of the schemes, according to residence

Figure 3.3a Women's perceptions about whether JSY has improved maternal and child health services, according to residence

Figure 3.3b Women's views about recommending the JSY to other women, according to residence

Figure 4.1 Association between JSY beneficiary status and awareness of antenatal care practices, according to residence

Figure 4.2 Association between JSY beneficiary status and awareness of postpartum care practices, according to residence

Figure 4.3 Association between JSY beneficiary status and awareness of best practices in immediate newborn care, according to residence

Figure 4.4 Association between JSY beneficiary status and awareness of best practices in breastfeeding, according to residence

Figure 5.1 Association between JSY beneficiary status and utilisation of antenatal care services: cross-sectional comparison of women's experiences during the most recent birth, according to residence

Figure 5.2 Trends in institutional delivery by type of health facility, 2004-2009

Figure 5.3 Association between JSY beneficiary status and utilisation of delivery care services: cross-sectional comparison of women's experiences during the most recent birth, according to residence

Figure 5.4 Association between JSY beneficiary status and utilisation of postpartum care services: cross-sectional comparison of women's experiences during the most recent birth, according to residence

Figure 5.5 Association between JSY beneficiary status and full immunization of infants: cross-sectional comparison of women's experiences during the most recent birth, according to residence 


\section{Acknowledgements}

This study has benefited immeasurably from the input of many. We are extremely grateful to the John D. and Catherine T. MacArthur Foundation for their support, which made this study possible.

The Department of Health and Family Welfare, Rajasthan granted permission to conduct the study and offered their unstinting support at all stages of the project and we take this opportunity to express our gratitude for their support and guidance to Meghraj Meena, Former District Reproductive and Child Health Officer, Alwar; Nanda Charan, Reproductive and Child Health Officer, Jodhpur; Subodh Agarwal and Ramesh Mathur, Former Chief Medical and Health Officers, Alwar and Jodhpur districts respectively; and Mohit Sharma, Former District Programme Manager, Jodhpur. Our thanks also go to the grass-root level workers of the department who generously supported the field team in data collection. The State Census Office in Rajasthan provided the project with census enumeration block maps and their support is gratefully acknowledged.

The Technical Advisory Group—Dinesh Agarwal, Kiran Ambwani, Dipa Nag Chowdhury, Aparajita Gogoi, Poonam Muttreja, Saroj Pachauri, Amit Mohan Prasad and Rajni Ved—provided invaluable advice in developing the study instruments, project design, and interpreting the findings.

We acknowledge with gratitude the contribution of Dinesh Agarwal, Lalit Dandona, Aparajita Gogoi and Anrudh Jain for reviewing an earlier draft of this report and providing insightful comments and suggestions.

We would like to gratefully acknowledge support received from Shveta Kalyanwala for developing the study instruments and training the field team, (Late) Rajesh Kumar for translating the instruments and Jyoti Moodbidri for her editorial contribution. The contributions of Komal Saxena in coding the qualitative transcripts, preparing the report and ably coordinating the printing of the report, Shilpi Rampal for preparing and testing the data entry programme in CSPro Software, M.A. Jose for ably managing the administrative aspects of this project, and B. Srihari for the overall management of the field work are much appreciated.

Finally, and most importantly, we would like to thank the women of Alwar and Jodhpur districts, Rajasthan who generously gave us their time and shared their views and experiences, and the investigators and other members of the field team who painstakingly collected the qualitative and survey data. 



\section{Executive summary}

The Janani Suraksha Yojana (JSY), launched in April 2005, is an ambitious scheme intended to encourage institutional delivery, and provide access to care during pregnancy and in the postpartum period, and thereby reduce maternal and infant mortality (Ministry of Health and Family Welfare, 2006). Evaluations of the JSY indicate that it has succeeded in increasing the use of antenatal care services and institutional deliveries, and reducing perinatal and neonatal deaths (Lim et al., 2010; UNFPA, 2009). However, information tends to be limited on the reach of the scheme to the most vulnerable and the extent to which the quality of maternal and newborn care services has improved or been compromised with the introduction of the scheme. To begin to fill this gap, the Population Council undertook a large-scale evaluation study of the JSY in rural and urban settings of the north-western state of Rajasthan, India.

A cross-sectional study, comprising a survey and in-depth interviews, was conducted between September 2009 and February 2010 in two districts of Rajasthan, namely, Alwar and Jodhpur. Respondents for the survey included women less than 35 years of age who had delivered in the one year preceding the interview. A total of 4,770 women were successfully interviewed. Respondents for in-depth interviews were selected from among survey respondents who fell into the following four categories: (a) women who had benefited from the JSY and were satisfied with the scheme, (b) women who had benefited from the JSY, but were not satisfied with the scheme, (c) women who had delivered at home and not received JSY benefits, and (d) women who had delivered in a health facility and not received JSY benefits. A total of 48 women were interviewed in-depth.

\section{Awareness of the JSY, although universal, remains superficial}

Findings highlight that awareness of the JSY is almost universal. Family members, friends and neighbours were the leading sources of information on the JSY, regardless of the place of residence. Although almost all women were aware of the JSY, fewer were correctly informed about the conditions for benefiting from the scheme, including the type of facility where they could deliver in order to qualify for JSY benefits, or about its entitlements such as a specified amount of cash and the assistance of Accredited Social Health Activists (ASHAs). For example, not a single woman was aware that a woman delivering at home is eligible for JSY benefits if she is aged 19 and above, belongs to a household registered as Below the Poverty Line (BPL) household and is having her first or second delivery. Moreover, just two-thirds of urban women and one-third of rural women knew that they were entitled to receive Rs. 1,000 and Rs. 1,400, respectively, and less than 1 percent knew that they were entitled to receive support from ASHAs during pregnancy, delivery and the postpartum period. 


\section{Awareness of the ASHA and schemes other than the JSY intended to promote safe motherhood, remains limited}

Awareness of the ASHA was also limited; fewer than one-half of women had heard of the ASHA. Among those who reported awareness, the most commonly known responsibilities of the ASHA included facilitating three antenatal check-ups, counselling about institutional delivery and escorting women to a health facility for delivery.

Awareness of schemes other than the JSY intended to promote safe motherhood such as the 108 ambulance service and the special nutritional supplementation scheme was also limited; fewer than one-half of women were aware of the ambulance service, and just one-quarter were aware of the special nutritional supplementation scheme.

\section{The reach of the JSY remains limited and inequitable}

Although all women in the state were eligible, fewer than half had benefited from the JSY. Findings, moreover, suggest that the reach of the JSY remains inequitable; the most vulnerable women were less likely than others to have availed of the JSY. Thus, women living in rural areas; those at high risk of maternal complications, that is, very young mothers or high-parity mothers; and those belonging to socially and economically excluded groups, for example, Muslim women, illiterate women and poor women, were less likely than others to have benefited from the scheme.

Findings, moreover, indicate that most of the women who had received cash assistance had obtained the full amount. Almost one-half of beneficiaries had received the cash amount within a week of delivery, although one in seven had not received it until between one and three months of delivery. Further, for the majority of beneficiaries, the amount received was as much as or more than the expenses incurred during delivery. Fewer than one-tenth of women also reported paying a bribe or making an unauthorised payment to the ASHA or a health care provider in order to get their monetary entitlement.

Women who had not availed of the JSY cash assistance mentioned primarily such reasons as perceived poor quality of delivery services at public sector health facilities, the preference of women themselves or their family members for a home delivery, constraints faced at the family level to go to a health facility for delivery, lack of awareness of the scheme or of the importance of institutional deliveries and concerns about the administration of the scheme.

The reach of the ASHA and schemes other than the JSY, intended to promote safe motherhood, is even more limited

Few women obtained non-monetary entitlements; for example, support from ASHAs or benefits of other schemes such as the 108 ambulance service and special nutritional supplementation scheme. Just one-quarter of all women had received assistance from the ASHA during pregnancy and even fewer, during delivery and the postpartum period. Likewise, just 5 percent of women had used the 108 ambulance service to go to a health facility for delivery, and hardly any had received a voucher for special nutritional supplements in the form of five kilograms of ghee. 


\section{Awareness of best practices in maternal and newborn care is greater among JSY beneficiaries than non-beneficiaries}

Findings underscore that JSY beneficiaries were better informed than non-beneficiaries about best practices related to the care of women during pregnancy, delivery and the postpartum period, as also to newborn care. For example, beneficiaries were more likely to report comprehensive awareness of antenatal care practices, awareness of at least one essential preparation to be made for a safe delivery and awareness of the importance of regular postpartum check-ups. They were also more likely to display comprehensive awareness of best practices related to the immediate care of the newborn, and awareness of best practices in breastfeeding and the immunisation schedule for infants. Compared to non-beneficiaries, they were, moreover, better informed about the complications of pregnancy, delivery and the postpartum period. However, no differences were observed in their awareness of selected complications in the newborn.

Findings also highlight rural-urban differentials in the association between JSY beneficiary status and women's awareness of maternal and child health care practices. Rural beneficiaries scored better than nonbeneficiaries on almost all indicators of awareness; however, in urban areas, notable differences were observed with respect to just two indicators, namely, comprehensive awareness of breastfeeding practices and awareness of the immunisation schedule. These findings likely reflect the differential access to information that women in rural and urban areas have, with urban women having greater access to a wide array of sources of information than rural women, thus limiting the effect of the JSY on improving women's awareness of maternal and newborn care practices in urban areas.

\section{Awareness of best practices in maternal and newborn care among women, in general, remains poor}

Although the JSY has contributed to improving women's awareness of best practices in maternal and newborn care, we note that levels of awareness remain low. For example, of the JSY beneficiaries, just 30 percent reported comprehensive awareness of antenatal care practices (that is, awareness of the importance of having regular check-ups, three or more check-ups and the first check-up in the first trimester), 40 percent knew about birth preparedness and 35 percent knew about the importance of routine postpartum check-ups. Awareness of best practices in newborn care, likewise, remains limited even among JSY beneficiaries. For example, just 16 percent of the beneficiaries had comprehensive awareness of best practices in immediate newborn care (that is, awareness of the importance of wiping dry and wrapping and not bathing the newborn immediately after birth and not applying any substance on the cord stump) and just 25 percent had comprehensive awareness of best practices in breastfeeding of the newborn (that is, awareness of the importance of immediate breastfeeding, feeding colostrum and exclusive breastfeeding for six months).

\section{Utilisation of maternal health services and adoption of best practices in newborn care have increased with the introduction of the JSY, especially in rural areas}

Findings underscore the contribution of the JSY to increasing the utilisation of maternal health services and the adoption of best practices in newborn care, especially in rural areas. 
In the area of antenatal care services, the JSY has promoted such practices as getting three or more antenatal check-ups and iron and folic acid supplements, as confirmed by the positive net association observed in both cross-sectional and panel analyses. With regard to getting an antenatal check-up in the first trimester, findings were mixed: although a positive association was observed in the cross-sectional analysis, no significant net effect was observed when we compared women's experiences before and after the inception of the JSY. Hence, it is difficult to say convincingly that the JSY has contributed to enabling women to receive an early antenatal check-up.

As far as delivery care services are concerned, the JSY has, without doubt enhanced institutional deliveries and skilled attendance at birth.

Likewise, the JSY has contributed to increasing the utilisation of postpartum care services by women, particularly in terms of receiving a check-up from health care personnel immediately after delivery, as confirmed by the positive net association observed in both cross-sectional and panel analyses. Findings also indicate a positive association between JSY experience and the acceptance of postpartum contraception.

Significant improvements in the adoption of best practices in newborn care were also evident. Among women who had given birth both prior to the introduction of the JSY and in the recent past, JSY beneficiaries were significantly more likely than non-beneficiaries to have received comprehensive care for their newborn and to have followed best practices in immediate breastfeeding of their newborn (that is, not feeding prelacteals, breastfeeding within an hour of delivery and feeding colostrum), as confirmed by the positive net association observed in cross-sectional and panel analyses. However, findings were mixed with regard to exclusive breastfeeding and full immunisation of infants; thus, although a positive net association between JSY experience and exclusive breastfeeding and full immunisation of infants was evident in cross-sectional analyses, no significant net effect was observed when we compared women's experiences before and after the introduction of the JSY. Hence, it is difficult to say convincingly that the JSY has contributed to promoting these practices. These findings suggest that the JSY may not be effective in influencing behaviours that require sustained efforts over long periods of time such as those involving prolonged breastfeeding and complying with the full immunisation schedule.

Findings, moreover, indicate a differential impact of the JSY programme in rural and urban areas. The JSY had a far more significant and consistent positive effect on the utilisation of maternal health services and adoption of best practices in newborn care by rural than urban women. It has enabled rural women to obtain three or more antenatal check-ups, iron and folic acid supplements, an institutional delivery, skilled attendance at birth and postpartum check-ups from health care personnel immediately after delivery besides encouraging them to obtain comprehensive immediate care for their newborn, to follow best practices in immediate breastfeeding of their newborn and exclusive breastfeeding of the infant for six months. In contrast, in urban areas, the contribution of the JSY was far more limited in that it enabled women to obtain an institutional delivery, skilled attendance at birth, and a postpartum check-up from health care personnel immediately after delivery. These urban-rural differences may reflect the differential access of rural and urban women to maternal and newborn health services, with urban women having greater access to a wide array of services than rural women, thus limiting the effects of the JSY on increasing women's utilisation of maternal health services and the adoption of best practices in newborn care. 


\section{Low utilisation of maternal health services and limited adoption of best practices in newborn care, in general, remain a major concern}

Notwithstanding the fact that the JSY has led to an increase in the utilisation of maternal health services and adoption of best practices in newborn care, the levels remain far from satisfactory. For example, only 59 percent of JSY beneficiaries had their first antenatal check-up in the first trimester and 79 percent had three or more antenatal check-ups. Moreover, despite having delivered in a health facility, only 80 percent of beneficiary women had received a postpartum check-up within two days of delivery and only 20 percent had adopted postpartum contraception. The adoption of best practices in newborn care, similarly, remains limited even among beneficiaries. For example, only 29 percent had breastfed their newborn within an hour of delivery, 78 percent had fed colostrum and 56 percent reported that they did not give any prelacteal feeds to the newborn.

\section{The quality of maternal health services, by and large, remains unchanged and poor}

Findings present a mixed picture with respect to the effect of the JSY on the quality of maternal health services received by women during pregnancy, delivery and the postpartum period. With regard to antenatal services, subsequent to the introduction of the JSY, improvements were observed in the percentages of women who received information related to pregnancy-related complications and four or more services during antenatal visits. No change was observed in the other indicators such as percentages of women who received information on birth preparedness, the importance of postpartum check-ups, newborn care or complications. Likewise, the nature of the health care provider's interactions with women-percentages of women reporting that the provider had asked them during routine check-ups whether they had experienced any complications, and reminded them about follow-up visits—remained unchanged.

Findings were mixed with regard to the effect of the JSY on the quality of delivery services as well. A positive net effect was apparent in terms of such practices as discharging women from the facility at least 24 hours following delivery and allowing an escort to stay with the woman during delivery. However, no change was observed in several other indicators, including the extent to which the recommended examinations were conducted by the service provider when women were admitted for delivery, active management of the third stage of labour, non-use of harmful delivery practices, women's easy access to health care providers and the providers' behaviour toward women delivering at the health facility, availability of supplies at the facility, and women's access to a respectful and clean health facility. Finally, no change was evident in the quality of postpartum services received by women subsequent to the introduction of the JSY.

Above all, findings underscore that the quality of services received by women during pregnancy, delivery and the postpartum period remains unacceptably poor. For example even among JSY beneficiaries, few women had received, in the course of antenatal services, comprehensive information about complications that may occur during pregnancy as well as about birth preparedness. Despite clear guidelines for pregnancy care and management of common obstetric complications by medical officers and auxiliary-nurse-midwives (ANMs) (Ministry of Health and Family Welfare, 2005), our study shows that evidence-based best practices in labour and delivery were rarely followed in the study settings. Such harmful practices as applying strong fundal 
pressure before delivery and the use of injections (most likely, oxytocin) to speed up delivery continue to characterise delivery care at the facility level. Limited access to medicines and other supplies as well as to a respectful and clean facility for delivery remain other major concerns.

\section{Maternal and newborn complications are slightly lower among JSY beneficiaries than non- beneficiaries, especially in rural areas}

Findings show some differences between JSY beneficiaries and non-beneficiaries in terms of experiences of maternal and newborn complications and treatment-seeking patterns, particularly in rural areas. Beneficiaries were less likely than non-beneficiaries to report that they had experienced one or more complications during pregnancy and that their newborn had experienced one or more complications. They were, moreover, more likely to have sought treatment for pregnancy-related complications. Differences were insignificant in terms of complications experienced during labour and delivery, and the postpartum period.

\section{Recommendations}

The findings of our study reiterate the need for programmatic attention to ensure the reach of the JSY to the most vulnerable and to improve the quality of maternal and newborn health services. They suggest a number of priority areas for action.

Strengthen efforts to better inform women, their family and the community, in general, about the JSY and other schemes intended to promote safe motherhood

Findings that women's awareness of the JSY, although universal, remains superficial, and their awareness of the ASHA and other schemes for promoting safe motherhood remains limited, call for programmes to better inform women, their family and the community, in general, about the salient features of these schemes. Given that family members and members of the social network were the major sources of information, communitylevel campaigns highlighting women's entitlements under these schemes need to be initiated. At the same time, ASHAs and other health care providers entrusted with the responsibility of enabling women to take advantage of these schemes need to be oriented about the importance of imparting detailed information about these schemes to women and their family members.

\section{Address the barriers faced by the most vulnerable in benefiting from the JSY}

Findings that the most vulnerable women-socio-economically as well as in terms of being at risk of experiencing maternal complications - were less likely than others to have availed of the JSY emphasise the need for targeted efforts to address the concerns that these groups have in accessing the scheme. As evident from the findings, moreover, programmes are needed that address women's concerns about the poor quality of services, their lack of awareness about their entitlements, their apprehensions about the administration of the JSY, and their cultural preferences and constraints. 


\section{Make efforts to improve the administration of the JSY and other safe motherhood schemes}

Although the majority of women who had availed of JSY benefits were satisfied with the scheme, some concerns remain. For example, one in seven beneficiary women did not receive the cash benefit until between one and three months of delivery and one in seven women had to pay a bribe or make an unauthorised payment to obtain it. Likewise, just one-quarter or fewer women had been assisted by ASHAs during pregnancy, delivery and the postpartum period. Clearly, efforts to improve the administration of the JSY and other safe motherhood schemes are needed.

\section{Address barriers, including lack of in-depth awareness among women, to adopting best practices in maternal and newborn care}

Findings that the utilisation of maternal health services and the adoption of best practices in newborn care by women, in general, are far from satisfactory emphasise the need for efforts to better understand the barriers, other than systemic issues, that women and their family experience, and to devise innovative approaches that enable them to overcome these barriers. Findings indicate that limited awareness of best practices in maternal and newborn care in the study settings is a key barrier. Programmes are needed that raise awareness among women and their family members about the importance of ensuring comprehensive care during pregnancy, making delivery-related preparations, ensuring appropriate care during the postpartum period and adopting best practices in newborn care. These efforts must also raise women's awareness of the danger signs that may occur during pregnancy, delivery and the postpartum period and appropriate facilities where treatment can be sought. Other barriers are less well-studied and need to be better understood, for example, family and community attitudes to adopting new behaviours, women's ability to override the perceptions of other family members in order to adopt best practices, and lack of involvement of men in the health care of their spouse and newborn.

\section{Improve the quality of services}

Findings underscore that perceived poor quality of services in public sector health facilities has deterred many women from accepting the benefits offered by the JSY. Findings, moreover, indicate that those who had availed of maternal health services continue to receive poor quality care, notwithstanding the fact that the introduction of the JSY has not compromised the quality of care. From the perspectives of increasing the uptake of government schemes intended to improve maternal and child health by women, and of making motherhood safe for them, efforts are needed to improve the quality of maternal and newborn health services. Further, actions are needed that enable health care providers to render maternal health care services in friendly and non-threatening ways. Actions are also needed to mobilise communities to undertake social auditing to improve the quality of services provided, and to create among women and their family members a sense of entitlement to health care and other services.

In conclusion, while the JSY has contributed significantly to increasing the utilisation of maternal health services and the adoption of best practices in newborn care, efforts are needed now to improve the quality of care and access to maternal and newborn health care services for the most vulnerable groups of women, concerns that require programmatic attention as the demand for services is enhanced. 



\section{CHAPTER 1}

\section{Introduction}

The Janani Suraksha Yojana (JSY), launched in April 2005, is an ambitious scheme intended to encourage institutional delivery, and provide access to care during pregnancy and in the postpartum period, and thereby reduce maternal and infant mortality (Ministry of Health and Family Welfare, 2006). Official statistics show a phenomenal increase in the number of JSY beneficiaries -0.7 million in 2005-06 to 10.2 million in 2009-10; as of September 2010, a total of 35 million women have benefited from the scheme (Ministry of Health and Family Welfare, 2010). Moreover, recent evaluations suggest that it has indeed succeeded in increasing institutional deliveries and the use of antenatal care (ANC) services (Lim et al., 2010; UNFPA, 2009). Although there have been several evaluations of the JSY, information tends to be limited on the reach of the scheme to the most vulnerable and the extent to which the quality of maternal and newborn care services has improved or been compromised with the introduction of the scheme. To begin to fill this gap, the Population Council undertook a largescale evaluation study of the JSY in rural and urban settings of the north-western state of Rajasthan, India.

This report presents findings from a survey of and in-depth interviews with women who had delivered in the one year preceding the interview.

\section{Background}

Although the maternal mortality ratio in India has declined, levels remain high; for example, it has declined from 301 per 100,000 births in 2001-2003 to 212 per 100,000 births in 2007-2009 (Office of the Registrar General, India, 2011). Similarly, while proportions of women reporting institutional deliveries or skilled attendance at birth have increased, the pace of increase has remained modest; for example, the percentage of women delivering in a health institution has increased from 34 in 1998-99 to 41 in 2005-06 (International Institute for Population Sciences and Macro International, 2007). In acknowledgement of this disturbing situation, the past decade has been witness to a number of initiatives for improving maternal and child health care. Several existing schemes have been revamped and new schemes initiated to encourage the utilisation of health services during pregnancy, delivery and the postpartum period. The National Rural Health Mission (NRHM), launched in 2005, marked a clear commitment to improving maternal, newborn and child health. Indeed, its goals are to reduce the maternal mortality ratio to 100 per 100,000 births and infant mortality to 30 per 1,000 live births, so as to attain universal access to women's health services, and achieve population stabilisation, gender and demographic balance (Ministry of Health and Family Welfare, 2005). Of particular note is the introduction of the JSY and the ASHA scheme under the NRHM.

The JSY is currently implemented in all states and union territories of India with a special focus on low-performing states (Ministry of Health and Family Welfare, 2006). ${ }^{1}$ Different criteria for

\footnotetext{
${ }^{1}$ Uttar Pradesh, Uttaranchal, Bihar, Jharkhand, Madhya Pradesh, Chhattisgarh, Assam, Rajasthan, Orissa, and Jammu and Kashmir; remaining states are categorised as high-performing states.
} 
eligibility have been applied for low- and high-performing states since October 2006. Under the scheme, in low-performing states, all pregnant women, irrespective of parity and economic status, who undergo institutional delivery, that is, deliver in a government health facility or an accredited private facility in rural areas are given Rs. 1,400, and in urban areas, Rs. 1,000. Additionally, ASHAs who assist pregnant women in rural and urban areas to access maternal health services are provided an incentive amount of Rs. 600 and Rs. 200, respectively. In high-performing states, ${ }^{1}$ in contrast, the scheme is restricted to women having their first or second delivery, women aged 19 and older, and women belonging to a BLP household. In both lowand high-performing states, poor pregnant women, aged 19 years and above who prefer to deliver at home are entitled to receive a cash assistance of Rs. 500 per delivery for up to two live births. Under the scheme, ASHAs serve as the link between the Government and pregnant women. They are entrusted with such responsibilities as: (a) identifying pregnant women and facilitating their registration for ANC; (b) ensuring that pregnant women receive at least three antenatal check-ups, including tetanus toxoid (TT) injections and iron and folic acid (IFA) tablets; (c) identifying a functional government health facility or an accredited private health facility for referral and delivery; (d) counselling pregnant women to undergo an institutional delivery; (e) arranging transport for pregnant women to reach the health facility for delivery or treatment of complications; (f) escorting pregnant women to a pre-determined health facility and staying with them till they are discharged; ( $g$ ) counselling women about breastfeeding the newborn within one hour of delivery and its continuation till the infant is 3-6 months of age; (h) arranging immunisation of the newborn till the age of 14 weeks; (i) making a postpartum visit within seven days of delivery to track the mother's health after delivery and facilitate obtaining care; and (j) promoting family planning services (Ministry of Health and Family Welfare, 2006).

Currently available evidence about the implementation of the JSY and its effect on women's access to maternal health services comes from a number of evaluations and other studies conducted after the introduction of the JSY to explore maternal health care practices. Barring the five-state evaluation conducted by UNFPA (UNFPA, 2009) and an evaluation that has drawn on data from two rounds of the Reproductive and Child Health District Level Household Surveys (2002-04 and 2007-09) (Lim et al., 2010), most studies conducted thus far have been typically small and unrepresentative. Besides, most have focused only on JSY beneficiaries, with very few including non-beneficiaries, and have recruited study participants conveniently-for example, from lists of beneficiaries available at sub-centre or Primary Health Centre (PHC) levels and from non-beneficiaries identified by key informants (Devadasan et al., 2008; Malini et al., 2008; Robinson, 2007; Sharma, 2008; Centre for Operations Research and Training, 2007a; 2007b; 2007c; 2007d; 2007e; 2007f; 2008a; 2008b). Almost all the studies conducted thus far, moreover, have focused on the situation in rural areas, and relatively little is known about JSY experiences in urban settings.

Thematically too, the information that can be gleaned from available evaluation studies remains sketchy. For example, although most evaluations of the JSY conclude that awareness of the scheme, in general, is almost universal, evidence remains limited as to the extent to which women are correctly

\footnotetext{
${ }^{1}$ All states other than Uttar Pradesh, Uttaranchal, Bihar, Jharkhand, Madhya Pradesh, Chhattisgarh, Assam, Rajasthan, Orissa, and Jammu and Kashmir.
} 
informed about the eligibility criteria for benefiting from the scheme and the monetary and nonmonetary entitlements under it. The few studies that have explored these issues to some extent suggest that awareness may not have been comprehensive (UNFPA, 2009; Sharma, 2008). Likewise, most evaluations, thus far, have focused on the extent to which the JSY may have influenced women's utilisation of maternal health services, particularly antenatal and delivery services. Even these studies, however, provide only limited information about the extent to which women received comprehensive services during pregnancy, delivery and the postpartum period.

Several studies, both those addressing the JSY, in particular, and those addressing delivery practices, more generally, have noted disturbing aspects of delivery-related care at the facility level. For example, studies in Rajasthan (Iyengar et al., 2009a; Iyengar, Iyengar and Gupta, 2009b) note that the use of oxytocin to speed up delivery and the application of forceful fundal pressure were widely practised both in home and facility-based deliveries, and post-delivery injections for active management of the third stage of labour were administered relatively infrequently. Even in deliveries conducted in PHCs, labour was monitored through repeated unhygienic vaginal examination, and drying and wrapping of the baby were delayed. Also noted by several authors is the tendency to discharge the woman within 24 hours of delivery (Iyengar et al., 2008; 2009a; Devadasan et al., 2008). Indeed, a survey in Rajasthan reports that 14 percent of respondents were discharged within six hours of delivery and 70 percent within 24 hours of delivery (Iyengar et al., 2008; 2009a). Likewise, the five-state study conducted by UNFPA reports that between one-third and four-fifths of JSY beneficiaries were discharged within a day of delivery (UNFPA, 2009). Besides, many authors have also questioned the ability of PHCs and their staff to meet the expanded demand generated by the JSY and provide quality delivery services to women. Evidence (for example, Sharma, 2008) suggests that two or three pregnant women occupying a single bed is not unusual at the PHC level, and that further increased demand would sorely strain the capacity of PHCs to provide quality services. Studies conducted prior to the introduction of the JSY, however, have also pointed to poor quality of pregnancy-related care (see, for example, Barnes, 2007). Little is known, therefore, about whether or not quality of care has been compromised following the introduction of the JSY. Indeed, so far, not a single study that evaluated the JSY has probed the quality of maternal health services received by its beneficiaries and nonbeneficiaries.

Additionally, although the JSY is almost universally known to women, studies indicate that many women continue to opt for a home delivery. For example, the five-state study conducted by UNFPA reports that between one-quarter and onehalf of women had delivered at home for the most recent birth (UNFPA, 2009). Little is known about the kinds of services received by those who opted for delivery at home and the extent to which these women were better off than if they had been JSY beneficiaries.

Finally, barring the evaluation that relied on data from the two rounds of Reproductive and Child Health District Level Household Surveys (2002-04 and 2007-09) (Lim et al., 2010), not a single study, thus far, has explored whether pregnancy outcomes or treatment-seeking patterns during pregnancy, delivery and the postpartum period differ between JSY beneficiaries and non-beneficiaries. Questions remain, moreover, about whether the prevalence of pregnancy-related morbidity and mortality among beneficiaries differs from that of non-beneficiaries. Also unclear are treatment-seeking patterns among 
beneficiaries, and the extent to which beneficiaries may be more likely than non-beneficiaries to make prompt decisions and seek care from appropriate health care providers.

In short, available evidence suggests that the JSY is indeed a promising and innovative scheme with huge potential for improving pregnancy-related care and outcomes. Early evidence is, however, mixed and suggests a number of obstacles in ensuring wider use of the scheme, ranging from inadequate understanding of the scheme and women's entitlements under it to poor quality of services and care at the health facility. Small and unrepresentative samples and other methodological concerns have also limited the insights that can be drawn from available evidence.

\section{Study objectives}

As described above, the JSY is intended to encourage institutional deliveries and provide access to care during pregnancy and in the postpartum period. While the provision of cash benefits for institutional delivery is the most salient feature of the JSY programme, an array of complementary services also falls under it, including assistance from the ASHA during pregnancy, delivery and the postpartum period. By better understanding women's perspectives and experiences regarding the JSY, our study sought to assess the extent to which both of these objectives of the JSY have been met.

Specifically, the objectives of the study were to explore:

- Awareness and perceptions of the JSY among recently delivered women

- The reach of the scheme among the most vulnerable women

- The extent to which JSY beneficiaries received their full monetary and non-monetary entitlements
- The effects of the JSY on the utilisation of maternal health services and the adoption of best practices in newborn care

- The effect of the JSY on the quality of maternal health services

- Differences, if any, in the levels of pregnancy- and newborn-related complications experienced and patterns of care-seeking among JSY beneficiaries and non-beneficiaries

\section{Study setting}

The study was conducted in the state of Rajasthan. With a population of 68.6 million in 2011, the state ranked eighth in terms of total population among states in India (Office of the Registrar General and Census Commissioner, India, 2011). With a child sex ratio of 883 females per 1,000 males in 2011, it registered one of the most skewed sex ratios in the country. The state lags behind the rest of India in terms of social indicators as well. For example, its overall literacy rate was 67 percent in 2011 compared to 74 percent nationally (Office of Registrar General and Census Commissioner, India, 2011). Further, with 65 percent of 20-24 year-old women married before age 18, it ranks second among all states in India in terms of the prevalence of early marriage (International Institute for Population Sciences and Macro International, 2008). Moreover, childbearing in adolescence is widely prevalent; two-fifths of currently married girls aged 15-19 years were already mothers and another one-tenth were pregnant at the time of the survey.

The state's performance in the health sector has also been poor. With a maternal mortality ratio of 318 per 100,000 live births, it records the third highest maternal mortality ratio among all states in India (Office of the Registrar General, India, 2011). Moreover, the utilisation of maternal health services is limited (see Table 1.1). A recent 
assessment, conducted in 2009-10, also reaffirms that the utilisation of maternal health services is far from satisfactory- 55 percent of women had three or more antenatal check-ups and 70 percent had delivered in a health facility (UNICEF, 2010). The coverage of centrally-sponsored programmes, like the JSY, to promote maternal health, also remains far from universal. For example, an evaluation conducted by the UNFPA reports that just onehalf of women who had delivered in the one year preceding the survey had received financial assistance under the JSY (UNFPA, 2009).

Two districts, Alwar and Jodhpur, were purposively selected for the study. These districts represent the state averages in selected sociodemographic and reproductive health indicators such as male and female literacy rates, percentage of girls married below the legal minimum age at marriage, percentage of women who were currently using contraception and percentage of women who had received skilled attendance at delivery. They also represent the eastern (Alwar) and western (Jodhpur) regions of the state. A few key indicators of the study districts are presented in Table 1.1.
The study was fielded in both urban and rural areas of the study districts. The selection of villages in rural areas and census enumeration blocks in urban areas within each district was done using a two-stage stratified systematic random sampling procedure. At the first stage of selection, three rural blocks and two or three urban blocks were selected. All the blocks were first explicitly stratified by population size and the percentage of population belonging to scheduled castes and tribes, and then implicitly stratified by the level of female literacy. The blocks were then selected systematically from the stratified list, with selection probability proportional to size. In total, six blocks in rural areas and five blocks in urban areas were thus selected for the study. At the second stage, villages in rural areas and census enumeration blocks in urban areas were selected within each selected block, using a similar scheme. A total of 196 sampling units were thus selected. Within each selected sampling unit, all households were surveyed; villages containing more than 300 households were segmented and one segment was randomly selected for the survey.

\section{Table 1.1}

Profile of the study districts and Rajasthan state

\begin{tabular}{|c|c|c|c|}
\hline Characteristics & Alwar District & Jodhpur District & Rajasthan State \\
\hline Population ${ }^{1}$ & $3,671,999$ & $3,685,681$ & $68,621,012$ \\
\hline Overall sex ratio $(\mathrm{F} / \mathrm{M})^{1}$ & 894 & 915 & 926 \\
\hline Child sex ratio $(0-6$ years $)(F / M)^{1}$ & 861 & 890 & 883 \\
\hline Male literacy $(\%)^{1}$ & 85.1 & 80.1 & 80.5 \\
\hline Female literacy $(\%)^{1}$ & 56.8 & 52.6 & 52.7 \\
\hline $\begin{array}{l}\text { Of those married in the last three years, females } \\
\text { married before age } 18(\%)^{2}\end{array}$ & 40.7 & 40.6 & 39.9 \\
\hline $\begin{array}{l}\text { Married women aged } 15-49 \text { currently using any } \\
\text { contraceptive method }(\%)^{2}\end{array}$ & 61.2 & 51.7 & 58.1 \\
\hline $\begin{array}{l}\text { Married women aged } 15-49 \text { who reported skilled } \\
\text { attendance at last delivery }(\%)^{2}\end{array}$ & 51.8 & 47.4 & 52.6 \\
\hline
\end{tabular}




\section{Study design}

A cross-sectional study, comprising a survey and in-depth interviews, was conducted between September 2009 and February 2010. The sample size for interviews with eligible women was fixed at 1,000 women each from the rural and urban areas in each district. In each district, the sample was weighted at the level of the sampling domain, that is, rural and urban areas. The sample weight for each district (the district weight) was calculated taking into account differential non-response rates as well as design weights for each domain. For the combined sample of the two districts, the overall sample weights were calculated as the product of the design weight for each district (after adjusting for non-response) and the district weight.

Respondents for the survey comprised women below 35 years of age who had delivered in the one year preceding the interview. A complete house-listing was carried out to identify eligible women in the PSUs selected for the study. All the eligible women who were identified were invited to participate in the study. We note that all identified women residing in the selected PSUs at the time of the survey were considered to be eligible irrespective of whether they were usual members of the household or visitors.

A detailed questionnaire was administered to eligible respondents. The instrument was developed and finalised with inputs from the Technical Advisory Committee of the project. It was translated into the local language, Hindi, pre-tested, and further modified. A data-entry package was prepared (using CSPro) that enabled interviewers to conduct interviews and record responses directly onto mini laptops, thus ensuring built-in consistency checks and rapid transmission of data from the field to the Council office. In addition to questions on socio- economic characteristics, the questionnaire included detailed questions about awareness of the JSY, perceptions about the JSY, experiences in accessing JSY benefits, reasons for not availing of JSY benefits among non-beneficiaries, awareness of maternal and newborn care practices, maternal and newborn care-seeking practices, the quality of the services received, and maternal and newborn complications experienced and treatment sought.

Respondents for in-depth interviews were selected from among survey respondents who fell into the following four categories: (a) women who had benefited from the JSY and were satisfied with the scheme; (b) women who had benefited from the JSY, but were not satisfied with the scheme; (c) women who had delivered at home and not received JSY benefits; and (d) women who had delivered in an eligible public or private health facility and not received JSY benefits. A quota for in-depth interviews to be conducted in each category was decided. Respondents were selected purposively from the four categories so as to represent different socioeconomic groups in the study area. An interview guide was prepared to collect in-depth information and was translated into Hindi.

Interviewers were recruited locally. A ten-day training workshop was organised to acquaint them with the method of conducting computer-assisted personal interviews, the questionnaire and interview guidelines. Data received from the field were regularly checked to assess quality, and feedback provided to the investigators.

A total of 5,924 women were identified during the house-listing exercise; of these, 4,770 women were successfully interviewed (Table 1.2). While less than 2 percent of eligible women refused to participate in the study, 17 percent of women were not interviewed as they could not be contacted even 
after three home visits; we note that the majority of these women were daughters of the head of the household who, we believe, were temporarily visiting their natal home at the time of the house-listing exercise but had returned to their marital home at the time of the survey. The survey data were analysed using SPSS. A total of 48 women were interviewed in-depth. Interviews were tape-recorded with the consent of the participants, transcribed in Hindi and translated into English. The transcripts were coded using Atlas-ti software.

The Technical Advisory Group provided guidance at key points throughout the project, and provided valuable advice and insights on designing the questionnaire and interpreting study findings.

\section{Analytic approaches}

The analytic approaches and the samples used for the analyses varied by the research questions that the study sought to answer, and are described in this section (see also Annexure 1).

The analysis pertaining to women's awareness of and experiences in obtaining JSY benefits drew on survey data from the full sample of women covered in the study, that is, 4,770 women who had delivered in the one year preceding the interview, and data from 48 in-depth interviews. Descriptive data on women's awareness of the JSY, ASHA and schemes other than the JSY, the reach of the JSY, women's experiences of obtaining JSY cash assistance, reasons for not availing of cash assistance among non-beneficiaries of the scheme, support received from the ASHA, and the reach of schemes other than the JSY, are presented separately for rural and urban areas. Survey findings are supplemented with insights from the in-depth interviews.

Differences in women's awareness of maternal and newborn care practices by beneficiary status were assessed using a cross-sectional sample of JSY beneficiaries and non-beneficiaries who had delivered in the one year preceding the interview; women who reported that they were yet to receive the benefits were excluded from the analysis, thus leading to a sample of 4,711 women. Mean values or percentages of outcome variables obtained for beneficiary and non-beneficiary groups were then compared to assess their associations, and t-tests and chi-square tests, as appropriate, were conducted to test the significance of these associations. Additionally, we used regression

\section{Table 1.2}

\section{Coverage of the study}

\begin{tabular}{|c|c|c|c|}
\hline Results of interviews & Combined & Urban & Rural \\
\hline Number of eligible women listed & 5,924 & 2,978 & 2,946 \\
\hline Number of women successfully interviewed & 4,770 & 2,372 & 2,398 \\
\hline Number of women partially interviewed & 31 & 5 & 26 \\
\hline $\begin{array}{l}\text { Number of women who refused to be } \\
\text { interviewed }\end{array}$ & 84 & 65 & 19 \\
\hline Number of women not at home & 1,024 & 530 & 494 \\
\hline $\begin{array}{l}\text { Number of women not interviewed } \\
\text { for other reasons, including those } \\
\text { incapacitated }\end{array}$ & 15 & 6 & 9 \\
\hline Response rate $(\%)$ & 80.1 & 79.7 & 81.4 \\
\hline Villages/Census enumeration blocks covered & 196 & 100 & 96 \\
\hline
\end{tabular}


analysis to control for the potentially confounding effects that such covariates as age, education, religion, caste, parity, household economic status, rural-urban residence and study district may have on the indicators of women's awareness of maternal and newborn care practices.

Two analytic approaches-cross-sectional and panel—were used to assess whether the JSY has contributed to an increase in the utilisation of maternal and newborn care services.

For the cross-sectional analysis, we used data from a matched sample of JSY beneficiaries and non-beneficiaries who had delivered in the one year preceding the interview, selected by the technique of propensity score matching. This analysis was restricted to the matched sample since the sociodemographic characteristics of those who had availed of cash assistance differed significantly from those who had not, as can be seen in Chapter 3. Propensity score matching is a statistical technique that allows us to control for potential self-selection bias by identifying those respondents from the non-beneficiary group who would be most likely to have availed of the benefits (Rosenbaum and Rubin, 1983; D’Agostino and Ralph, 1998). The propensity score of an individual is the conditional probability of availing of the benefits, given the individual's background characteristics. At any given value of the propensity score, the conditional distribution of the background variables is the same for both beneficiaries and non-beneficiaries (Rosenbaum and Rubin, 1983). For calculating the propensity score for availing of JSY benefits, such background characteristics as women's age, educational attainment, parity, religion, caste and household wealth quintile were considered. Once the propensity score was calculated, the value was used to identify a respondent from the non-beneficiary group with the nearest possible value to that of a beneficiary, without replacement. In other words, once a respondent was matched, she was included in the analysis sample; she could not be matched more than once. Propensity score matching was carried out separately for rural and urban samples, and samples thus selected were pooled and weighted using normalised weights for the total district population. As expected, women in the beneficiary group and the matched non-beneficiary group tended to have similar distributions of the background characteristics used to calculate the propensity score (see Annexure 2). A total of 3,434 women-1,718 beneficiaries and 1,716 non-beneficiaries-who had delivered in the one year preceding the interview, thus selected, constituted the sub-sample used for the crosssectional analyses pertaining to differences in the utilisation of maternal health services and adoption of best practices in newborn care. We compared the experiences of beneficiaries and non-beneficiaries during the most recent birth. Mean values of outcome variables obtained for the beneficiary and non-beneficiary groups were then compared to assess the extent to which utilisation of maternal health services and adoption of best practices in newborn care differed between the two groups; t-tests were used to test the significance observed in the bivariate comparisons. Additionally, we used regression analysis to account for potentially confounding effects that covariates other than those included in the construction of the propensity score-rural-urban residence and study district, for example, may have on the outcome measures.

While the cross-sectional analyses provide a snapshot of the association between JSY experiences and the utilisation of maternal health services and adoption of best practices in newborn care, we note that we cannot ascertain the net effect that can be clearly attributed to the JSY because of the crosssectional nature of the data used. Hence, we selected 
a sub-sample of women who had experienced a birth both before and after the JSY was introduced from the full sample (4,770 women who had delivered in the one year preceding the interview). Any birth that had taken place before November 2006 when the JSY became a generalised scheme with all the restrictive criteria removed in low-performing states, including Rajasthan, was considered as a preJSY birth. We note that, for all women who had delivered before and after the introduction of the JSY, we collected detailed information pertaining to their utilisation of maternal health services and adoption of best practices in newborn care as also the quality of maternal health services received with reference to two births, that is, the birth that took place before the introduction of the JSY and the one that occurred thereafter. This enabled us to generate a panel dataset from the original cross-sectional study. Based on information related to whether or not they had availed of JSY cash assistance for the most recent birth, these women were then categorised into beneficiaries and nonbeneficiaries. As with the cross-sectional sample, in view of the fact that those who had received cash assistance differed significantly from those who had not done so in terms of a number of socio-economic characteristics, JSY beneficiaries in the sub-sample were explicitly matched with individuals in the non-beneficiary group using the propensity score matching method. A total of 1,207 women-606 beneficiaries and 601 non-beneficiaries-who had delivered before and after the introduction of the JSY, thus selected, constituted the sub-sample for the panel analyses.

We used the difference-in-difference (DiD) estimation approach to assess the net effect of the JSY on the utilisation of maternal health services and adoption of best practices in newborn care (Ashenfelter, 1978; Ashenfelter and Card, 1985).
The DiD estimator measures the treatment effect by estimating the difference between outcome measures at two time points for both the treated observations and the controls (that is, JSY beneficiaries and nonbeneficiaries, respectively, in the present study) and then comparing the difference between the groups. This strategy ensures that any variables that remain constant over time (but are unobserved) and that are correlated with the selection decision and the outcome variable will not bias the estimated effect (Buckley and Shang, 2003). Paired t-tests were first used to assess the significance of change over time, if any, in both the groups. Additionally, we computed the difference in outcome measures at two time points (before and after the introduction of the JSY) and regressed this on a dummy variable, indicating whether or not the respondents had availed of JSY benefits and socio-demographic covariates other than those included in the construction of the propensity score that may have potentially confounding effects on the outcome measures as specified in the model below:

$$
Y_{i, 1}-Y_{i, 0}=\delta+\pi X_{i}+\gamma D_{i, 1}+\dot{\varepsilon}_{i}
$$

where, $Y_{i, 1}-Y_{i, 0}$ is the difference between the repeated outcome measures for each woman, $\delta$ is the effect of time, $X_{i}$ is the covariate, $\pi$ is difference in the effect of the covariate on the outcome for each of the two time points, $D_{i, 1}$ is the treatment indicator coded as 1 if the woman had availed of JSY benefits and 0 otherwise, $\gamma$ is the treatment effect, that is, the additional change in outcome due to the programme, and $\varepsilon_{i}$ is the difference between errors at time 1 and time 0 . We note that all the outcome indicators presented in this report are expressed as percentages and $\gamma$ represents the percentage change in the outcome attributable to the programme over and above the average change that would have taken place in the absence of the programme $(=\delta)$. The additional covariates entered 
in the model included parity at the pre-JSY birth, number of children born after the introduction of the JSY including the most recent one, rural-urban residence, and study district. With this approach, we estimated the net effect of the JSY after controlling for potentially confounding factors and ensured that any variables that remain constant over time, including unobserved variables that are correlated with the receipt of JSY cash assistance and the outcome variables, did not bias the estimated impact.

We drew on the sub-sample of women who had delivered before and after the introduction of the JSY to assess whether the JSY has contributed to improving or compromising the quality of maternal health services. As earlier, these women were categorised into beneficiaries and non-beneficiaries, based on whether or not they had availed of JSY cash assistance for the most recent birth. We note that, unlike in the case of analyses pertaining to the effect of the JSY on the utilisation of maternal health services, we used the unmatched sample of women for analysing the effect of the JSY on the quality of services, on the assumption that the quality of services received by women is not affected by the respondent's propensity to avail of JSY benefits. A total of 1,652 women-795 beneficiaries and 857 non-beneficiaries-who had delivered before and after the introduction of the JSY, thus selected, constituted the sub-sample used for the analysis. We compared the quality of maternal health services received by beneficiaries and non-beneficiaries for pre- and post-JSY births. Paired t-tests were first used to assess the significance of change over time, if any, in both the groups. As earlier, we also assessed the net effect using difference-in-difference estimation. Since we used the unmatched sample of women in these analyses, we controlled for such covariates as age, education, religion, caste, household economic status, parity at the pre-JSY birth, number of children born after the introduction of the JSY, rural-urban residence and study district.

Finally, in order to assess differences in complications experienced by women during pregnancy, delivery and the postpartum period, as well as by their newborn, and in the treatmentseeking patterns of those who reported experiences of complications by beneficiary status, we used a cross-sectional sample of JSY beneficiaries and non-beneficiaries who had delivered in the one year preceding the interview; women who reported that they were yet to receive the benefits were excluded from the analysis, thus leading to a sample of 4,711 women. As earlier, percentages of outcome variables obtained for beneficiary and non-beneficiary groups were compared to assess associations, and t-tests were conducted to test the significance of these associations. Additionally, we used regression analysis to control for the potentially confounding effects that such covariates as age, education, religion, caste, parity, household economic status, ruralurban residence and study district may have on the outcome measures.

\section{Characteristics of respondents' households}

Table 1.3 presents selected characteristics pertaining to the households of the women who participated in the study. Distribution by religion suggests that 78 percent of the households were Hindu, 21 percent were Muslim and the remaining 2 percent belonged to other religions; rural-urban differences were modest. Caste-wise distribution indicates that the largest group belonged to other backward castes (48\%), followed by scheduled castes and general castes (24\% and 19\%, respectively). Scheduled tribes comprised 9 percent of the households. Rural-urban differences indicate that 
the rural sample consisted of larger proportions of households belonging to scheduled tribes and scheduled castes than did the urban sample $(11 \%$ versus $3 \%$ of scheduled tribe households; $26 \%$ versus $19 \%$ of scheduled caste households) and conversely, a smaller proportion of households belonging to general castes (15\% versus $32 \%)$.

Household economic status was measured using a wealth index composed of household asset data on ownership of selected durable goods, including means of transportation, as well as data on access to a number of amenities (see Annexure 3 for details).
Index scores ranged from 0 to 58; households were ranked according to the index score and then divided into quintiles, with the first quintile representing households having the lowest wealth status and the fifth quintile representing households with the highest wealth status. We note that while the use of separate indexes for urban and rural areas has been increasingly recommended, we did not have an adequate number of cases to construct separate indexes. The distribution of households by wealth quintiles shows that one-half $(51 \%)$ of urban households were in the wealthiest (fifth)

\section{Table 1.3}

Selected characteristics of respondents' households, according to residence

\begin{tabular}{|c|c|c|c|}
\hline Characteristics & Combined & Urban & Rural \\
\hline \multicolumn{4}{|l|}{ Religion (\%) } \\
\hline Hindu & 77.8 & 72.9 & 79.3 \\
\hline Muslim & 20.6 & 24.8 & 19.4 \\
\hline Other $^{1}$ & 1.5 & 2.3 & 1.4 \\
\hline \multicolumn{4}{|l|}{ Caste (\%) } \\
\hline Scheduled castes & 24.3 & 18.9 & 25.9 \\
\hline Scheduled tribes & 8.8 & 2.5 & 10.6 \\
\hline Other backward castes & 47.7 & 46.5 & 48.0 \\
\hline General castes & 19.0 & 31.8 & 15.1 \\
\hline \multicolumn{4}{|l|}{ Wealth quintile (\%) } \\
\hline First quintile & 20.0 & 2.5 & 25.3 \\
\hline Second quintile & 20.0 & 6.5 & 24.1 \\
\hline Third quintile & 20.0 & 12.5 & 22.2 \\
\hline Fourth quintile & 20.0 & 27.3 & 17.8 \\
\hline Fifth quintile & 20.0 & 51.2 & 10.6 \\
\hline \multicolumn{4}{|c|}{ Possession of BPL card (\%) } \\
\hline Yes & 17.4 & 11.0 & 19.3 \\
\hline No & 79.2 & 86.8 & 76.9 \\
\hline Don't know & 3.5 & 2.3 & 3.8 \\
\hline Number of women & 4,770 & 2,372 & 2,398 \\
\hline
\end{tabular}


quintile; in contrast only one-tenth (11\%) of rural households were in this quintile. Likewise, onequarter of rural households were in the poorest (first) quintile compared to only 3 percent of urban households. As far as possession of the BPL card was concerned, findings suggest that just one-sixth of households owned a BPL card; more rural than urban households reported so (19\% versus $11 \%)$.

\section{Characteristics of respondents}

Selected socio-demographic characteristics and reproductive experiences of respondents are summarised in Table 1.4. Age profiles suggest that urban respondents were slightly older than rural respondents (25 years versus 23 years). Underscoring the prevalence of early marriage in the study settings, findings indicate that respondents were married, on average, at age 16; rural respondents were married almost three years earlier than their urban counterparts (15.5 years versus 18.3 years). Educational profiles suggest that just one-half of respondents had ever enrolled in school and the median years of completed schooling was just two years. Rural-urban differences were wide; while urban respondents, on average, had completed seven years of schooling, over one-half of rural respondents had never been to school. Further, one-half of respondents had been engaged in unpaid work in

\section{Table 1.4}

Selected socio-demographic characteristics and reproductive experiences of respondents, according to residence

\begin{tabular}{|c|c|c|c|}
\hline Characteristics & Combined & Urban & Rural \\
\hline \multicolumn{4}{|l|}{ Age (years) } \\
\hline Mean age & 23.6 & 24.6 & 23.3 \\
\hline \multicolumn{4}{|l|}{ Age at marriage (years) } \\
\hline Mean age at marriage ${ }^{1}$ & 16.2 & 18.3 & 15.5 \\
\hline \multicolumn{4}{|l|}{ Educational status (\%) } \\
\hline Ever enrolled in school & 51.0 & 74.0 & 44.1 \\
\hline Median years of schooling successfully completed & 2 & 7 & NC \\
\hline \multicolumn{4}{|l|}{ Current work status (\%) } \\
\hline Unpaid work in the last 12 months & 50.9 & 9.0 & 63.5 \\
\hline Paid work in the last 12 months & 24.4 & 15.4 & 27.0 \\
\hline \multicolumn{4}{|l|}{ Reproductive experience (\%) } \\
\hline Mean number of pregnancies & 3.0 & 2.5 & 3.1 \\
\hline Mean number of children ever born & 2.6 & 2.1 & 2.7 \\
\hline Delivered in a public sector health facility & 47.0 & 55.2 & 44.5 \\
\hline Delivered in a private health facility & 15.4 & 28.0 & 11.6 \\
\hline Delivered at home ${ }^{2}$ & 36.7 & 16.5 & 42.7 \\
\hline Number of women & 4,770 & 2,372 & 2,398 \\
\hline
\end{tabular}

Note: ${ }^{1}$ Excludes 10 women who did not know their age at marriage. ${ }^{2} 1 \%$ of women delivered in transit. NC: Not calculated as over 50\% of respondents had never been to school. Percentages and means indicated in the table are weighted; the number of respondents is unweighted. 
the 12 months preceding the interview; in contrast, just one-quarter had been engaged in paid work. Rural respondents were considerably more likely than their urban counterparts to have engaged in paid or unpaid work.

A profile of the reproductive experiences of respondents, also presented in Table 1.4, indicates that the study participants, on average, had three pregnancies, ranging from 2.5 among urban respondents to 3.1 among rural respondents. The mean number of children ever born ranged from 2.1 among urban respondents to 2.7 among rural respondents. Finally, almost one-half of women (47\%) had delivered their last child in a public sector health facility, one-seventh $(15 \%)$ in a private health facility and one-third (37\%) at home. Ruralurban differences indicate that urban women were more likely than rural women to have delivered in a public or private sector facility, and conversely, less likely to have delivered at home.

\section{Structure of the report}

The report is structured as follows. Apart from this opening chapter, Chapters 2 and 3 examine women's awareness of the JSY and their experiences in availing of JSY benefits, respectively. While Chapter 4 compares in-depth awareness of maternal and newborn care practices among JSY beneficiaries and non-beneficiaries, Chapters 5 and 6 discuss the effects of the JSY on women's utilisation of maternal health services and adoption of best practices in newborn care, and on the quality of maternal health services received, respectively. Chapter 7 compares the maternal and newborn complications experienced and treatment sought by JSY beneficiaries and non-beneficiaries. Chapter 8 summarises the main findings of the study, and offers programme recommendations.

All means, medians and percentages indicated in the tables have been weighted using normalised weights for the total district population. However, in order to show the total number of women interviewed, unweighted numbers of respondents are provided in each table. Because numbers are unweighted and percentages are weighted, we caution readers against deriving numbers based on the percentages provided in the tables. 


\section{CHAPTER 2}

\section{Awareness of the Janani Suraksha Yojana}

This chapter presents findings on women's awareness of the JSY. Specifically, it describes the extent to which women were aware of the criteria for benefiting from the scheme, the benefits to which women are entitled and the types of support that $\mathrm{ASHAs}^{1}$ are expected to provide. The findings draw from analyses of the full sample of 4,770 women who had delivered in the one year preceding the interview.

\section{Awareness of the JSY}

Table 2.1 presents the percentage of women who reported awareness of the JSY, according to residence. Findings indicate that almost all women, regardless of the place of residence, were aware of the JSY (98\%). Moreover, two-thirds of the women had heard about the scheme prior to their most recent pregnancy (69\%), with more urban than rural women reporting so (75\% versus $67 \%)$. Another one-fifth reported that they had become aware of the JSY during their most recent pregnancy (22\%) and 7 percent, after their delivery. Family members, friends and neighbours were the leading sources of information of the JSY, regardless of the place of residence; almost three-quarters of women reported so $(73 \%)$. Other important sources of information included ANMs and medical officers, reported by one-third of women. Some 11-12 percent each mentioned ASHAs, and Anganwadi Workers (AWWs), traditional birth attendants or other local unqualified practitioners, as their information sources. Rural-urban differences were notable with regard to percentages of women citing selected sources of information on the JSY. Thus, rural women were more likely than their urban counterparts to cite health care providers, including frontline health workers; 34 percent of rural women compared to 25 percent of urban women reported that they had become aware of the JSY through ANMs or medical officers. Similar rural-urban differences were evident with regard to percentages of women citing an ASHA (13 versus 4) and an AWW, traditional birth attendant or other local unqualified practitioner (14 versus 5 ) as their information source. In contrast, more urban than rural women mentioned that the mass media, posters and bill boards had made them aware of the JSY (22\% versus $5 \%)$.

Although almost all women were aware of the JSY, fewer were correctly informed about the criteria for benefiting from the scheme, as evident from Table 2.2. With regard to women's awareness of the type of facility where they could deliver in order to receive JSY benefits, findings indicate that over 90 percent of women, regardless of the place of residence, knew that a woman delivering in a government health facility is eligible for JSY benefits. In contrast, not a single woman was aware that a woman delivering at home is also eligible if she is aged 19 and above, belongs to a BPL household

\footnotetext{
${ }^{1}$ Although ASHAs were originally recruited to serve in the rural areas under the NRHM, states are allowed to select ASHAs in urban areas as well; as such, ASHAs have been recruited in the urban areas of both study districts (personal communication, District Programme Manager, Alwar and Jodhpur districts, respectively).
} 
Table 2.1

Percentage of women reporting awareness of the JSY, according to residence

\begin{tabular}{|c|c|c|c|}
\hline & Combined & Urban & Rural \\
\hline Aware of the JSY & 97.9 & 97.6 & 97.9 \\
\hline \multicolumn{4}{|l|}{ Timing of awareness of the JSY ${ }^{1}$} \\
\hline Before the index pregnancy & 68.6 & 75.0 & 66.7 \\
\hline During the index pregnancy & 22.1 & 15.9 & 24.0 \\
\hline After the index delivery & 7.1 & 6.8 & 7.2 \\
\hline \multicolumn{4}{|l|}{ Source of information on the JSY ${ }^{2}$} \\
\hline ASHA & 11.1 & 3.9 & 13.2 \\
\hline $\begin{array}{l}\text { AWW/Traditional birth attendant/Unqualified } \\
\text { medical practitioner }\end{array}$ & 11.7 & 4.7 & 13.8 \\
\hline ANM/Medical officer & 31.6 & 24.8 & 33.6 \\
\hline Family member/Friend/Neighbour & 73.2 & 77.4 & 72.0 \\
\hline Women's group/NGO & 0.6 & 1.1 & 0.4 \\
\hline Mass media/Posters/Bill boards & 8.6 & 21.5 & 4.7 \\
\hline Other & 0.1 & 0.2 & 0.1 \\
\hline Number of women & 4,770 & 2,372 & 2,398 \\
\hline
\end{tabular}

and is having her first or second delivery; this is not surprising given the limited efforts to inform women and the community at large that women are entitled to receive some cash assistance for home deliveries under certain conditions. Likewise, just 2 percent of women were aware that a woman delivering in an accredited private facility qualifies for JSY benefits, even though the study districts had 11 such facilities (10 in Alwar and one in Jodhpur, personal communication, District Programme Manager, Alwar and Jodhpur, respectively).

Findings, moreover, suggest that the fact that women qualified for JSY benefits, irrespective of their age, parity and household economic status was not universally known. For example, four-fifths (79\%) of women knew that a woman delivering in an accredited government or private health facility is entitled to receive JSY benefits even if she is rich. Even fewer knew that a woman delivering in an accredited government or private health facility can avail of JSY benefits for any number of births $(62 \%)$ and that she can get these benefits regardless of her age (60\%). Rural-urban differences for all the awareness indicators were narrow (Table 2.2).

Awareness of the type of government health facility where women could deliver to qualify for JSY benefits was also limited (Table 2.2). For example, just one-quarter of women knew that deliveries conducted in a normal sub-centre, that is, a subcentre that is not accredited to conduct deliveries, are ineligible for JSY benefits, with more rural than urban women reporting so (28\% versus $13 \%$ ). 
Table 2.2

Percentage of women reporting correct awareness of eligibility conditions for availing of the JSY, according to residence

\% of women who knew that
A woman delivering in a government health
facility is eligible for JSY benefits

A woman delivering at home is eligible for JSY benefits, if she meets selected conditions ${ }^{1}$

A woman delivering in an accredited private facility is eligible for JSY benefits

A woman delivering in an accredited government or private health facility is eligible for JSY benefits even if she is rich

A woman delivering in an accredited government or private health facility can avail of JSY benefits for any number of births

A woman delivering in an accredited government or private health facility can avail of JSY benefits regardless of her age

Deliveries in normal, that is, non-accredited subcentres $^{2}$ are ineligible for the JSY

Deliveries in primary health centres are eligible for JSY benefits

Deliveries in community health centres are eligible for JSY benefits

Deliveries in a district hospital are eligible for JSY benefits

The amount of cash entitlement under the JSY, if a woman delivers in a hospital is Rs. 1,400 (rural area) and Rs. 1,000 (urban area) ${ }^{3}$

A woman is entitled to support from an ASHA during pregnancy, delivery and the postpartum period

A woman can lodge a complaint with a government office/official, if she experiences difficulties in availing of JSY benefits ${ }^{4}$

Number of women

\section{Combined}

93.5

Urban

94.3

93.3

0.0

0.0

1.0

4,770

Note: ${ }^{1}$ If the woman is aged 19 and above, belongs to a BPL household and is having her first or second delivery. ${ }^{2}$ As per JSY guidelines, deliveries conducted in sub-centres accredited by the stateldistrict authorities are considered as institutional deliveries. Hence, women delivering in such centres are eligible for cash assistance. Accredited sub-centres are centres located in government buildings with such facilities as electricity, water and other medical requirements for basic obstetric services including drugs, equipment and the services of trained midwives for conducting normal deliveries. ${ }^{3}$ Rural respondents who reported the cash benefit as Rs.1,400 and urban respondents who reported it as Rs.1,000 were considered as having correct awareness. ${ }^{4}$ Respondent may not be referring to the grievance cell. Percentages indicated in the table are weighted; the number of respondents is unweighted. 
Even the fact that deliveries in PHCs, $\mathrm{CHCs}$ and district hospitals are eligible for JSY benefits was not universally known-just 59, 76 and 81 percent of women, respectively, knew about it. Further, rural-urban differences in women's awareness of the type of JSY-eligible government health facility were notable. A larger proportion of urban than rural women knew that deliveries performed in district hospitals are eligible for JSY benefits (94\% versus $77 \%$ ); in contrast, more rural than urban women knew that deliveries in PHCs and CHCs are also eligible (69\% versus $28 \%$ and $87 \%$ versus $39 \%$, respectively). Rural-urban differences may perhaps be attributed to differences in facilities that are typically relied on by women in rural and urban areas, respectively.

Table 2.2 also indicates that not many women were correctly informed about the amount of the monetary entitlement under the JSY. Just 66 percent of urban women and 32 percent of rural women knew that they were entitled to receive Rs.1,000 and Rs.1,400, respectively. Further, hardly any womenless than 1 percent-knew that they were entitled to receive support from ASHAs during pregnancy, delivery and the postpartum period. Finally, just one-quarter of women knew that a woman could lodge a complaint with a government office if she experiences any difficulty in accessing JSY benefits. We note, however, that these women may not necessarily have referred to the grievance cell.

Evidence from in-depth interviews indicates that notwithstanding its source, the information received by women regarding the JSY was skewed and, at times, incorrect. Of the 48 women who were interviewed in-depth, 27 reported being told that they would qualify for the cash benefit if they delivered in a government facility and another 10, if they opted for an institutional delivery. None of the women reported being informed that they could avail of JSY benefits if they delivered in an accredited private facility, or at home if they meet selected conditions. Indeed, some (six women) were emphatically told that they would not get any money if they delivered at home. For example:

$$
\begin{aligned}
& \text { She (ASHA) told me that 'all those who deliver } \\
& \text { in the hospital can avail of the benefits of the } \\
& \text { scheme; those who give birth to their child at } \\
& \text { home cannot...' [ } 25 \text { years, rural Alwar, received } \\
& \text { information from ASHA, ANM, medical } \\
& \text { officer, neighbours] }
\end{aligned}
$$

...At the government hospital; they did not tell me about any other hospital. [24 years, rural Alwar, received information from an AWW]

The dai (traditional birth attendant) told me that I could get Rs.1,400 if I deliver my child in the hospital; she only informed me about the money... (She said) those who deliver their child at Mundawar (Community Health Centre) get money. That's all I was told... [23 years, rural Alwar, received information from ASHA, traditional birth attendant and neighbours]

Findings, moreover, suggest that those who were informed that deliveries at government health facilities were eligible for JSY benefits were rarely informed about the different types of government facilities where they could (for example, PHC, CHC, district hospital) or could not (for example, normal sub-centre) avail of these benefits:

The nurse said that whatever we spend on the delivery of the child, we get it back.... One doesn't get money from the private hospital, we have to spend money in private hospitals. That's all she said. [27 years, urban Jodhpur, received information from an ANM]

As many as 34 of the 48 in-depth interviews contained discussions about whether women were 
informed about the amount of money that they are entitled to under the JSY. Of these, while 20 reported the correct amount, others did not seem to have been given any information or had been told that they would receive an amount other than that stipulated in the scheme as the following excepts illustrate:

She did not tell me anything about the amount; she just told me that I would receive money. [25 years, rural Jodhpur, received information from a neighbour]

The nurse told me that a woman receives money there (hospital)...I don't know how much money a woman gets, she didn't tell me anything about it. [21 years, rural Jodhpur, received information from an ANM]

She informed me that I would get money if I deliver my child in the government hospital; she told me that I would get Rs.1,400 for a boy child and Rs.1,600 for a girl child. [21 years, rural Alwar, received information from an ASHA]

I heard from my neighbours that a woman gets Rs.1,400 if she delivers a girl child and Rs.1,000 if she delivers a male child. [20 years, urban Alwar, received information from neighbours]

\section{Awareness of the ASHA and her responsibilities}

The study explored women's awareness of the ASHA and her responsibilities, in several ways. First, they were asked whether they had heard about the ASHA or whether they were aware of any woman other than the ANM/AWW who contacts women during their pregnancy and childbirth. Second, in order to assess their awareness of the ASHA's responsibilities, women were asked to list the types of support provided by the ASHA about which they had heard; subsequently, the interviewers mentioned the types of support typically provided by the ASHA that the respondent had not mentioned spontaneously, and inquired whether the respondent perceived each of these as a responsibility of the ASHA. We note that although ASHAs were originally recruited to serve in the rural areas under the NRHM, states are allowed to select ASHAs in urban areas as link workers (Ministry of Health and Family Welfare, n.d); accordingly, ASHAs have been recruited in the urban areas of both study districts (personal communication, District Programme Manager, Alwar and Jodhpur, respectively). A companion study of ASHAs in the villages and urban wards in which women were surveyed shows that ASHAs were serving in 79 of the 96 villages and 54 of the 100 urban wards (Santhya et al., 2011).

Findings show that awareness of the ASHA was limited; fewer than one-half (46\%) of women had heard of the ASHA (Table 2.3). Even in the villages and urban wards in which ASHAs had been recruited, only 56 percent of women had heard of them. Awareness, without doubt, was more common in rural than in urban areas $(52 \%$ versus 26\%). Further, among those who had heard about ASHAs, the most commonly known responsibilities, reported by 82-92 percent of women, included facilitating three antenatal check-ups, counselling about institutional delivery and escorting women to a health facility for delivery. That arranging transport to reach the health facility, making postpartum visits within seven days of delivery and facilitating immunisation of the newborn were also the ASHA's responsibilities were known to even fewer (56-60\%). Such roles of the ASHA as informing women about an eligible government or private health facility for delivery, staying with the woman till she is discharged, and counselling women 
Table 2.3

Percentage of women reporting awareness of the ASHA and her responsibilities, according to residence

\begin{tabular}{|c|c|c|c|}
\hline & Combined & Urban & Rural \\
\hline Heard of ASHA & 46.1 & 26.2 & 52.1 \\
\hline Number of women & 4,770 & 2,372 & 2,398 \\
\hline Aware that the ASHA is responsible for: & & & \\
\hline $\begin{array}{l}\text { Facilitating ANC registration of pregnant } \\
\text { women }^{1}\end{array}$ & 13.4 & 8.3 & 12.7 \\
\hline $\begin{array}{l}\text { Facilitating three antenatal check-ups of pregnant } \\
\text { women }^{2}\end{array}$ & 92.0 & 93.1 & 91.8 \\
\hline $\begin{array}{l}\text { Counselling pregnant women to undergo an } \\
\text { institutional delivery }\end{array}$ & 85.3 & 90.3 & 84.5 \\
\hline $\begin{array}{l}\text { Informing pregnant women about eligible } \\
\text { government/private health facility for delivery }{ }^{1}\end{array}$ & 3.1 & 1.0 & 3.5 \\
\hline $\begin{array}{l}\text { Arranging transport for pregnant women to } \\
\text { reach health facility for delivery }\end{array}$ & 56.0 & 63.7 & 54.8 \\
\hline $\begin{array}{l}\text { Escorting pregnant women to a health facility } \\
\text { for delivery }\end{array}$ & 82.0 & 82.7 & 81.9 \\
\hline $\begin{array}{l}\text { Staying with the pregnant woman till she is } \\
\text { discharged from the health facility }\end{array}$ & 4.4 & 5.9 & 4.2 \\
\hline $\begin{array}{l}\text { Making a postpartum visit to women within } 7 \\
\text { days of delivery }{ }^{2}\end{array}$ & 60.3 & 70.9 & 58.7 \\
\hline Counselling women about breastfeeding ${ }^{1}$ & 2.0 & 3.5 & 1.8 \\
\hline Arranging immunisation of the newborn ${ }^{1}$ & 58.2 & 56.1 & 58.5 \\
\hline Counselling women about family planning ${ }^{1}$ & 5.5 & 10.4 & 4.8 \\
\hline Number of women heard of ASHA & 1,981 & 763 & 1,218 \\
\hline
\end{tabular}

Note: ${ }^{1}$ Spontaneous responses. ${ }^{2}$ Spontaneous or prompted responses. Percentages indicated in the table are weighted; the number of respondents is unweighted.

about breastfeeding and family planning were rarely identified (reported by just 3-6\% of women who had heard about ASHAs). Rural-urban differences were modest for the most part; even so, women in rural areas were less likely than urban women to have heard about such responsibilities of ASHAs as arranging transport and making postpartum visits within seven days of delivery.

In the course of in-depth interviews too, women who had heard about ASHAs, typically identified such responsibilities of ASHAs as facilitating antenatal check-ups, informing women about immunisation, in particular; counselling them to undergo an institutional delivery; escorting them to a health facility for delivery and reminding mothers about immunising their newborn, as the following excerpts suggest:

She informed us when one (pregnant woman) should get the injection; after delivery of the child, she advised us to take our children for immunisation. [25 years, rural Alwar]

Their responsibility is to take a pregnant woman for check-up, accompany her at the time of delivery, take care of her at the facility, and get 
her vaccinated. After the delivery of the child, they take the child for vaccinations too. [24 years, urban Alwar]

\section{Awareness of schemes other than the JSY}

The study also included questions to assess women's awareness of schemes, other than the JSY, intended to promote safe motherhood, such as the 108 ambulance service (the telephone number to be dialled for the free ambulance service, to go to a health facility) and the special nutritional supplementation scheme (provision of 5 kilograms of ghee to recently delivered women). Findings presented in Figure 2.1 show that fewer than onehalf of women (44\%) reported awareness of the ambulance service, with more urban than rural women reporting so (61\% versus $39 \%)$. Even fewer $(16 \%)$ were aware that the ambulance service is free of cost. Moreover, insights from in-depth interviews of women who had heard of the 108 ambulance service, albeit aired by a few, indicate misconceptions

Figure 2.1: Awareness of schemes other than the JSY among women, according to residence

$\%$ of women who were aware of

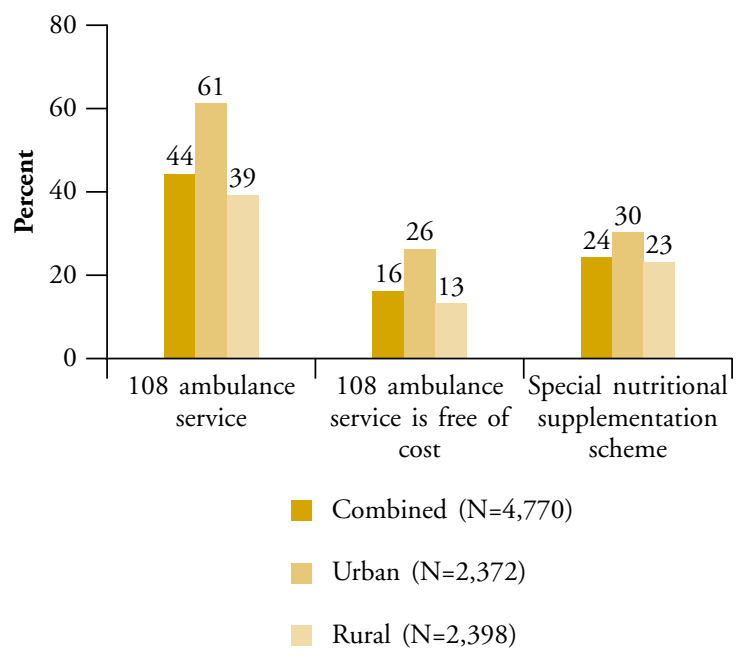

Note: Percentages indicated in the figure are weighted; the number of respondents is unweighted. about it. For example, as evident from the excerpts below, some women believed that the service is meant for doctors and that it charges a certain amount of money, while a few others said that they did not know the telephone number to dial or the amount charged for the service:

I have heard from Madam (health care provider) about the government vehicle, but I don't know how much money it charges. [23 years, rural Alwar]

I have heard that there is a vehicle which is being run by the government that takes patients to the hospital, but it had not come to my place. I don't know the number to call to obtain the ambulance service. [18 years, rural Jodhpur] I heard one year ago that it (ambulance) comes to take pregnant women to the hospital for delivery. My neighbours talked about it. I have heard about it from them only; it takes Rs. 150 or Rs.300; I don't know exactly how much. [25 years, urban Jodhpur]

It (ambulance) comes only for doctors; it is not for everyone. [34 years, urban Alwar]

It (ambulance service) charges Rs.250. I have called the service at the time of the birth of my child. [22 years, rural Jodhpur,]

With regard to the special nutritional supplementation scheme, findings suggest that just one-quarter of women had heard about it, with slightly more urban than rural women reporting so $(30 \%$ versus $23 \%)$. Again, during in-depth interviews, women who had heard of the scheme reported misconceptions such as, the scheme is available only to women who give birth to a female child and that ghee is given as a substitute for money. 


\section{Summary}

Findings presented in this chapter highlight the near universal awareness of the JSY among women. Family members, friends and neighbours were the leading sources of information about the JSY for both rural and urban women. Nevertheless, fewer were correctly informed about the conditions for benefiting from it, including the type of facility where they could deliver in order to qualify for JSY benefits, or the benefits they were entitled to such as a cash amount and various types of support from ASHAs. For example, not a single woman was aware that a woman delivering at home is eligible for JSY benefits if she is aged 19 and above, belongs to a BPL household and is having her first or second delivery. Moreover, just two-thirds of urban women and one-third of rural women knew that they were entitled to receive Rs.1,000 and Rs.1,400, respectively, and hardly any-less than 1 percent-knew that they were entitled to receive support from ASHAs during pregnancy, delivery and the postpartum period.

Awareness of the ASHA was limited; fewer than one-half of women had heard of the ASHA. Among those who reported awareness, the most commonly known responsibilities of the ASHA included facilitating three antenatal check-ups, counselling about institutional delivery and escorting women to a health facility for delivery. Although twice as many rural as urban women had heard about the ASHA, they were less likely than urban women to mention such responsibilities of ASHAs as arranging transport to reach a health facility for delivery and making postpartum visits within seven days of delivery.

Finally, awareness of schemes other than the JSY intended to promote safe motherhood such as the 108 ambulance service and special nutritional supplementation scheme was also limited; fewer than one-half of women were aware of the ambulance service and just one-quarter were aware of the special nutritional supplementation scheme. 


\section{CHAPTER 3}

\section{Women's experiences in accessing JSY benefits and their perceptions about the JSY}

In this chapter, we present findings of women's experiences in accessing the benefits of the JSY. Specifically, it describes the reach of the JSY with a special focus on the most vulnerable groups, the extent to which JSY beneficiaries had received their full monetary and non-monetary entitlements, reasons for not availing of JSY benefits among non-beneficiaries, women's experiences in utilising schemes other than the JSY and finally, their perceptions about the JSY. The findings draw on the full sample of women, that is, 4,770 women who had delivered in the one year preceding the interview.

\section{Reach of the JSY}

Table 3.1 presents the percentage of women who had received JSY benefits by selected background characteristics, according to residence. Findings show that although all the women in our sample were eligible for the JSY, fewer than one-half had benefited from it (46\%). A slightly larger proportion of urban than rural women so reported $(52 \%$ versus $45 \%)$. Differences by age indicate that women who had delivered at a young age (less than 18 years) and at ages 30-34 were less likely than others to have received the cash benefit (40-41\% versus $44-51 \%$ ). The pattern remained fairly similar in rural and urban areas, although rural women aged 25-29 were also less likely to have obtained the cash benefit. Religious differentials show that Muslim women and women belonging to other religions were less likely than Hindu women to have received the cash benefit (33-35\% versus 49\%). While this pattern was also observed in rural areas, a somewhat different pattern was observed in urban areas where Muslim women were most likely, and women belonging to other religions were least likely, to have received the cash benefit. Differences by caste and tribe suggest that women belonging to scheduled tribes were more likely than those belonging to scheduled castes, other backward castes and general castes to have obtained the cash entitlement (56\% versus $45-47 \%$ ). While a similar pattern was evident in rural areas, the pattern in urban areas was somewhat different in that women belonging to scheduled tribes were less likely than others to have received the cash benefit (32\% versus $48-57 \%)$.

Educational differentials, also presented in Table 3.1 , indicate that the reach of the JSY increased from 39 percent among women with no schooling to 58 percent among those who had completed 8-11 years of schooling, and declined thereafter to 45 percent among those who had completed 12 or more years of schooling. A similar pattern was observed in urban areas; however, in rural areas, the reach of the JSY increased steadily with the number of completed years of schooling, from 38 percent among those with no schooling to 58 percent among those who had completed 12 or more years of schooling. As regards economic differentials, findings suggest that regardless of their place of residence, women belonging to poorer households were less 
likely than others to have obtained the cash benefit; 36 percent of women belonging to households in the poorest quintile (the first) compared to 43-52 percent of those in the remaining quintiles had received the cash benefit. Differences by BPL status were narrow.

Findings further show that the coverage of the JSY decreased steadily with parity: from 53 percent among first parity women to 37 percent among those with parity of four or more; the pattern was similar in both urban and rural settings (Table 3.1). Differences by place of delivery suggest that irrespective of their place of residence, 92 percent of women who had delivered in an eligible government or private health facility (that is, in a model subcentre, PHC, CHC, district hospital or accredited private hospital) had received the cash entitlement. However, among eligible women who had delivered at home (those aged 19 and above, belonging to
BPL households and having their first or second birth), just one woman had received it. This is not surprising given the limited efforts to inform women and the community at large that women are entitled to receive the cash benefit for home deliveries if they fulfil certain conditions, Finally, a negligible minority of non-eligible women (4\%) had received the cash benefit; these women included those who had delivered at home but did not meet the JSY eligibility criteria, those who had delivered in transit, and those who had delivered in a normal (non-accredited) sub-centre or non-accredited private hospital.

Findings presented in Table 3.1 further indicate that both rural and urban women who were aware of the JSY prior to their most recent delivery were as likely to receive the cash benefit as those who came to know about it during the pregnancy or after delivery ( $44 \%$ versus $46 \%$ and $52 \%$ versus

\section{Table 3.1}

Percentage of women who received JSY benefits by selected background characteristics, according to residence

\begin{tabular}{|l|c|c|c|}
\hline Background characteristics & Combined & Urban & \\
\hline Age (years) & & & Rural \\
\hline$<18$ & 40.9 & $*$ & 41.3 \\
\hline $18-19$ & 50.5 & 59.7 & 49.2 \\
\hline $20-24$ & 48.3 & 56.1 & 41.1 \\
\hline $25-29$ & 43.6 & 49.4 & 38.7 \\
\hline $30-34$ & 39.8 & 41.8 & \\
\hline Religion & & & 48.8 \\
\hline Hindu & 49.4 & 51.6 & 27.5 \\
\hline Muslim & 35.3 & 55.7 & \\
\hline Other ${ }^{1}$ & 33.3 & 28.0 & \\
\hline Caste & & & 44.3 \\
\hline Scheduled castes & 45.3 & 50.0 & 57.2 \\
\hline Scheduled tribes & 55.5 & 32.1 & 41.5 \\
\hline Other backward castes & 44.9 & 56.6 & 45.9 \\
\hline General castes & 46.8 & 48.1 & \\
\hline
\end{tabular}


Table 3.1: (Cont'd)

\begin{tabular}{|c|c|c|c|}
\hline Background characteristics & Combined & Urban & Rural \\
\hline \multicolumn{4}{|c|}{$\begin{array}{l}\text { Educational level (completed years of } \\
\text { schooling) }\end{array}$} \\
\hline None & 39.4 & 46.9 & 38.4 \\
\hline $1-7$ years & 52.3 & 58.5 & 50.4 \\
\hline $8-11$ years & 57.8 & 63.4 & 54.5 \\
\hline 12 and above & 45.4 & 38.0 & 58.2 \\
\hline \multicolumn{4}{|l|}{ Wealth quintile } \\
\hline First & 36.2 & 39.3 & 36.0 \\
\hline Second & 42.9 & 47.9 & 42.5 \\
\hline Third & 51.5 & 53.6 & 51.2 \\
\hline Fourth & 51.9 & 59.8 & 48.3 \\
\hline Fifth & 48.8 & 48.8 & 49.1 \\
\hline \multicolumn{4}{|l|}{ Possession of a BPL card } \\
\hline Yes & 46.2 & 57.0 & 44.4 \\
\hline No & 46.7 & 51.7 & 45.0 \\
\hline Don't know & 36.1 & 44.0 & 34.8 \\
\hline \multicolumn{4}{|l|}{ Parity } \\
\hline 1 & 53.3 & 55.2 & 52.6 \\
\hline $2-3$ & 46.0 & 51.0 & 44.4 \\
\hline $4+$ & 37.3 & 45.8 & 36.1 \\
\hline \multicolumn{4}{|l|}{ Place of delivery } \\
\hline Hospital $^{2}$ & 91.9 & 92.4 & 91.8 \\
\hline Home $^{3}$ & * & - & * \\
\hline Other ${ }^{4}$ & 3.9 & 0.8 & 4.6 \\
\hline \multicolumn{4}{|c|}{ Pre-pregnancy awareness of the JSY } \\
\hline Yes & 45.9 & 51.8 & 43.9 \\
\hline No & 47.1 & 53.1 & 45.7 \\
\hline \multicolumn{4}{|c|}{ Interactions with the ASHA during pregnancy } \\
\hline Yes & 59.7 & 52.0 & 60.4 \\
\hline No & 42.1 & 52.0 & 38.4 \\
\hline \multicolumn{4}{|l|}{ District } \\
\hline Alwar & 48.5 & 43.3 & 49.3 \\
\hline Jodhpur & 43.9 & 55.9 & 37.9 \\
\hline Total & 46.3 & 52.1 & 44.5 \\
\hline
\end{tabular}

Note: ${ }^{1}$ Other includes Christians, Sikhs and Jains. ${ }^{2}$ Model sub-centres, PHCs, CHCs, district hospitals, accredited private hospitals. ${ }^{3}$ Deliveries to women aged 19 and above, belonging to BPL households and having first or second delivery. ${ }^{4}$ Noneligible deliveries, including those at home to women aged below 19, not belonging to BPL households and of 3+ parity; or at non-accredited sub-centres and non-accredited private hospitals, or in transit. () Based on 25-49 unweighted cases. ${ }^{*}$ Percentage not shown, based on fewer than 25 unweighted cases. Percentages indicated in the table are weighted; the number of respondents is unweighted. 
$53 \%$, respectively). However, interaction with an ASHA during pregnancy was positively associated with women receiving the JSY cash benefit; thus, 60 percent of women who had interacted with an ASHA during pregnancy compared to 42 percent of those with no such interaction had received the benefit. This difference, however, was observed only in rural areas. Finally, findings suggest that a slightly larger percentage of women in Alwar than Jodhpur had received the cash benefit (49 versus 44). The pattern differed by rural-urban residence; while more women from Jodhpur than Alwar had received such assistance in urban areas (56\% versus $43 \%)$, the reverse was observed in rural areas $(38 \%$ versus 49\%).

\section{Experiences of accessing JSY cash} assistance

Several questions were posed to women who had received JSY cash assistance in order to better understand their experiences in procuring such assistance, including the amount received, the person who motivated them to seek JSY benefits, the time taken to receive the cash amount, the number of installments in which the amount was paid to them, the mode of payment, the items on which they spent the money received and the extent to which the money received compensated for the expenses incurred during delivery. They were also asked whether they had received any help from ASHAs or other health workers in accessing their monetary entitlement, and whether they had to pay any bribe or make an unauthorised payment to obtain it.

As seen in Table 3.2, the majority (90\%) of women who had accepted JSY cash assistance had received the stipulated amount or more; in most cases, the latter included women who had arranged their own transportation rather than relying on the ASHA to arrange it and hence, had legitimately received an additional sum of Rs.300 toward meeting transport expenses. A larger proportion of urban than rural women reported having received the stipulated amount or more (96\% versus 88\%). Even so, it may be noted that one-tenth of beneficiary women had received less than their entitlement. In the course of in-depth interviews as well, most women affirmed that they had received the stipulated amount or more as the following excerpts illustrate:

\section{I had received Rs.1,400; I did not face any}

problem. [27 years, rural Alwar]

I had received Rs.200 toward the fare for hiring the vehicle. I had also received Rs.1,400 at the time of the delivery of my child. [24 years, rural Jodhpur]

\section{I had received Rs.1,000; I didn't face any \\ problem. [28 years, urban Jodhpur]}

Findings further indicate that family members, friends and neighbours, followed by ANMs and medical officers, were the leading persons who had motivated women to seek JSY benefits ( $45 \%$ and 36\%, respectively) (Table 3.2). One-quarter of women reported that the ASHA had encouraged them to do so, while another one-sixth reported that they were self-motivated. Rural-urban differences in women's reports of persons who had motivated them to seek JSY benefits were notable; informal social interaction (apart from self-motivation) seemed to be more influential in urban areas while the formal provider network was more effective in rural areas. For example, in urban areas, the majority of women said that their motivators were family members, friends and neighbours (61\%) or that they were self-motivated (31\%); the corresponding percentages in rural areas were 39 and 11, respectively. In rural areas, ANMs and medical officers as well as ASHAs had played a leading role in motivating women to seek JSY benefits ( $40 \%$ and $32 \%$, respectively); the 
Table 3.2

Percentage of women who received JSY benefits by their experiences of accessing cash assistance, according to residence

\section{\begin{tabular}{|l|l|l|l}
\hline JSY experiences & Combined & Urban & Rural
\end{tabular}}

JSY amount received ${ }^{1}$

Combined

Urban

Rural

Less than stipulated amount ${ }^{2}$

Stipulated amount ${ }^{3}$

More than the stipulated amount

Person who motivated the respondent to avail of the JSY ${ }^{4}$

ASHA

$$
9.3
$$

AWW

ANM/Doctor

Family members/Friends/Neighbours

Self

Other

Time taken to receive JSY money

Within a week of delivery

Between one week and one month of delivery

1-3 months of delivery

4-6 months of delivery

More than 6 months of delivery

Number of instalments received

One

Two

Mode of payment

Cash

Cheque/Draft

\section{Extent to which JSY money compensated for expenses} incurred for delivery 5,6

Less than the expenses incurred for delivery

As much as the expenses incurred for delivery

More than the expenses incurred for delivery

Items on which JSY money was spent ${ }^{4}$

Own care

Child care

Transport expenses incurred for delivery

Paying the provider

Repaying a loan

Family expenses

Husband/Family members took away

Saved for future

Other

\section{Received assistance from ASHA/other health workers in} getting JSY money

Payment of bribe/Unauthorised payment

Number of women who received JSY cash assistance
52.6

37.2

\begin{tabular}{|r|r|r|}
\hline 25.0 & 6.3 & 31.6 \\
\hline 7.0 & 2.4 & 8.6 \\
\hline 35.8 & 24.7 & 39.7 \\
\hline 44.7 & 61.1 & 39.0 \\
\hline 16.4 & 31.1 & 11.2 \\
\hline 1.8 & 2.1 & 1.7 \\
\hline & & \\
\hline 48.8 & 74.9 & 39.7 \\
\hline 34.7 & 19.0 & 40.2 \\
\hline 14.5 & 5.2 & 17.7 \\
\hline 1.8 & 0.5 & 2.2 \\
\hline 0.2 & - & 0.3 \\
\hline & & \\
\hline 99.3 & 99.5 & 99.3 \\
\hline 0.7 & 0.5 & 0.7 \\
\hline & & \\
\hline 2.9 & 0.5 & 3.9 \\
\hline 97.1 & 99.5 & 96.1 \\
\hline
\end{tabular}

11.5

41.8

45.8

31.6

8.6

39.7

39.0

1.2

1.7

39.7

40.2

17.7

2.2

0.3

9.3

0.7

96.1

\begin{tabular}{|r|r|r|}
\hline 23.4 & 34.8 & 19.5 \\
\hline 1.4 & 3.6 & 0.7 \\
\hline 53.4 & 38.3 & 58.7 \\
\hline & & \\
\hline 70.0 & 64.6 & 71.8 \\
\hline 11.1 & 9.1 & 11.9 \\
\hline 3.7 & 0.9 & 4.7 \\
1.7 & 0.9 & 2.0 \\
0.7 & 0.3 & 0.9 \\
\hline 1.8 & 4.7 & 14.3 \\
\hline 12.1 & 6.8 & 14.0 \\
\hline .1 & 17.6 & 6.1 \\
\hline 1.7 & 2.4 & 1.5 \\
\hline
\end{tabular}

\begin{tabular}{|l|l|l|}
\hline 42.4 & 28.0 & 47.5 \\
\hline
\end{tabular}

\begin{tabular}{l|r|r}
15.0 & 3.1 & 19.1
\end{tabular}

\begin{tabular}{|l|l|l|}
$\mathbf{2 , 2 3 2}$ & $\mathbf{1 , 1 7 0}$ & $\mathbf{1 , 0 6 2}$ \\
\hline
\end{tabular}

Note: ${ }^{1} 1 \%$ reported that they did not remember the amount received. ${ }^{2}$ No overlap with payment of bribe or unauthorised payment. ${ }^{3}$ Rs. 1,400 in case of rural respondents and Rs.1,000 in case of urban respondents. ${ }^{4}$ Multiple responses given. ${ }^{5}$ Data on expenses incurred for delivery were not available for $22 \%$ of JSY beneficiaries. ${ }^{6}$ Delivery expenses included provider fees, cost of drugs and supplies, laboratory tests and room charges. Percentages indicated in the table are weighted; the number of respondents is unweighted. 
corresponding percentages in urban areas were 25 and 6 , respectively.

Table 3.2 also indicates that significant proportions of women had not received the cash assistance promptly and that, by and large, rural women were less likely than their urban counterparts to have received it without delay. Thus, almost onehalf $(49 \%)$ of beneficiaries had received the cash amount within a week of delivery; considerably fewer rural than urban women so reported ( $40 \%$ versus 75\%). Likewise, one-third of women (35\%) had to wait for between one week and less than a month of delivery to receive the money, and another oneseventh for one to three months following delivery, with more rural than urban women reporting so ( $40 \%$ versus $19 \%$ and $18 \%$ versus $5 \%$, respectively). Almost all the women had received the cash in a single installment (99\%) by cheque (97\%).

In order to assess the extent to which cash assistance received under the JSY had compensated for their delivery-related expenses, women were asked about the money they had spent on provider fees, drugs and supplies, laboratory tests and room charges. A comparison of the amount received and expenses incurred indicates that while a little more than one-half of JSY beneficiaries (55\%) had received as much as or more than the expenses incurred during delivery, one-quarter of beneficiary women $(23 \%)$ had received less than the amount they had spent (Table 3.2). Most women who had received cash assistance had spent the money on selfcare (70\%); slightly more rural than urban women so reported ( $72 \%$ versus $65 \%)$.

Over two-fifths of women (42\%) also reported that they had been assisted by an ASHA or other health worker to get their cash entitlement; more rural than urban women so reported ( $48 \%$ versus 28\%). Qualitative data indicate that such assistance included getting the 'mother and child card' prepared, completing various formalities at the health facility, accompanying women or family members to the facility to collect the cheque for the JSY entitlement and escorting women to the bank to encash the cheque:

No, I didn't face any problem at the bank as didi (ASHA) was with me...I deposited the cheque in the bank and got the money. [25 years, rural Alwar]

I didn't get time to go to the hospital to collect the cheque; my husband went with her (ASHA) and brought the cheque. [24 years, rural Jodhpur]

She had done everything nicely. She helped me in getting my card (mother and child card); she had filled out the form and taken it to the doctor. [21 years, urban Jodhpur]

A small minority of women (7\%) reported having paid a bribe or made an unauthorised payment to the ASHA or a health care provider to get their cash entitlement; slightly more rural than urban women so reported ( $8 \%$ versus $2 \%$ ). As evident from the excerpts given below, this included cases in which a health care provider had misappropriated the money under the pretext of fees and cost of medicines as well as women who had paid the health care provider voluntarily:

They had not given it (cheque) immediately; they told me that I could not get it soon. When they gave the money to me, they had given me a cheque for Rs.1,300. He (doctor) told me that he had charged Rs.100 toward his fees. [21 years, rural Alwar]

I had received Rs.1,400, but she (nurse) took Rs.400. for attending the delivery. We gave her Rs.200, but she refused and told us that she 
would take Rs.400 only. She told us that she takes money from everyone whose delivery she attends. [21 years, rural Alwar]

I had received Rs.1,400, but she (nurse) had deducted Rs.900; she told me that it was toward medicines and gave me Rs.500.... I had received cash and not a cheque... I did not complain to anyone, I am illiterate, I don't know to whom I could have complained. [26 years, rural Jodhpur]

I received Rs.900 only. They (doctors) had given a cheque to my husband for Rs.900 only and said that I would get only this much money as I had not gone for regular check-ups. [18 years, rural Jodhpur]

She (ASHA) had not asked for any money, but I had given (her) some on my own. [26 years, urban Alwar]

\section{Reasons for not availing of JSY cash} assistance

All women who had not availed of JSY cash assistance were probed about the reason/s for not doing so; findings are presented in Table 3.3 and Figure 3.1. The leading reason was poor perceived quality of delivery services at public sector health facilities; 47 percent of non-beneficiaries reported that they had taken a deliberate decision to deliver at home or in a private health facility and forego JSY cash assistance because of the poor quality of care at public sector facilities, including undignified care and unnecessary reliance on such procedures as episiotomy and caesarean delivery. A larger proportion of urban than rural women so reported (68\% versus $41 \%)$. During in-depth interviews, nonbeneficiaries cited several dimensions of poor quality of delivery care, including verbal abuse, denial of proper and timely care, not paying attention to women's concerns and non-availability of the service provider, that had deterred them from seeking delivery services at public sector health facilities and therefore, from obtaining JSY cash assistance:

I wanted to deliver my child at home because one of my sisters who had delivered a girl child had suffered badly at the government hospital because they had left the 'dirt' in her stomach after the birth of the child; she had to go to the hospital again for a 'clean up'. After seeing her (plight), I lost the courage to deliver my child at the hospital. My mother-in-law had also seen my sister's condition, that's why they (in-laws) did not pressurise me. It happened with my neighbour too. They (health care providers) don't give proper attention. They attend to the woman only after the head of the child is visible, and don't touch the woman after the birth of the child. They scold and shout when the woman is suffering from pain; they don't handle the woman correctly or encourage her. [24 years, urban Alwar, nonbeneficiary, delivered at home]

My family members wished that I should deliver in a health facility, but I refused.... I was scared because the nurses there do not take care of women properly. [20 years, urban Alwar, nonbeneficiary, delivered at home]

My family members had asked me to deliver at the government hospital, but I did not go there. I am scared of hospitals and that's why I decided to deliver my child at home. They keep women alone (do not allow them to bring a companion into the labour room). The doctors and nurses scold women. [25 years, urban Jodhpur, nonbeneficiary, delivered at home]

I had not availed of the benefit of the scheme because no one listens there (at the government facility). I had never gone to the government hospital for consultation, so why should I go there 
Table 3.3

Percentage of women by reasons for not availing of JSY cash assistance, according to residence

Reasons

\section{Quality of care-related}

Non-dignified treatment by providers at hospitals

Unnecessary use of episiotomy, caesarean delivery etc

At least one quality of care-related reason

\section{Individual/ family preferences and constraints}

Preference for a home delivery

Family members' objection to institutional delivery

Lack of time to go to the hospital for delivery

Lack of escort to go to the hospital

At least one preferences and constraints-related reason

\section{Awareness-related}

Lack of awareness of the JSY at the time of delivery

Lack of awareness of the importance of institutional delivery

At least one awareness-related reason

\section{Administration of JSY scheme-related}

Cumbersome process of obtaining cash assistance

Corruption in the disbursement of cash assistance

Insufficient cash assistance

Delayed discharge from hospital

At least one JSY administration-related reason

\section{Access-related}

Non-availability of female doctor at the facility

Long distance to government hospitals

Lack of transportation

At least one access-related reason

\section{Economic}

Non-requirement of cash assistance

\section{Other reasons}

Delivery before expected due date

Non-compliance with formalities for receiving cash assistance

Other

\section{Number of women who had not availed of JSY cash} assistance

\section{Combined}

43.7

4.0

46.9

6.5

3.2

7.9

0.9

18.5

5.7

8.1

13.8

1.8

0.5

6.0

0.3

8.1

4.4

1.9

1.8

4.2

3.6

8.0

5.7

0.2

13.4

4.4

6.1

9.2

15.3

8

1.0

2.0

5

0.2

0.6

2.9

6.9

.3

0.4

0.3

4.2

9.1

4

1.3

5.2

1.5

2.0

0.2

1.1

3.1

8.1

1.1

1.4

0.6

1.7

0.2

0.2

0.2

Note: Percentages indicated in the table are weighted; the number of respondents is unweighted. Information on reasons was not available for $8 \%$ of the women who had not availed of JSY cash assistance. 
for delivery?... I used to go to the private hospital because they don't shout at you there. [25 years, urban Jodhpur, non-beneficiary, delivered at home]

I heard from my neighbours that doctors pay attention to women only when half of the baby's head comes out; they don't take care of women properly. [21 years, urban Alwar, nonbeneficiary, delivered at home]

My children (twins) were born at night. When we reached the hospital, it was closed as the doctors and nurses had gone on leave for Diwali. One of the twins was delivered just outside the hospital gate (on the way back) and the second soon after I reached home. [22 years, rural Alwar, non-beneficiary, delivered in transit and at home]

The preference of women or their family members for a home delivery and the constraints faced by women at the family level, including lack of an escort and time to visit a health facility for delivery were cited by 19 percent of nonbeneficiaries, and slightly more rural than urban women so reported (20\% versus 13\%):

If my family members had taken me to the hospital, I would have gone. [22 years, rural Jodhpur, non-beneficiary, delivered at home]

It was my wish because the child is delivered better at home. My family members also wished that I should deliver my child at home. [19

years, rural Jodhpur, non-beneficiary, delivered at home]

About 14 percent of non-beneficiaries reported that they had not been aware of the JSY at the time of their delivery or of the importance of institutional deliveries. Those who reported lack of awareness of the scheme said that had they known about it earlier, they would have taken advantage of it:

Figure 3.1: Major reasons given by women for not availing of JSY cash assistance, according to residence

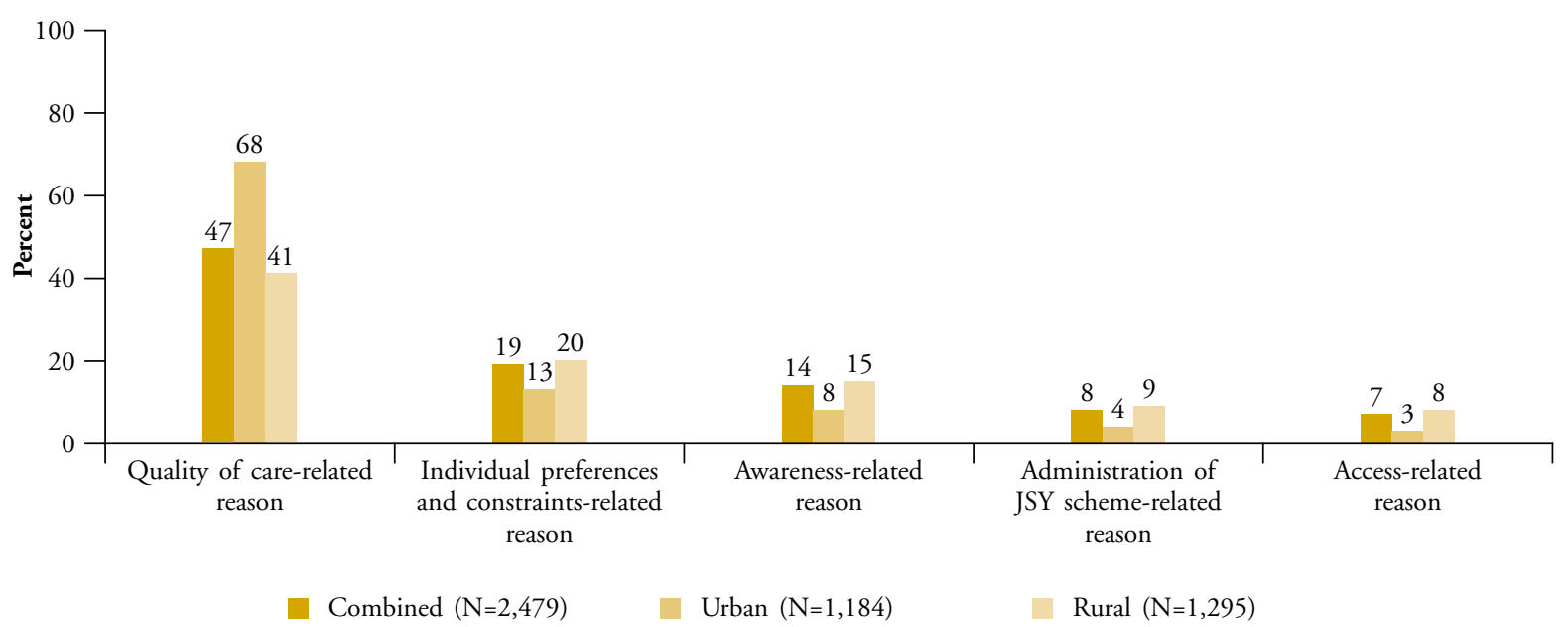

Note: Percentages are based on women who had not received JSY cash assistance. Information on reasons for not availing of the assistance was not available for $8 \%$ of women. Percentages indicated in the figure are weighted; the number of respondents is unweighted. 
I didn't know about it (JSY) at the time of the birth of my daughter; I came to know after her birth. As I didn't know, I had gone to a private hospital for delivery. Had I known earlier, I would have gone to a government hospital. [25 years, rural Alwar, non-beneficiary, delivered in a private hospital]

Further, 8 percent of non-beneficiaries cited various concerns related to the administration of the JSY that had deterred them from taking advantage of the cash assistance. These included concerns that the amount provided was not sufficient to cover the expenses incurred for delivery, that it would entail a longer stay at the health facility, that the process of accessing the amount was cumbersome and that there was too much corruption in the implementation of the scheme. For example:

My son fell ill and was admitted in the children's ward; I was alone. They (hospital staff) did not give me the card (mother and child card) when I went to the children's ward. So I couldn't get the money. When I asked the nurse, she said, 'How can you get the money when you were not on the bed?' [34 years, urban Alwar, non-beneficiary, delivered at a government hospital]

I thought that I would have spent more than Rs.1,400 if I had gone to the hospital for delivery. That's why I delivered my child at home. [18 years, rural Jodhpur, non-beneficiary, delivered at home]

Other reasons cited by non-beneficiaries included those related to access to a health facility, the family's economic status, non-compliance with the formalities required to receive the cash assistance and wrong assessment of the expected time or date of delivery, as indicated by the following excerpts:
They told us that we would not get money as we had taken the cottage ward (private ward where one pays for services). [20 years, urban Jodhpur, non-beneficiary, delivered in a government hospital]

I didn't know that the child would be born that day; that's why I couldn't avail of the benefits of the scheme. I had gone for a sonography and she (health care provider) told me that I would deliver on the 21st and there was still one more month for the child to arrive. However, she (my daughter) was born before the expected date of delivery given to me. [26 years, rural Alwar, non-beneficiary, delivered at home]

I had been vaccinated at a private hospital, so I didn't have the mother and child card. They (staff at the government hospital) told me that I would not get money as I didn't have the card. [25 years, rural Jodhpur, non-beneficiary, delivered in a government hospital]

\section{Support received from the ASHA}

As per JSY guidelines, the responsibilities of ASHAs include identifying pregnant women, facilitating their registration for ANC, counseling them about institutional delivery, escorting them for delivery and making a postpartum visit within seven days of delivery. The study contained several questions to assess the extent to which the respondents had received assistance from the ASHA during pregnancy, delivery and the postpartum period. Table 3.4 summarises the extent and kind of support received by women from the ASHA during their most recent pregnancy, regardless of whether or not they had received JSY cash assistance. As mentioned in Chapter 2, ASHAs were serving in 79 of the 96 villages and 54 of the 100 urban wards included in this survey. 
Table 3.4

Percentage of women by type of assistance received from the ASHA during pregnancy, delivery and the postpartum period, according to residence

\begin{tabular}{|c|c|c|c|}
\hline Type of assistance received & Combined & Urban & Rural \\
\hline \multicolumn{4}{|l|}{ During pregnancy } \\
\hline Helped with registering for antenatal check-up & 17.6 & 5.6 & 21.2 \\
\hline $\begin{array}{l}\text { Visited respondent at home to inform about antenatal } \\
\text { check-up }\end{array}$ & 12.1 & 6.1 & 13.8 \\
\hline Assisted in getting antenatal check-ups & 16.3 & 5.8 & 19.4 \\
\hline Assisted in getting tetanus toxoid injection & 19.3 & 6.6 & 23.1 \\
\hline Assisted in getting iron and folic acid supplements & 15.0 & 5.4 & 17.8 \\
\hline Provided information on pregnancy-related care & 13.2 & 5.9 & 15.4 \\
\hline Any of the above & 23.5 & 8.9 & 27.9 \\
\hline Number of women & 4,770 & 2,372 & 2,398 \\
\hline \multicolumn{4}{|l|}{ During delivery } \\
\hline Arranged transport & 1.7 & 0.1 & 2.4 \\
\hline Accompanied respondent to the hospital for delivery & 16.5 & 3.2 & 22.4 \\
\hline Stayed at the hospital till respondent was discharged & 11.4 & 1.9 & 15.7 \\
\hline Any of the above & 17.3 & 3.6 & 23.4 \\
\hline $\begin{array}{l}\text { Number of women who had delivered in a health } \\
\text { facility }\end{array}$ & 3,320 & 1,990 & 1,330 \\
\hline \multicolumn{4}{|l|}{ During the postpartum period } \\
\hline Visited respondent at home & 11.9 & 4.4 & 14.2 \\
\hline Provided information on self-care and newborn care & 11.8 & 5.4 & 13.7 \\
\hline Any of the above & 13.8 & 6.3 & 16.1 \\
\hline Number of women & 4,770 & 2,372 & 2,398 \\
\hline
\end{tabular}

Note: Percentages indicated in the table are weighted; the number of respondents is unweighted.

Findings suggest that few women had received assistance from the ASHA, particularly during delivery and the postpartum period. For example, just one-quarter of all women $(24 \%)$ had received the ASHA's help during pregnancy, with more rural than urban women reporting so (28\% versus $9 \%)$. Even in the villages and urban wards served by ASHAs, only 30 percent of women had received pregnancy-related assistance from an ASHA. The type of assistance typically provided by the ASHA included enabling women to get immunised (19\%), facilitating antenatal registration (18\%) and antenatal check-ups (16\%), and helping women to get iron and folic acid supplements (15\%). In-depth interviews too confirmed that the ASHA had mainly helped pregnant women to get vaccinated; of the 28 women who discussed this issue, 19 reported that the ASHA had informed and reminded them about their vaccination days and, at times, also escorted them to the health facility for vaccination. For example: 
I had gone to the Anganwadi when I was 3-4 months pregnant to get vaccinated. I met her (ASHA) there and she reminded me to come for vaccination in the fifth month. [24 years, urban Alwar].

She had come once to inform me about vaccinations. [21 years, rural Alwar]

She used to accompany me to the hospital to get vaccinated. [21 years, urban Jodhpur]

Table 3.4 further indicates that even fewer women had received assistance from the ASHA during delivery; of those who had delivered in a health facility, just 17 percent (and 22\% of those in the villages and urban wards served by ASHAs) so reported. Such assistance was mainly in the form of accompanying women to the hospital for delivery (17\%) and staying with them till they are discharged (11\%); just 2 percent of women reported that the ASHA had arranged transportation to take them to the health facility. Likewise, as regards postpartum assistance, just 14 percent of women (and 17\% of those in the villages and urban wards served by ASHAs) said that the ASHA had assisted them mainly by way of visiting them at home following delivery, and counselling them about self-care and newborn care.

The study also probed women who were not escorted by an ASHA to a health facility for delivery about whether or not they had asked the ASHA to accompany them and if not, the reasons for not doing so. Findings summarised in Table 3.5 indicate that just 6 percent of the women who were probed had indeed asked the ASHA to accompany them to the health facility; more rural than urban women had done so ( $8 \%$ versus $1 \%)$. Those who had not asked the ASHA for escort cited a number of reasons for not doing so. The leading reason, cited by one-half of women, was lack of awareness of the
ASHA or of her responsibility to escort women to the health facility for delivery; more urban than rural women gave this reason ( $70 \%$ versus 36\%). The other leading reasons were lack of contact with the ASHA during pregnancy, reported by 22 percent of women $(15 \%$ and $26 \%$ of urban and rural women, respectively) and lack of time to call the ASHA, reported by 8 percent of women $(2 \%$ and $11 \%$ of urban and rural women, respectively).

\section{Reach of schemes other than the JSY}

The study also assessed the reach of schemes, other than the JSY, that are intended to promote safe motherhood, such as the 108 ambulance service, and the special nutritional supplementation scheme among women who had delivered in a health facility. Although the transportation allowance is part of the ASHA package, it is given to women when the ASHA does not organise transport to go to a health facility for delivery (Ministry of Health and Family Welfare, 2006). Hence, the study also assessed the percentages of women who had received this allowance.

Findings suggest that only a minority of women had availed of these schemes (Figure 3.2). For example, a little over one-quarter of women (30\%) reported that they had received the transportation allowance; rural women were almost five times more likely than urban women to have received the allowance (39\% versus 8\%) (Figure 3.2). Likewise, just 6 percent of women had called for the 108 ambulance service and 5 percent had used it to go to a health facility for delivery. We note that many women, particularly those residing in areas close to the health facility, may not have called for the service as they were not entitled to the transportation allowance. Finally, hardly any women $(0.2 \%)$ had received a voucher for special nutritional supplements in the form of five kilograms of ghee. 
Table 3.5

Of those not escorted by an ASHA to a health facility for delivery, percentage of women who had approached the ASHA to escort them, and of those who had not approached the ASHA, percentage reporting reasons for not doing so, according to residence

\begin{tabular}{|c|c|c|c|}
\hline & Combined & Urban & Rural \\
\hline $\begin{array}{l}\text { Respondent approached ASHA to accompany her to the } \\
\text { health facility for delivery }\end{array}$ & 5.5 & 1.3 & 7.9 \\
\hline $\begin{array}{l}\text { Number of women who had delivered in a health } \\
\text { facility and were not escorted by an ASHA }\end{array}$ & 2,943 & 1,903 & 1,040 \\
\hline Reasons for not approaching the ASHA & & & \\
\hline $\begin{array}{l}\text { Lack of awareness of ASHA/ASHA's responsibility to escort } \\
\text { women to a health facility for delivery }\end{array}$ & 49.1 & 70.1 & 36.4 \\
\hline No contact with ASHA during pregnancy & 21.8 & 15.0 & 25.9 \\
\hline Lack of time to call ASHA & 7.5 & 1.9 & 10.9 \\
\hline No ASHA in the village/neighbourhood & 5.3 & 6.4 & 4.7 \\
\hline No contact details of ASHA & 3.4 & 0.5 & 5.2 \\
\hline Closer location of the health facility & 2.7 & 2.2 & 2.9 \\
\hline Relationship with ASHA not good & 0.6 & 0.1 & 0.9 \\
\hline Delivery at natal home/ in a private hospital & 2.3 & 1.7 & 2.7 \\
\hline To save transportation money & 1.1 & 0.1 & 1.7 \\
\hline No particular reason & 4.5 & 1.9 & 6.0 \\
\hline $\begin{array}{l}\text { Number of women who had delivered in a health } \\
\text { facility and had not approached the ASHA to escort } \\
\text { them to the facility }\end{array}$ & 2,820 & 1,865 & 955 \\
\hline
\end{tabular}

Note: Percentages indicated in the table are weighted; the number of respondents is unweighted. Information on reasons was not available for $3 \%$ of the women.

Figure 3.2: Reach of schemes other than the JSY: percentage of women who had availed of the schemes, according to residence

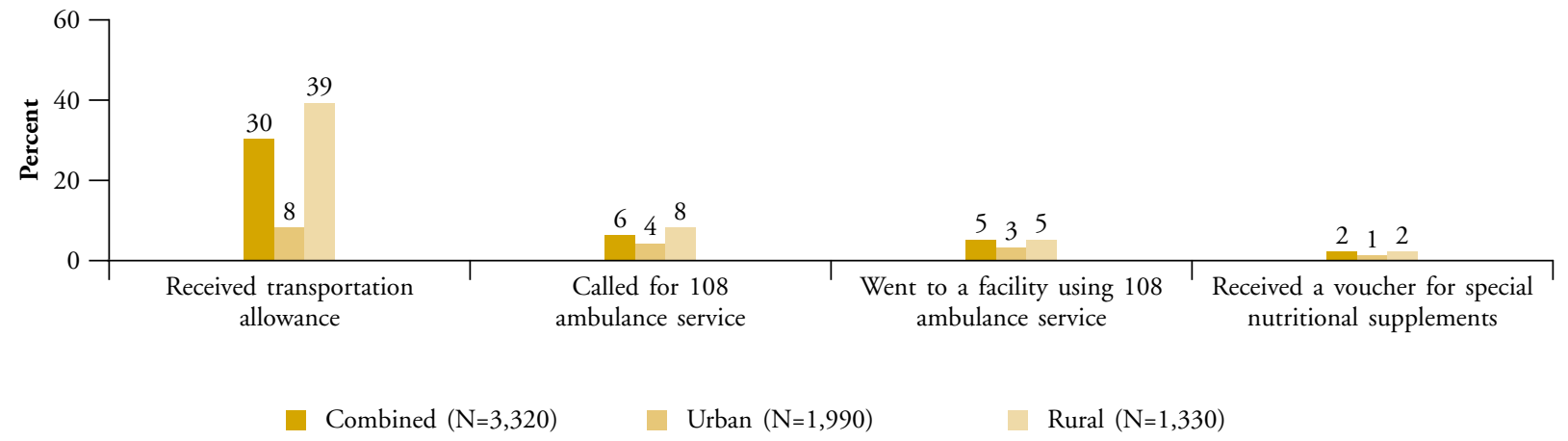

Note: Percentages are based on women who had delivered in a health facility. Percentages indicated in the figure are weighted; the number of respondents is unweighted. 


\section{Perceptions about the JSY}

In order to assess women's perceptions about the JSY, all women, regardless of whether or not they had availed of cash assistance, were asked whether they perceived any improvement in maternal and child health services with the introduction of the JSY. Beneficiaries, in addition, were asked whether they would recommend the scheme to others in the community. These aspects were probed in detail during in-depth interviews too. Survey findings, presented in Figure 3.3a, indicate that almost three-quarters of women, irrespective of rural-urban residence, perceived that maternal and child health services had improved with the introduction of the JSY. Moreover, among those who had received cash assistance, almost everyone reported that they would recommend the scheme to other women in the community (Figure 3.3b).

Qualitative data indicate that women perceived improvements in several areas, ranging from better provision of information on maternal and child

Figure 3.3a: Women's perceptions about whether JSY has improved maternal and child health services, according to residence

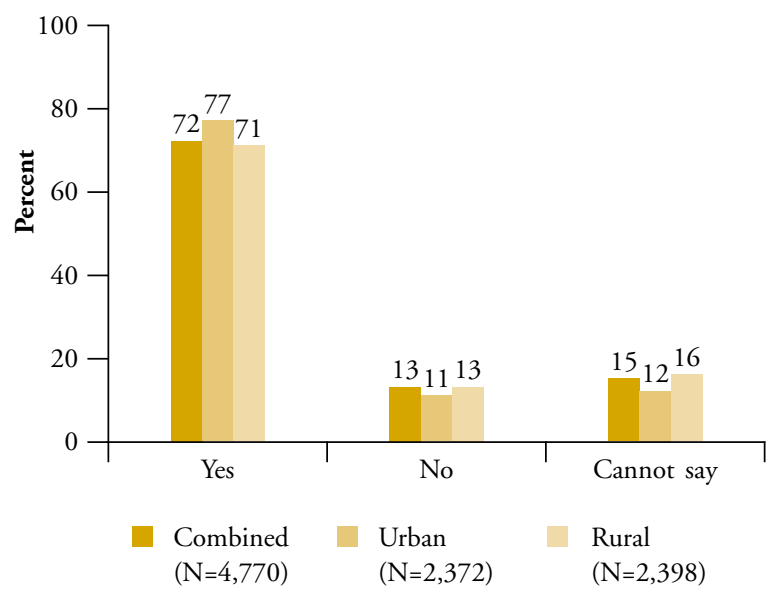

Note: Percentages indicated in the figure are weighted; the number of respondents is unweighted.
Figure 3.3b: Women's views about recommending the JSY to other women, according to residence

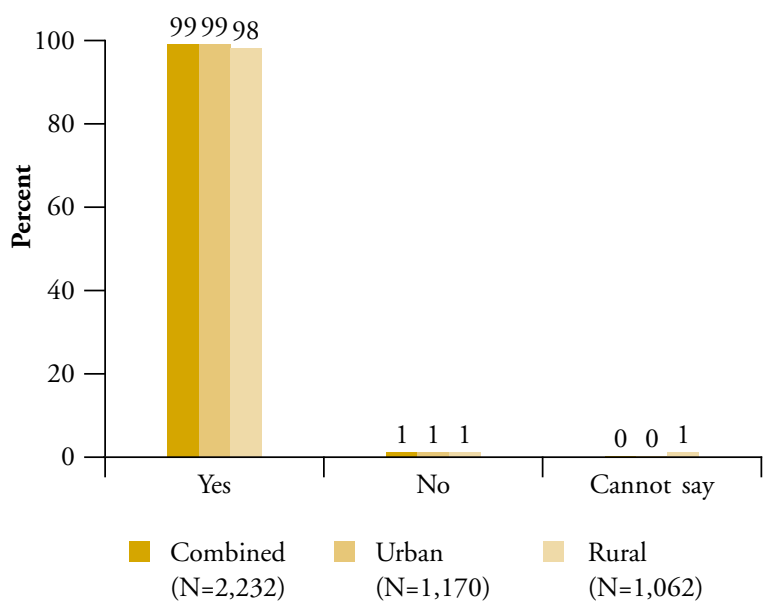

Note: Percentages are based on women who had received JSY cash assistance. Percentages indicated in the figure are weighted; the number of respondents is unweighted.

health care, safer management of delivery, better treatment at the facility by providers, improved access to services and, above all, coverage of some of the cost incurred for delivery, as the following narratives show:

Of course, there is improvement in the health of mothers as well as children. Earlier, people were not so educated (about institutional delivery) and many deliveries in the village used to take place at home, attended only by traditional birth attendants. There used to be problems; for example, in cutting the umbilical cord, and some children used to turn blue or die; but if they face any problem in the hospital, they can be checked up and treated promptly. Earlier, in villages, women had to bear pain for many days if a problem occurred during delivery, and some mothers used to die; it doesn't happen in a hospital as they go for an operation in case labour pain is prolonged. Earlier, we had to go to the hospital on our own and since we don't know the doctors, they don't take care of us properly; now, 
as the ASHA accompanies us to the hospital, doctors also talk properly and treat us properly. We also had to spend money from our own pockets, now we get Rs.1,400 from the scheme and we can at least pay the conveyance charges and purchase medicines etc. with this money. [25 years, rural Alwar]

Earlier, there were no facilities; now there are so many facilities. Earlier, no one used to go to hospitals, but now everyone goes to the hospital. Earlier, no one used to get money, but now everyone gets money. Earlier, we did not get so much advice or information, but now they advise us about everything. [23 years, rural Alwar]

The improvement is that they (ASHAs) take care of women at home, help them in getting check-ups, accompany them to the hospital and take them back home..... One gets facilities like ambulance, medicine and money. [24 years, urban Alwar]

Now, they take proper care of women. [26 years, rural Jodhpur]

Nowadays, everyone goes to the hospital; they get money which they can use to purchase ghee and milk. There is improvement; definitely. [23 years, rural Alwar]

There is improvement. Earlier, women in labour were not able to reach the doctor or nurse in time, but now there is an ambulance service by which any pregnant woman can reach the hospital in time. The delivery is done normally and they do a caesarian delivery, if required. The doctors also take care of women properly, give medicines, and vaccinate the mother and the child on time. A woman gets Rs.1,000 and ghee. Madam (health care provider) gives advice about family planning. [28 years, urban Jodhpur]
Nowadays, all vaccinations are given on time and the child is delivered safely. [26 years, rural Alwar]

Earlier, one had to spend money, but now one gets money after the delivery. So there is definitely some improvement. [18 years, rural Jodhpur] Earlier, the child used to be delivered at home, but now most women go to the hospital for delivery because of which there is less danger to the life of the child and the mother..... Moreover, the ambulance service (available to reach the hospital in time) is a big improvement. [19 years, rural Alwar]

The hospital is in the village itself-people get medicines from the village hospital; children are delivered there. [22 years, rural Alwar]

A couple of women observed improvements even at the family level, as evident from the excerpts below:

Family members take care of the woman in case she experiences any problem because one gets a cash benefit. [25 years, rural Alwar]

Because of money, family members take good care of women nowadays. [32 years, urban Alwar]

Although the majority of women reported improvements in maternal and child health services, it is notable that 13 percent of the women did not perceive such improvements and some 15 percent were unsure about it. Those who said that there was no improvement echoed concerns about additional costs incurred for delivery, lack of facilities and lack of care. For example:

What improvement? One ends up spending double the amount of money which one receives.

[21 years, rural Alwar] 
There is no improvement because no one pays attention to women. What would I do with that money if I had to face a problem and spend more money? There is no guarantee that the child will be delivered properly and come home alive.

[21 years, urban Alwar]

What can happen just by receiving money when there are no proper facilities in the hospital?

[24 years, rural Jodhpur]

The condition has worsened; one has to wait for half-an-hour to see the doctor and then the doctor gives you just five minutes. [24 years, urban

Alwar]

\section{Summary}

Although all women in the state were eligible, fewer than half had benefited from the JSY. Findings, moreover, suggest that the reach of the JSY remains inequitable; those most vulnerable were less likely than others to have received the cash benefit. Thus, women living in rural areas; those at high risk of maternal complications that is, very young mothers or high-parity mothers; those belonging to socially and economically excluded groups, for example, Muslim women; illiterate women and poor women, were less likely than others to have received JSY benefits. However, in rural areas, interaction with an ASHA during pregnancy was positively associated with women receiving the cash benefit.

Family members, friends and neighbours, followed by ANMs and medical officers, were the leading persons who motivated women to seek JSY benefits. Rural-urban differences were notable; while informal social interaction (apart from self-motivation) was more influential in urban areas the formal provider network was more effective in rural areas.

Findings, moreover, indicate that most JSY beneficiaries had obtained the full amount, and almost one-half had received it within a week of delivery. It may be noted, however, that one in seven women had to wait for between one and three months of delivery. Further, for the majority of beneficiaries, the cash assistance was as much as or more than the expenses incurred during delivery. Fewer than one-tenth of women also reported paying a bribe or making an unauthorised payment to the ASHA or health care provider to get their monetary entitlement.

Few women got non-monetary entitlements, for example, support from ASHAs or benefits of other schemes such as the 108 ambulance service and special nutritional supplementation scheme. Just onequarter of all women had received assistance from the ASHA during pregnancy, and even fewer during delivery and the postpartum period. Likewise, just 5 percent had used the 108 ambulance service to go to a health facility for delivery, and hardly any women had received a voucher for special nutritional supplements in the form of five kilograms of ghee.

Women who had not availed of the JSY cash assistance primarily mentioned such reasons as perceived poor quality of delivery services at public sector health facilities, preference of the women themselves or their family members for a home delivery, constraints faced at the family level to go to a health facility for delivery, lack of awareness of the scheme or of the importance of institutional deliveries, and concerns about the administration of the scheme.

Finally, almost three-quarters of women, regardless of rural-urban residence, perceived that maternal and child health services had improved following the introduction of the JSY. Moreover, among those who had received cash assistance, almost everyone reported that they would recommend the scheme to other women in the community. 


\section{CHAPTER 4}

\section{Association between JSY beneficiary status and awareness of maternal and child health care practices}

This chapter focuses on findings with regard to the association between JSY beneficiary status and awareness of maternal and child health care practices among women. Five themes were used to explore this association, namely, awareness of antenatal care practices, awareness of birth preparedness, awareness of postpartum care practices, awareness of newborn care practices, and awareness of complications that may occur during pregnancy, delivery and the postpartum period, as well as those that may occur in newborns.

As described in Chapter 1, the analyses presented in this chapter draw on the sample of beneficiaries and non-beneficiaries, that is, 2,232 beneficiaries and 2,479 non-beneficiaries, who had delivered in the one year preceding the interview; women who reported that they were yet to receive JSY benefits were excluded from the analysis. A comparison of the mean values or percentages of outcome variables obtained for beneficiary and non-beneficiary groups permitted us to assess the association between JSY beneficiary status and women's awareness of selected maternal and child health care practices, and t-tests or chi-square tests, as appropriate, to test the significance of the association. Additionally, as mentioned in Chapter 1, we used regression analysis to control for the potentially confounding effects that such background characteristics as age, education, religion, caste, parity, household economic status, rural-urban residence and study district may have on the outcome measures.
We also note that while cash benefits are the most salient feature of the JSY, an array of services fall under the programme, including assistance to be provided by the ASHA during pregnancy, delivery and the postpartum period. This assistance encompasses a number of activities including raising awareness building. Hence, we hypothesise that awareness of maternal and child health care practices may differ between women who had benefited from the JSY and those who had not. At the same time, we caution readers against inferring causality given the cross-sectional nature of the data used.

\section{Association between JSY beneficiary status and awareness of antenatal care practices}

Three indicators were used to capture women's awareness of antenatal care practices. They assessed whether or not respondents were aware that a woman should have regular antenatal check-ups even if she is feeling well, that a woman should have at least three antenatal check-ups, and that a woman should ideally have her first antenatal check-up in the first trimester. Additionally, a summary measure of comprehensive awareness of antenatal care practices, based on women who reported awareness of all three indicators, was calculated.

Findings, presented in Figure 4.1, show that beneficiaries were significantly more likely than non-beneficiaries to report awareness of antenatal practices. For example, 87 percent of beneficiaries 
compared to 78 percent of non-beneficiaries knew that a woman should have regular antenatal checkups even if she is feeling well (Figure 4.1-A). Likewise, 59 percent of beneficiaries compared to 48 percent of non-beneficiaries were aware that a woman should ideally have her first antenatal check-up in the first trimester. Although narrow, differences in the percentages of beneficiaries and non-beneficiaries reporting awareness that a woman should have at least three antenatal check-ups and comprehensive awareness of antenatal care practices were also statistically significant ( $42 \%$ versus $38 \%$ and $30 \%$ versus $25 \%$, respectively). A similar pattern was observed in rural areas (Figure 4.1-C); in urban areas, however, differences by beneficiary status were observed only with regard to awareness of the importance of regular antenatal check-ups,

Figure 4.1: Association between JSY beneficiary status and awareness of antenatal care practices, according to residence

\section{A. Combined}

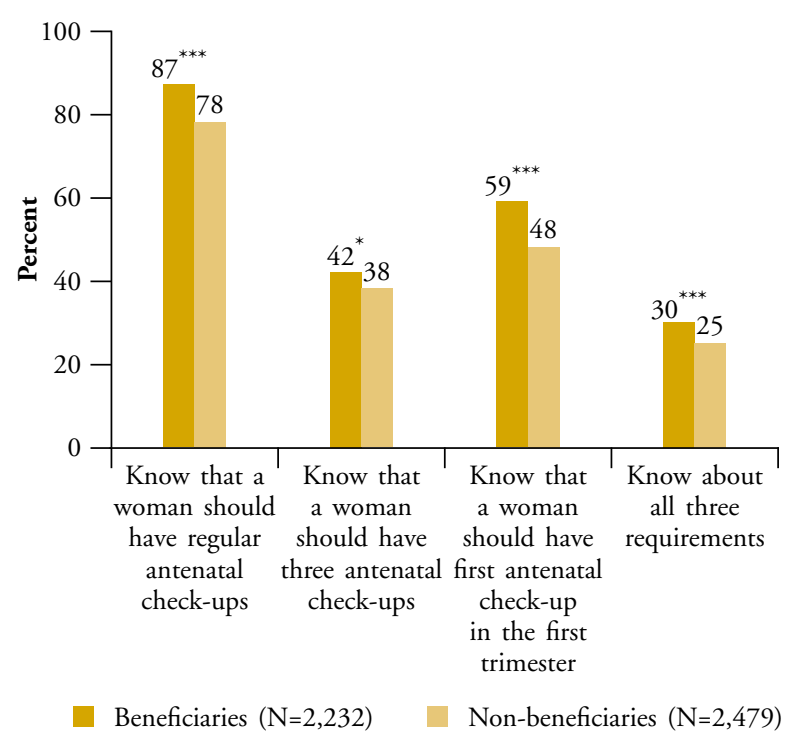

Note: Percentages indicated in the figure are weighted; the number of respondents is unweighted. ${ }^{*} p \leqslant 0.05 ;{ }^{* * *} p \leqslant 0.001$.

\section{B. Urban}

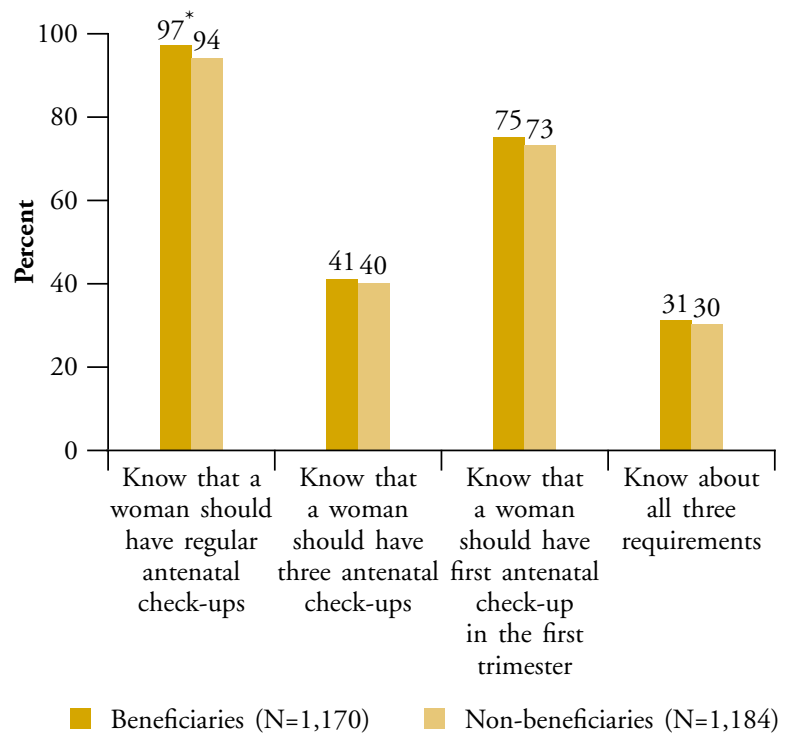

Note: Percentages indicated in the figure are weighted; the number of respondents is unweighted. ${ }^{*} p \leqslant 0.05$.

\section{Rural}

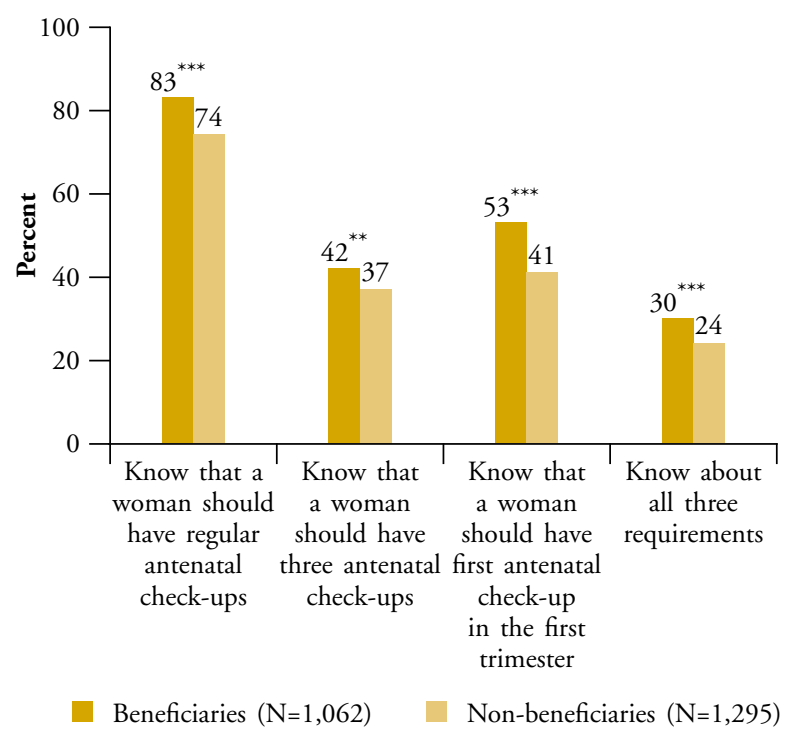

Note: Percentages indicated in the figure are weighted; the number of respondents is unweighted. ${ }^{* *} p \leqslant 0.01 ;{ }^{* * *} p \leqslant 0.001$. 
with slightly more beneficiaries than non-beneficiaries reporting awareness (97\% versus $94 \%)$ (Figure 4.1-B).

Findings of the multivariate analysis also indicate that beneficiaries were more likely than nonbeneficiaries to report comprehensive awareness of antenatal care practices after controlling for potentially confounding factors [adjusted odds ratio $(\mathrm{AOR})=1.15 ; 95 \%$ confidence interval $(\mathrm{CI})=1.00-$ 1.31]. When the rural and urban samples were analysed separately, however, no such association was observed.

\section{Association between JSY beneficiary status and awareness of key elements of birth preparedness}

The study explored women's awareness of birth preparedness by asking them to name the essential preparations that a woman should make for a safe delivery. Women were considered to have some awareness of birth preparedness if they reported that a woman should identify a hospital or trained midwife for her delivery, make arrangements for transportation, save money for delivery expenses, identify a referral health facility in case of an emergency or keep items necessary for a safe delivery with her in case she opts for a home delivery.

Findings, presented in Table 4.1, Panel A, indicate that beneficiaries were better informed about the essential preparations required for a safe delivery than were non-beneficiaries in that a larger percentage of beneficiaries than non-beneficiaries were able to name at least one key element of birth preparedness ( $40 \%$ versus $32 \%$ ). With regard to awareness of the individual elements of birth preparedness, differences were significant only with respect to awareness of the importance of making transportation arrangements to reach the health facility ( $15 \%$ of beneficiaries versus
$8 \%$ of non-beneficiaries) and saving money to meet delivery expenses (23\% of beneficiaries versus 16\% of non-beneficiaries). A similar pattern was evident in rural areas; in urban areas, however, no significant differences by beneficiary status were observed. In regression analyses too, differences by beneficiary status remained significant for the overall and rural samples when controlled for potentially confounding factors; beneficiaries were 1.3-1.4 times more likely than non-beneficiaries to be aware of at least one essential preparation for a safe delivery (Table 4.1, Panel B).

\section{Association between JSY beneficiary status and awareness of postpartum care practices}

Women's awareness of postpartum care practices was captured by three indicators that assessed whether or not respondents were aware that a woman should have a postpartum check-up even if she is feeling well, that a woman should have her first postpartum check-up within a few hours or, at best, within two days of delivery and that a woman should have at least three postpartum check-ups.

Findings, illustrated in Figure 4.2, indicate that beneficiaries were, by and large, more likely than non-beneficiaries to report awareness of postpartum care practices. For example, 35 percent of beneficiaries compared to 26 percent of nonbeneficiaries knew that a woman should have a postpartum check-up even if she is feeling fine (Figure 4.2-A). Likewise, 16 percent of beneficiaries compared to 10 percent of non-beneficiaries were aware that a woman should have her first postpartum check-up within a few hours or, at best, within two days of delivery. However, irrespective of their beneficiary status, fewer than 5 percent of women knew that a woman should have at least three postpartum check-ups. While similar patterns 


\section{Table 4.1}

Percentage of women reporting awareness of key elements of birth preparedness by JSY beneficiary status, according to residence

\begin{tabular}{|c|c|c|c|c|c|c|}
\hline \multirow[t]{2}{*}{$\begin{array}{l}\text { Indicators of awareness of } \\
\text { birth preparedness }\end{array}$} & \multicolumn{2}{|c|}{$\begin{array}{c}\text { Combined } \\
N=4,711\end{array}$} & \multicolumn{2}{|c|}{$\begin{array}{c}\text { Urban } \\
N=2,354\end{array}$} & \multicolumn{2}{|c|}{$\begin{array}{c}\text { Rural } \\
\mathbf{N}=2,357\end{array}$} \\
\hline & $\begin{array}{c}\text { Beneficiaries } \\
\mathrm{N}=2,232\end{array}$ & $\begin{array}{l}\text { Non- } \\
\text { beneficiaries } \\
\mathrm{N}=2,479\end{array}$ & $\begin{array}{c}\text { Beneficiaries } \\
N=1,170\end{array}$ & $\begin{array}{c}\text { Non- } \\
\text { beneficiaries } \\
\text { N=1,184 }\end{array}$ & $\begin{array}{c}\text { Beneficiaries } \\
\mathrm{N}=1,062\end{array}$ & $\begin{array}{c}\text { Non- } \\
\text { beneficiaries } \\
\text { N=1,295 }\end{array}$ \\
\hline
\end{tabular}

A. Bivariate results

A woman should identify

a hospital or trained midwife for delivery (\%)

14.3

13.7

17.8

20.7

13.0

11.9

A woman should arrange for transportation to reach the health facility (\%)

$15.1^{* * *}$

8.0

10.8

12.2

$16.6^{* * *}$

6.9

A woman should save money for delivery expenses (\%)

$22.7^{* * *}$

16.4

21.6

20.2

$23.1^{* * *}$

15.4

A woman should identify a referral health facility to go to in case of an emergency (\%)

A woman should keep items for safe delivery/ delivery kit with her, in case she opts for a home delivery (\%)

At least one of the above essential preparations to be made (\%)

\section{B. Logistic regression results ${ }^{\circledR}$}

At least one essential

$1.31^{* * *}$
preparation to be made

(1.16 to 1.49$)$

1.08

(0.84 to 1.39$)$

\section{$1.36^{* * *}$}

(1.17 to 1.58$)$

Note: ${ }^{\circledR}$ After controlling for age, education, religion, caste, household economic status, parity, rural-urban residence and study district; odds ratios greater than 1 indicate the extent to which JSY beneficiaries were more likely than non-beneficiaries to be informed about birth preparedness; values in parentheses indicate 95\% confidence interval. Percentages indicated in the table are weighted; the number of respondents is unweighted. ${ }^{* * *} p \leqslant 0.001$.

were observed in rural areas (Figure 4.2-C), no such differences were observed in urban areas (Figure 4.2-B).

Results of logistic regression analyses, using percentages of women who were aware of the importance of postpartum check-ups, show that differences by beneficiary status remained significant for the overall and rural samples when controlled for potentially confounding factors. Beneficiaries were 1.3-1.4 times as likely as non-beneficiaries to be aware of the importance of postpartum check-ups (AOR=1.34; $\mathrm{CI}=1.17-154$ for the overall sample; $\mathrm{AOR}=1.37$; $\mathrm{CI}=1.16-1.61$ for the rural sample). No such association was observed for the urban sample. 


\section{Association between JSY beneficiary}

\section{status and awareness of newborn care}

\section{practices}

The study explored women's awareness of several dimensions of best practices in newborn care namely, immediate care of the newborn, breastfeeding practices and immunisation.

Figure 4.2: Association between JSY beneficiary status and awareness of postpartum care practices, according to residence

\section{A. Combined}

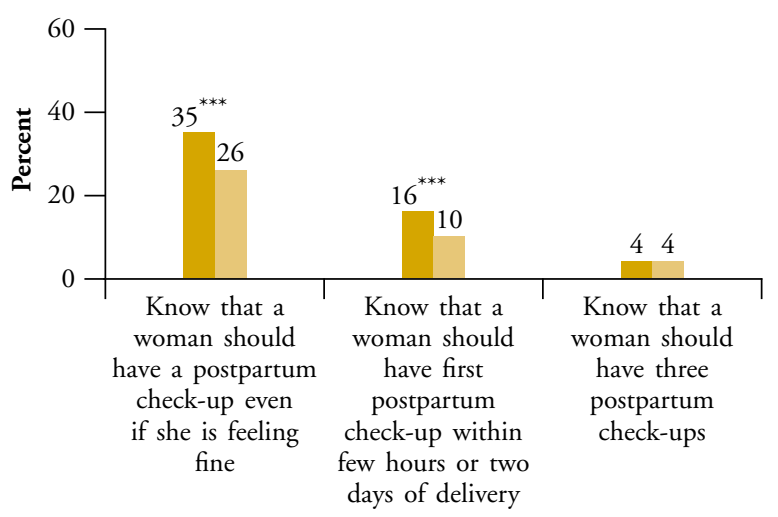

Beneficiaries $(\mathrm{N}=2,232)$

Non-beneficiaries $(\mathrm{N}=2,479)$

Note: Percentages indicated in the figure are weighted; the number of respondents is unweighted. ${ }^{* * *} p \leqslant 0.001$.

\section{B. Urban}

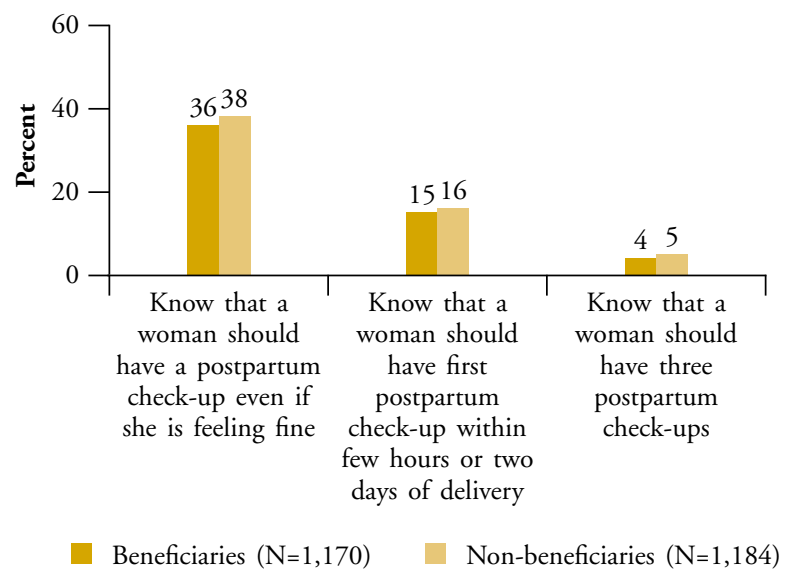

Note: Percentages indicated in the figure are weighted; the number of respondents is unweighted.

\section{Rural}

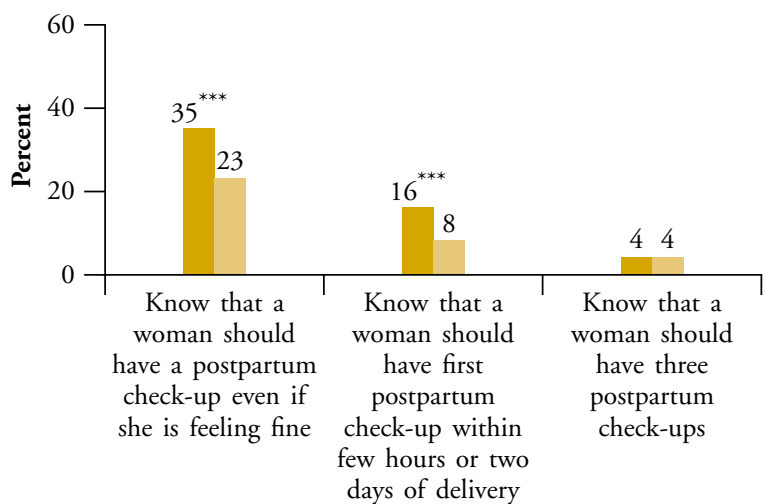

Beneficiaries $(\mathrm{N}=1,062)$

Non-beneficiaries $(\mathrm{N}=1,295)$

Note: Percentages indicated in the figure are weighted; the number of respondents is unweighted. ${ }^{* * *} p \leqslant 0.001$.

\section{Awareness of best practices in immediate newborn care}

Awareness of immediate care of the newborn was studied by assessing whether or not women knew that a newborn should be wiped dry rather than bathed immediately after birth and that nothing should be applied on the cord stump. A summary indicator of comprehensive awareness of best practices in immediate newborn care, reflecting percentages of women who were knowledgeable about both these aspects, was also calculated.

Findings presented in Figure 4.3 depict a mixed picture about awareness of these best practices among beneficiaries vis-à-vis non-beneficiaries. Beneficiaries were more likely than non-beneficiaries to report that a newborn should be wiped dry and not be bathed immediately ( $49 \%$ versus $28 \%$ ); however, they were as informed as non-beneficiaries that it is not good to apply any substance on the cord stump (26\% versus 25\%) (Figure 4.3-A). So also, with regard to comprehensive awareness of immediate newborn care, beneficiaries were more likely than non-beneficiaries to report awareness 
(16\% versus $8 \%)$. The pattern was similar in rural areas (Figure 4.3-C); in urban areas, differences were evident only with regard to percentages reporting that a newborn should be wiped dry and not bathed immediately (Figure 4.3-B).

Results of regression analyses using comprehensive awareness of best practices in immediate newborn care as the dependent variable indicate that beneficiaries were twice as likely as non-beneficiaries

Figure 4.3: Association between JSY beneficiary status and awareness of best practices in immediate newborn care, according to residence

\section{A. Combined}

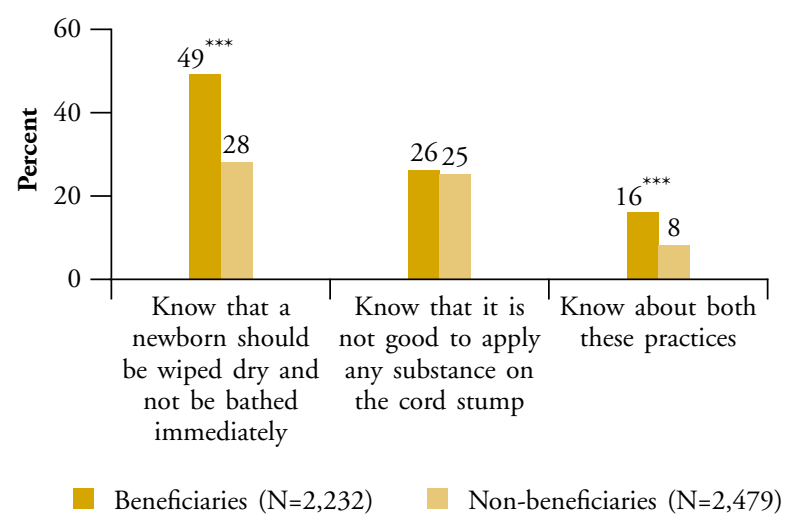

Note: Percentages indicated in the figure are weighted; the number of respondents presented is unweighted. ${ }^{* * *} p \leqslant 0.001$.

\section{B. Urban}

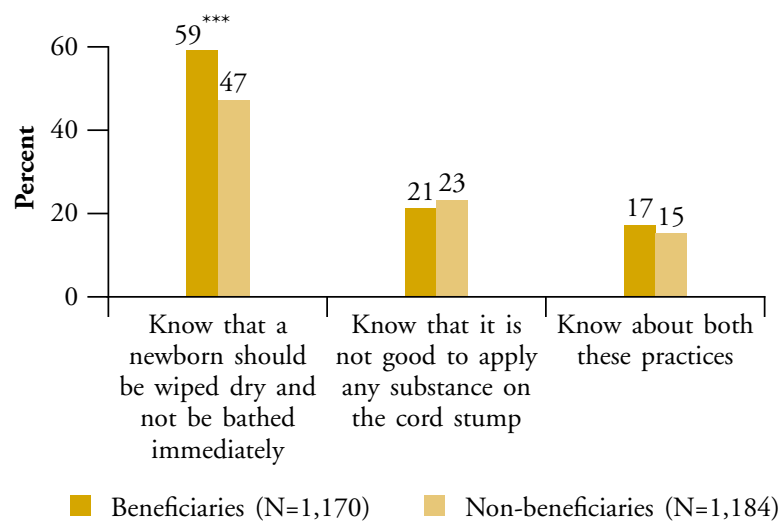

Note: Percentages indicated in the figure are weighted; the number of respondents presented is unweighted. ${ }^{* * *} p \leqslant 0.001$.

\section{Rural}

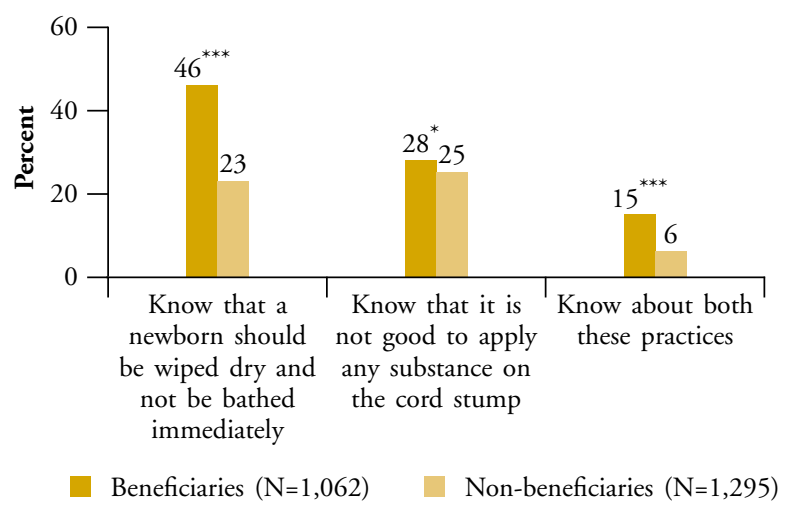

Note: Percentages indicated in the figure are weighted; the number of respondents presented is unweighted. ${ }^{*} p \leqslant 0.05 ;{ }^{* * *} p \leqslant 0.001$.

to report such awareness even after controlling for potentially confounding factors $(\mathrm{AOR}=2.0$, $\mathrm{CI}=1.62-2.38)$. In rural areas, beneficiaries were 2.4 times more likely than non-beneficiaries to report such awareness $(\mathrm{AOR}=2.39 ; \mathrm{CI}=1.88-3.03)$; no such association was observed in urban areas.

\section{Awareness of best practices in breastfeeding}

The study used three indicators to assess awareness of best practices in breastfeeding, namely, whether or not women were aware that a newborn should be breastfed immediately, that is, within an hour of delivery; that a newborn should be fed colostrum, and that a newborn should be exclusively breastfed for six months. An indicator of comprehensive awareness of best practices in breastfeeding as measured by percentages aware of all three practices was also calculated. Figure 4.4 presents the findings.

Awareness of best practices in breastfeeding was more likely to be reported by beneficiaries than non-beneficiaries, regardless of the indicator used and rural-urban residence (Figure 4.4). Beneficiaries were significantly more likely than non-beneficiaries to report that a newborn should 
Figure 4.4: Association between JSY beneficiary status and awareness of best practices in breastfeeding, according to residence

\section{A. Combined}

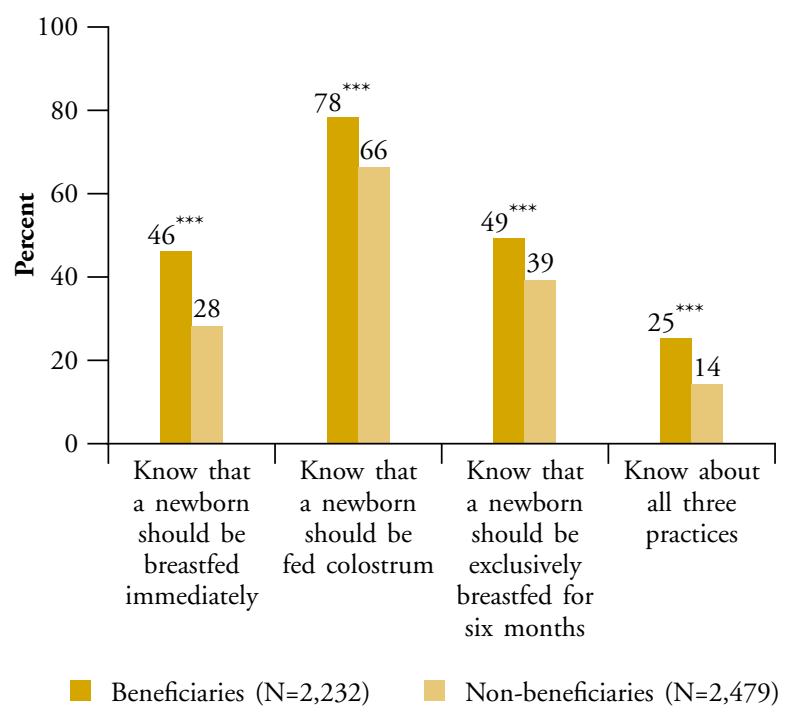

Note: Percentages indicated in the figure are weighted; the number of respondents is unweighted. ${ }^{* * *} p \leqslant 0.001$.

\section{B. Urban}

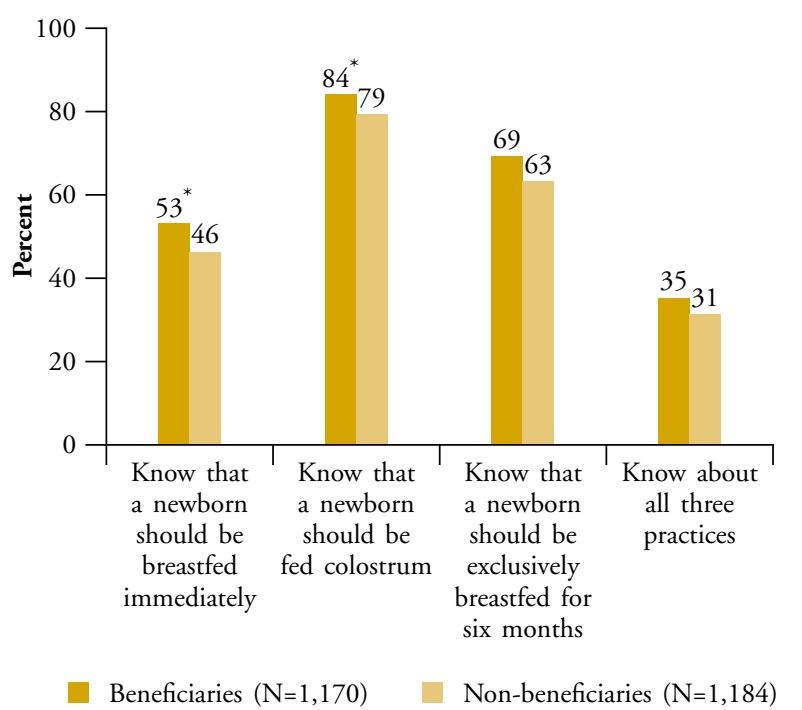

Note: Percentages indicated in the figure are weighted; the number of respondents is unweighted. ${ }^{*} p \leqslant 0.05$.

\section{Rural}

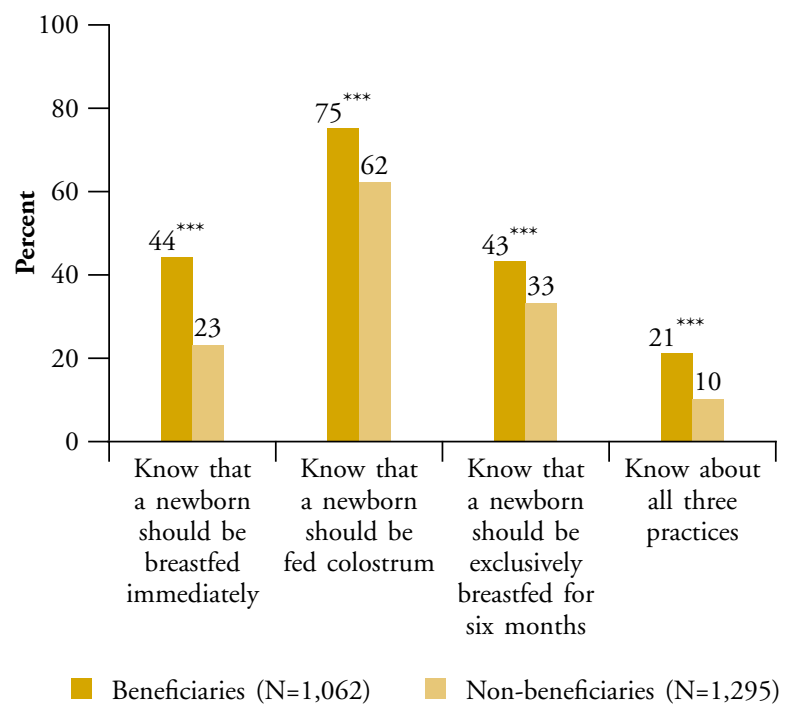

Note: Percentages indicated in the figure are weighted; the number of respondents is unweighted. ${ }^{* * *} p \leqslant 0.001$.

be breastfed immediately ( $46 \%$ versus $28 \%$ ), fed colostrum (78\% versus 66\%) and exclusively breastfeed for six months (49\% versus 39\%) (Figure 4.4-A). They were also more likely to report comprehensive awareness of best practices in breastfeeding (25\% versus $14 \%$ ). In regression analyses using comprehensive awareness of best practices in breastfeeding as the dependent variable, differences by beneficiary status remained significant even after controlling for potentially confounding factors; beneficiaries were almost twice as likely as non-beneficiaries to display comprehensive awareness of best practices in breastfeeding $(\mathrm{AOR}=1.85$; $\mathrm{CI}=1.57-2.19)$. This pattern was also observed in both urban (AOR=1.43; $\mathrm{CI}=1.08-1.88)$ and rural areas $(\mathrm{AOR}=1.84 ; \mathrm{CI}=1.49-2.28)$.

\section{Awareness of the immunisation schedule for infants}

To assess women's awareness of the immunisation schedule for infants, respondents were asked about 
the number of doses of the BCG, oral polio, DPT and measles vaccines to be given to an infant as well as the timing of the first dose of the BCG, oral polio and DPT vaccines. Additionally, a summary measure that summed women's responses to these individual immunisation awareness indicators was calculated. The respondent was assigned a score of 1 for each question that was correctly answered, and 0 otherwise. The scores were summed up to create an index, ranging in value from 0 indicating no awareness to 7 , indicating a high level of awareness $($ Cronbach's alpha $=0.75)$.

Findings indicate that awareness of the immunisation schedule differed widely by beneficiary status, with beneficiaries scoring better than nonbeneficiaries on all the indicators, except the number of doses of the oral polio vaccine to be administered to the newborn (Table 4.2, Panel A). Specifically, beneficiaries were more likely than non-beneficiaries to be aware that a newborn should be given one dose of BCG vaccine (64\% versus $53 \%$ ) at birth (30\% versus $19 \%$ ), the first dose of oral polio vaccine at birth (29\% versus $23 \%$ ), the first dose of DPT vaccine at six weeks (24\% versus $17 \%)$; and three doses of DPT vaccine (31\% versus $26 \%$ ) and a single dose of measles vaccine (36\% versus $28 \%$ ). The pattern remained, by and large, similar in both rural and urban areas; with urban areas showing wider differences than rural areas.

Results of regression analyses using the index of awareness of the immunisation schedule as the dependent variable indicate that beneficiaries were clearly better informed than non-beneficiaries about the immunisation schedule for infants, regardless of rural-urban residence (regression coefficient of 0.34, 0.54 and 0.25 for the overall, urban and rural samples, respectively) (Table 4.2, Panel B).

\section{Association between JSY beneficiary status and awareness of maternal and newborn complications}

Our study also assessed differences in women's awareness of the complications that may occur during pregnancy, delivery and the postpartum period as well as among the newborn by JSY beneficiary status. This was done by ascertaining whether they recognised at least one of an array of selected symptoms of complications that necessitate the intervention of a health care provider. We assessed women's awareness of complications occurring during pregnancy by their recognition of at least one of the following symptoms: severe headache, blurred vision, high blood pressure, swelling around ankles, puffiness of face, fits, high fever, vaginal bleeding, foulsmelling vaginal discharge, jaundice and anaemia, as a pregnancy-related complication for which they should seek assistance from a health care provider. Likewise, awareness of labour- and delivery-related complications were assessed by their recognition of at least one of the following symptoms: abnormal foetal presentation, prolonged labour, obstructed labour, heavy bleeding, fits, foetal distress and retained placenta, as a complication associated with labour and delivery, as that requiring the attention of a health care provider. With regard to awareness of complications related to the postpartum period, we assessed whether women recognised at least one of the symptoms namely, heavy bleeding, high fever, foul-smelling vaginal discharge and fits, as a complication linked to the postpartum period, requiring the services of a health care provider. Finally, we also assessed whether respondents identified at least one of the symptoms namely difficulty in breathing, fast breathing, high fever, difficulty in suckling, stiffness of the body, no bowel 


\section{Table 4.2}

Percentage of women reporting awareness of the immunisation schedulle for infants by JSY beneficiary status, according to residence

\begin{tabular}{|c|c|c|c|c|c|c|}
\hline \multirow[t]{2}{*}{$\begin{array}{l}\text { Indicators of awareness of } \\
\text { immunisation schedule }\end{array}$} & \multicolumn{2}{|c|}{$\begin{array}{c}\text { Combined } \\
\mathrm{N}=4,711 \\
\end{array}$} & \multicolumn{2}{|c|}{$\begin{array}{c}\text { Urban } \\
\mathrm{N}=2,354\end{array}$} & \multicolumn{2}{|c|}{$\begin{array}{c}\text { Rural } \\
\mathbf{N}=2,357\end{array}$} \\
\hline & $\begin{array}{c}\text { Beneficiaries } \\
\mathbf{N}=2,232\end{array}$ & $\begin{array}{c}\text { Non- } \\
\text { beneficiaries } \\
\mathbf{N}=2,479\end{array}$ & $\begin{array}{c}\text { Beneficiaries } \\
\mathbf{N}=2,479\end{array}$ & $\begin{array}{c}\text { Non- } \\
\text { beneficiaries } \\
\mathbf{N}=\mathbf{1 , 1 8 4}\end{array}$ & $\begin{array}{c}\text { Beneficiaries } \\
\mathrm{N}=1,184\end{array}$ & $\begin{array}{c}\text { Non- } \\
\text { beneficiaries } \\
\mathbf{N}=\mathbf{2 , 2 3 2}\end{array}$ \\
\hline
\end{tabular}

\section{A. Bivariate results}

A newborn should be given one dose of BCG

$$
63.9^{* * *}
$$
vaccine $(\%)$

$29.5^{* * *}$

19.3 at birth (\%)

A newborn should be given four doses of oral polio vaccine by age one $(\%)$

A newborn should be given the first dose of oral polio vaccine at birth (\%)

A newborn should be given three doses of DPT vaccine (\%)
$59.0^{* * *}$

1.8

$77.3^{* *}$

11.0

14.0

$47.0^{*}$

39.5

$40.0^{* *}$

46.2

$3.2^{* * *}$

26.0

(

(17.3

$46 \sin$

69.6

$59.2^{* * *}$

49.1

42.1

$19.1^{* * *}$
A newborn should be given the first dose of DPT vaccine at six weeks (\%)

$24.4^{* * *}$

$35.5^{* * *}$

28.0
$0.34^{* * *}$

(0.24 to 0.44$)$ given a single dose of

Index of awareness of immunisation schedule for infants (score 0-7) (Mean)
$2.3^{* * *}$
B. Linear regression results ${ }^{\circledR}$

Index of awareness of the immunisation schedule for infants Note: ${ }^{\circledR}$ After controlling for age, education, religion, caste, household economic status, parity, rural-urban residence and study
district,; a positive regression coefficient suggests the extent to which JSY beneficiaries were more likely than non-beneficiaries to be informed about the immunisation schedule; values in parentheses indicate 95\% confidence interval. Percentages indicated in the table are weighted; the number of respondents is unweighted. ${ }^{*} p \leqslant 0.05 ;{ }^{* *} p \leqslant 0.01 ;{ }^{* * *} p \leqslant 0.001$. 


\section{Table 4.3}

Percentage of women reporting awareness of maternal and newborn complications by JSY beneficiary status, according to residence
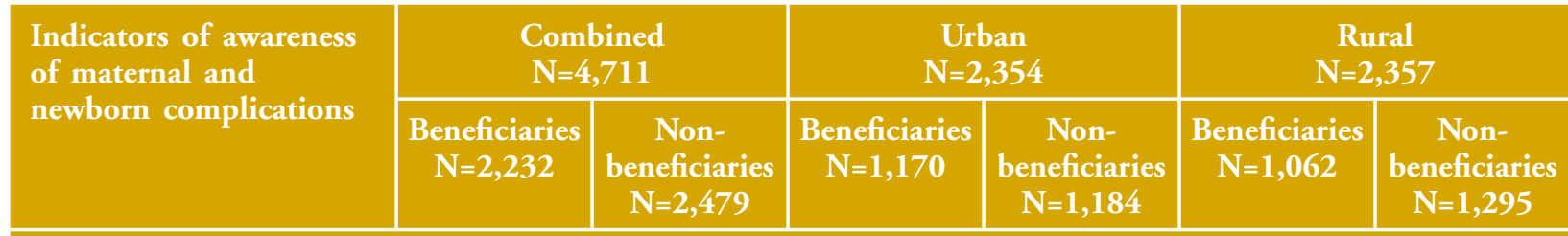

\section{A. Bivariate results}

At least one selected complication during pregnancy $^{1}(\%)$

$$
50.8^{* * *}
$$

55.7

56.4

$49.1^{* * *}$

At least one selected complication during labour and delivery $^{2}(\%)$

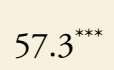

55.7

54.1

$57.9^{* * *}$

48.7

At least one selected complication during the postpartum period ${ }^{3}(\%)$

$30.3^{* * *}$

30.4

69.6

$73.8^{* *}$

$1.27^{* * *}$

(1.13 to 1.44 ) pregnancy

At least one selected complication during labour and delivery

At least one selected complication during the postpartum period

At least one selected complication in the newborn
$1.29^{* * *}$
(1.14 to 1.46 )
$1.22^{* *}$
(1.06 to 1.39 )
1.14
(1.00 to 1.30$)$
1.21
(0.94 to 1.55$)$
1.11
(0.85 to 1.45$)$
0.91
(0.67 to 1.22 )

1.12

(0.87 to 1.45$)$
$1.30^{* * *}$

(1.13 to 1.50$)$

$1.27^{* * *}$

(1.10 to 1.47 )

1.15

(0.98 to 1.34 )

$1.21^{*}$

(1.04 to 1.40$)$

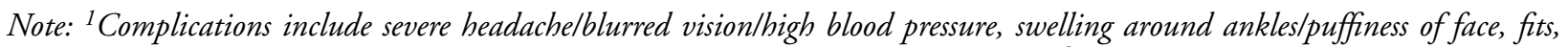
high fever, vaginal bleeding, foul-smelling vaginal discharge, jaundice and anaemia. ${ }^{2}$ Complications include: abnormal foetal presentation, prolonged labour, obstructed labour, heavy bleeding, fits, foetal distress and retained placenta. ${ }^{3}$ Complications include: heavy bleeding, high fever, foul-smelling vaginal discharge and fits. ${ }^{4}$ Complications include: newborn doesn't breathe, has fast breathing, has high fever, cannot suckle breast, body gets stiff, does not have bowel movement or urinate within 24 hours, has infected umbilical cord, diarrhoea, jaundice and less than normal movements. ${ }^{\circledR}$ After controlling for age, education, religion, caste, household economic status, parity, rural-urban residence and study district; odds ratios greater than 1 indicate the extent to which JSY beneficiaries were more likely than non-beneficiaries to be informed about maternal and newborn complications, and odds ratios less than 1 indicate the extent to which beneficiaries were less likely than non-beneficiaries to be informed about maternal and newborn complications; values in parentheses indicate $95 \%$ confidence interval. Percentages indicated in the table are weighted; the number of respondents is unweighted. ${ }^{*} \leqslant 0.05 ;{ }^{* *} p \leqslant 0.01 ;{ }^{* * *} p \leqslant 0.001$. 
movement or urination within 24 hours, infected umbilical cord, diarrhoea, jaundice and less than the normal movements as a complication in the newborn for which they should seek the help of a health care provider.

Findings presented in Table 4.3, Panel A, show that beneficiaries were better informed about maternal as well as newborn complications than nonbeneficiaries. For example, 51 percent of beneficiaries compared to 43 percent of non-beneficiaries reported awareness of at least one selected pregnancy complication. Similar differences were observed with respect to women's awareness of at least one selected complication associated with labour and delivery (57\% versus $50 \%)$, the postpartum period $(30 \%$ versus $26 \%)$ and in the newborn (74\% versus $70 \%)$. While this pattern recurred in rural areas, differences were insignificant in urban areas.

Regression analyses also reaffirmed these patterns. Beneficiaries were 1.2-1.3 times as likely as non-beneficiaries to report awareness of at least one selected complication during pregnancy, delivery and the postpartum period, respectively. However, the bivariate association observed for awareness of complications did not remain significant in multivariate analysis in the case of awareness of newborn complications. Rural-urban differences observed in bivariate analyses were repeated, for the most part, in multivariate analyses (Table 4.3, Panel B).

\section{Summary}

Findings presented in this chapter underscore that women who availed of JSY benefits were better informed than non-beneficiaries about best practices pertaining to the care of women during pregnancy, delivery and the postpartum period and about the care of the newborn. For example, beneficiaries were more likely than non-beneficiaries to report comprehensive awareness of antenatal care practices, awareness of at least one essential preparation to be made for a safe delivery and awareness of the importance of regular postpartum check-ups. They were also more likely to display comprehensive awareness of best practices in immediate newborn care and in breastfeeding, and awareness of the immunisation schedule for infants. Additionally, compared to non-beneficiaries, they were better informed about the complications of pregnancy, delivery and the postpartum period. No differences were observed in their awareness of selected complications in the newborn.

Findings also highlight that the association between women's awareness of maternal and child health care practices and JSY experiences differed in rural and urban areas. Rural beneficiaries scored better on nine out of 10 indicators; in urban areas, however, notable differences were observed with respect to just two indicators, namely, comprehensive awareness of best practices in breastfeeding and awareness of the infant immunisation schedule. These findings may well reflect the differential access to information that women in rural and urban areas have, with urban women having greater access to a wide array of information sources than rural women, thus limiting the effect that the JSY may have on improving their awareness of maternal and newborn care practices. 


\section{Effects of the JSY on the utilisation of maternal health services and adoption of best practices in newborn care}

In this chapter, we focus on findings concerning the contribution of the JSY to women's utilisation of maternal health services and adoption of best practices in newborn care. Specifically, it explores the effects of the JSY on the services received by women during the antenatal period, at delivery and during the postpartum period, including postpartum contraception. It also assesses the effect of the JSY on the adoption of best practices in newborn care.

As described in Chapter 1, two types of analytic approaches were used. First, cross-sectional analysis was conducted to explore the associations between the receipt of JSY benefits and the utilisation of maternal health services and the adoption of best practices in newborn care by women, drawing on a matched sample of women who had availed of JSY benefits for the birth in the one year preceding the interview and those who had not done so $(1,718$ and 1,716 women, respectively). Mean values of outcome variables obtained for the beneficiary and non-beneficiary groups were compared to assess differences, if any, in the utilisation of maternal health services and the adoption of best practices in newborn care between these groups; t-tests were used to test the significance of the bi-variate comparisons. Additionally, regression analysis was used to account for potentially confounding effects that covariates other than those included in the construction of the propensity score-rural-urban residence and study district, for example-may have on the outcome measures. We caution readers against inferring causality from these analyses given the cross-sectional nature of the data used.

Second, panel analysis was conducted to assess the effects of the JSY on the utilisation of maternal health services and adoption of best practices in newborn care, drawing on a matched sample of women who had experienced a birth before as well as after the JSY was introduced. To assess the net effect of the JSY, we used the difference-indifference (DiD) estimator, described in Chapter 1 , that measures the treatment effect by estimating the difference between outcome measures before and after the introduction of the JSY for both beneficiaries and non-beneficiaries-606 and 601 women, respectively, and then comparing the difference between these groups. Paired t-tests were first used to assess the significance of change over time, if any, in both the groups. Additionally, the difference in outcome measures at the two time points was computed and regressed on a dummy variable indicating whether or not the respondents had availed of JSY benefits, and socio-demographic covariates other than those included in the construction of the propensity score that may have potentially confounding effects on the outcome measures. We note that the sub-samples used for the analyses varied by the type of indicators used. 


\section{Utilisation of antenatal care services}

The utilisation of antenatal care services was assessed by four indicators, namely, whether women had received an antenatal check-up during the first trimester, whether they had received three or more antenatal check-ups, whether they had received two or more doses of tetanus toxoid injection, and whether they had received or purchased iron and folic acid (IFA) supplements.

\section{Association between JSY beneficiary status and utilisation of antenatal care services}

Findings of the cross-sectional comparison of antenatal care experiences among beneficiaries and non-beneficiaries during the most recent birth, presented in Figure 5.1, indicate notable differences in the utilisation of antenatal services between the two groups. Beneficiaries were significantly more likely than non-beneficiaries to have received all the antenatal services considered in our analysis (differences of 10-15 percentage points) (Figure 5.1-A). Specifically, they were more likely to have had an antenatal check-up in the first trimester (59\% versus $49 \%$ ), received three or more antenatal check-ups (79\% versus 64\%) and two or more doses of tetanus toxoid injection ( $80 \%$ versus $66 \%$ ), and received or purchased iron and folic acid supplements (79\% versus 64\%). Similar findings were observed in rural (Figure 5.1-C) and urban (Figure 5.1-B) areas, although differences by beneficiary status were insignificant with regard to urban women having had their first check-up during the first trimester of pregnancy.

Results of regression analyses indicate that the net association between the utilisation of the antenatal care services and JSY beneficiary status remained significant even after controlling for potentially confounding factors (Table 5.1a). Beneficiaries were
Figure 5.1: Association between JSY beneficiary status and utilisation of antenatal care services: cross-sectional comparison of women's experiences during the most recent birth, according to residence

\section{A. Combined}

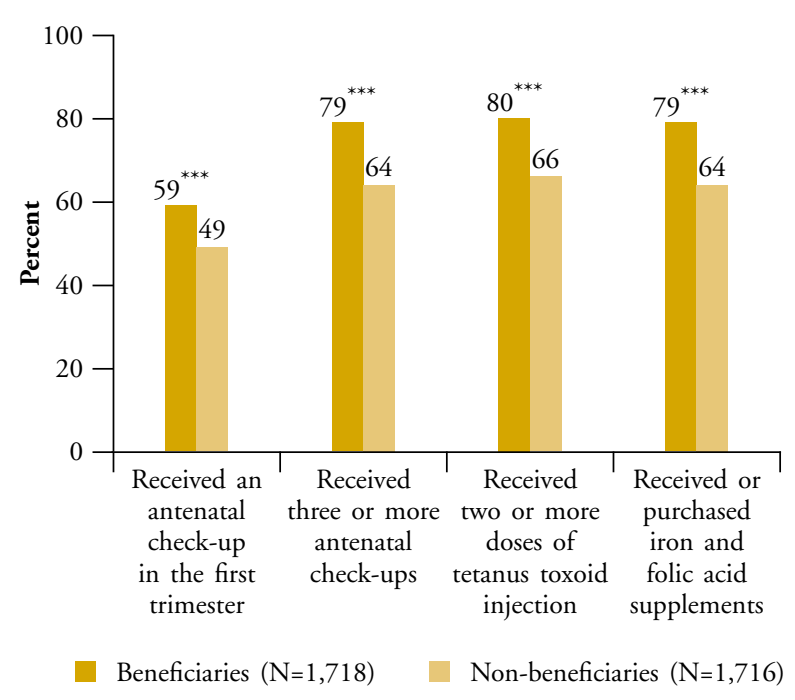

Note: Percentages indicated in the figure are weighted; the number of respondents is unweighted. ${ }^{* * *} p \leqslant 0.001$.

\section{B. Urban}

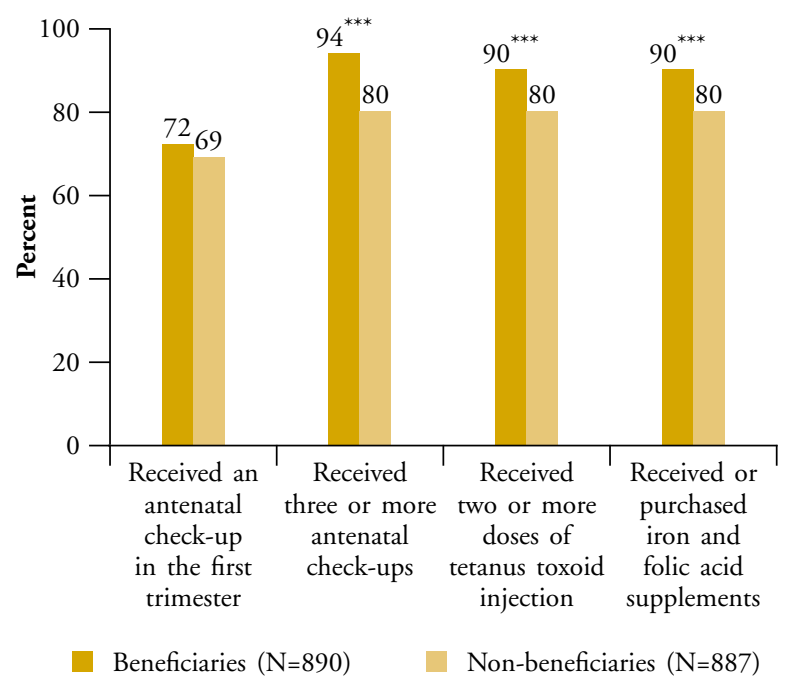

Note: Percentages indicated in the figure are weighted; the number of respondents is unweighted. ${ }^{* * *} p \leqslant 0.001$. 


\section{Rural}

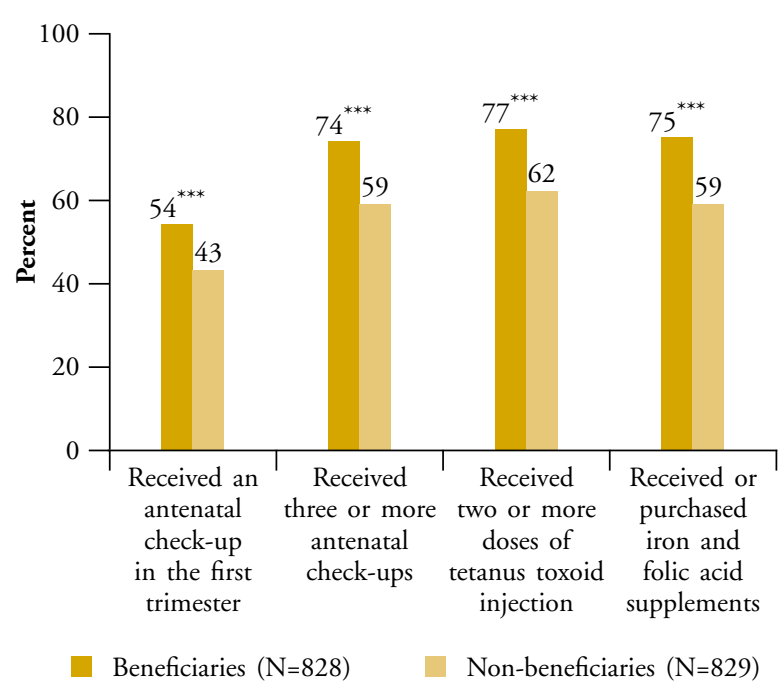

Note: Percentages indicated in the figure are weighted; the number of respondents is unweighted. ${ }^{* * *} p \leqslant 0.001$.

1.4 times as likely as non-beneficiaries to have received an antenatal check-up within the first trimester and twice as likely as non-beneficiaries to have received three or more antenatal check-ups, two or more doses of tetanus toxoid injection, and iron and folic acid supplements. Patterns remained, by and large, similar when rural and urban samples were analysed separately.

\section{Effect of the JSY on the utilisation of antenatal care services}

Table $5.1 \mathrm{~b}$ presents a comparison of the antenatal care services received before and after the introduction of the JSY by the sub-sample of women who had experienced a birth at both these points in time, categorised into beneficiaries and non-beneficiaries based on whether or not they had availed of JSY benefits for the birth that took place in the one year preceding the interview. Findings underscore improvements in the utilisation of antenatal care services, regardless of the indicator used following introduction of the JSY. Although improvements were evident in both groups in terms of percentages receiving an antenatal checkup in the first trimester, three or more antenatal check-ups, and receiving/purchasing iron and folic acid supplements, beneficiaries showed greater improvements than non-beneficiaries (8-21 points versus 4-15 points).

\section{Table 5.1a}

Association between JSY beneficiary status and utilisation of antenatal care services by women, according to residence: logistic regression results ${ }^{\circledR}$

\begin{tabular}{|c|c|c|c|}
\hline $\begin{array}{l}\text { Indicators of utilisation of antenatal care } \\
\text { services }\end{array}$ & $\begin{array}{l}\text { Combined } \\
\mathrm{N}=3,434\end{array}$ & $\begin{array}{l}\text { Urban } \\
\mathrm{N}=1,777\end{array}$ & $\begin{array}{c}\text { Rural } \\
\mathrm{N}=1,657\end{array}$ \\
\hline Received an antenatal check-up in first trimester & $\begin{array}{c}1.41^{* * *} \\
(1.23 \text { to } 1.63)\end{array}$ & $\begin{array}{c}1.19 \\
(0.88 \text { to } 1.61)\end{array}$ & $\begin{array}{c}1.49^{* * *} \\
(1.27 \text { to } 1.75)\end{array}$ \\
\hline Received three or more antenatal check-ups & $\begin{array}{l}2.18^{* * *} \\
(1.86 \text { to } 2.55)\end{array}$ & $\begin{array}{l}3.88^{* * *} \\
(2.44 \text { to } 6.18)\end{array}$ & $\begin{array}{l}2.00^{* * *} \\
(1.69 \text { to } 2.37)\end{array}$ \\
\hline $\begin{array}{l}\text { Received two or more doses of tetanus toxoid } \\
\text { injection }\end{array}$ & $\begin{array}{l}2.08^{* * *} \\
(1.77 \text { to } 2.44)\end{array}$ & $\begin{array}{c}2.19^{* * *} \\
(1.46 \text { to } 3.27)\end{array}$ & $\begin{array}{c}2.04^{* * *} \\
(1.71 \text { to } 2.43)\end{array}$ \\
\hline $\begin{array}{l}\text { Given or purchased iron and folic acid } \\
\text { supplements }\end{array}$ & $\begin{array}{l}2.03^{* * *} \\
(1.73 \text { to } 2.37)\end{array}$ & $\begin{array}{l}2.20^{* * *} \\
(1.48 \text { to } 3.26)\end{array}$ & $\begin{array}{l}1.96^{* * *} \\
(1.65 \text { to } 2.33)\end{array}$ \\
\hline
\end{tabular}




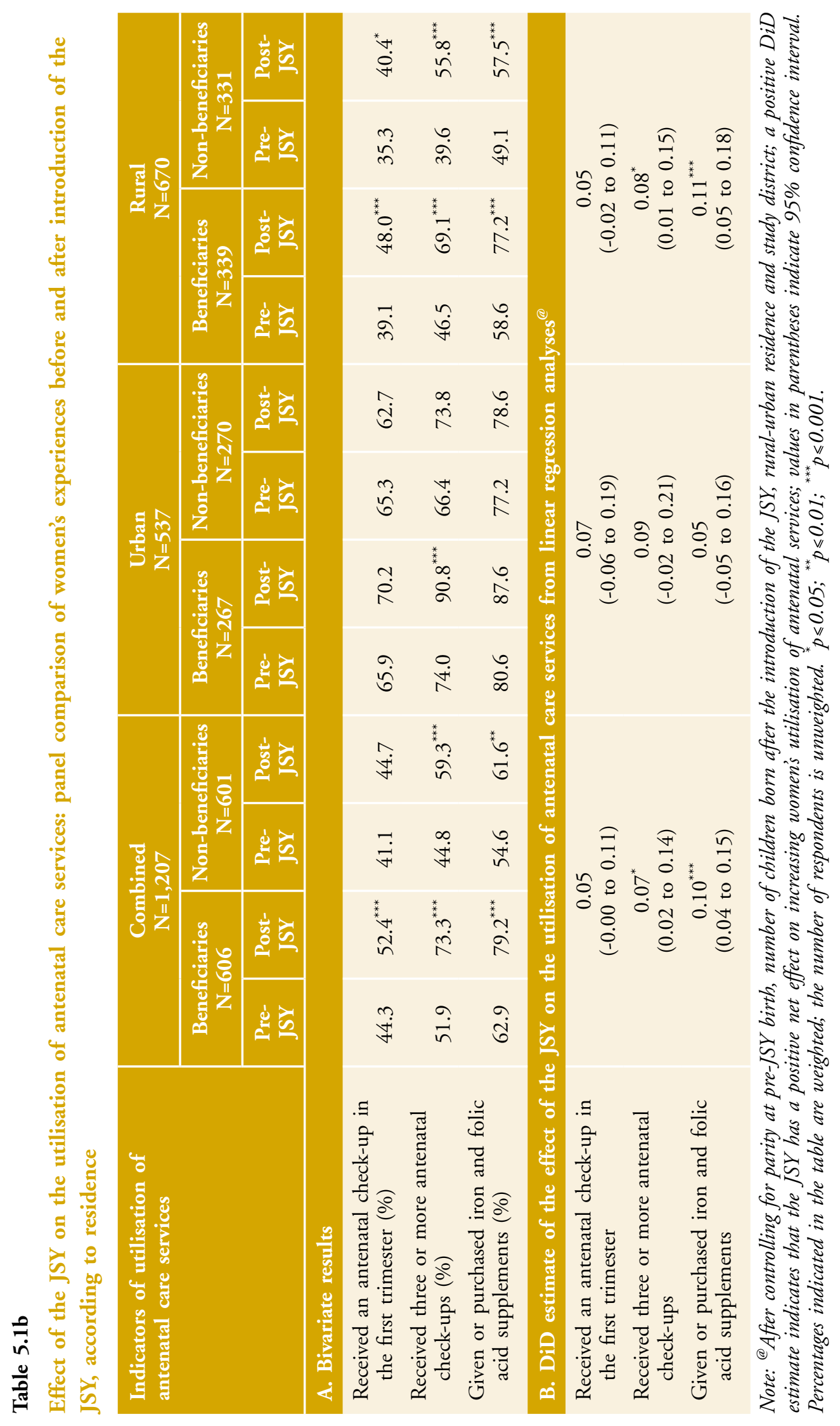


Separate analyses of rural and urban samples show a differential impact of the JSY on the utilisation of antenatal services (Table 5.1b, Panel A). In urban areas, just one indicator-percentages receiving three or more antenatal check-upsincreased between pre- and post-JSY births by 17 points among beneficiaries compared to a 7-point increase among non-beneficiaries. In rural areas, in contrast, notable improvements were evident in all three indicators-9-22 points among beneficiaries compared to 5-16 points among non-beneficiaries.

Results of regression analyses show that even after controlling for potentially confounding factors, the net effect of the JSY remained positive and statistically significant with regard to women receiving three or more antenatal check-ups, and iron and folic acid supplements (Table 5.1b, Panel B). Findings further show that the JSY has contributed to a 7 percent additional increase in women receiving three or more check-ups and a 10 percent additional increase in women receiving iron and folic acid supplements. While a similar positive net effect was observed in rural areas (8\% and 11\% net increase, respectively), no such effect was evident in urban areas when the analysis controlled for potentially confounding factors. We note, however, that reverse causation cannot be ruled out, with women receiving antenatal care more likely than others to avail of JSY benefits subsequently.

\section{Utilisation of delivery care services}

As observed by previous evaluations (Lim et al., 2010; UNFPA, 2009), data on institutional deliveries among births that had taken place during the six years preceding the interview, presented in Figure 5.2, underscore that institutional deliveries increased significantly among study participants with the introduction of the JSY: from a 11-point increase between 2004 and 2006 to an increase of 29 points between 2006 and 2009. Findings, moreover, indicate that much of this increase has taken place in public sector health facilities.

Figure: 5.2: Trends in institutional delivery by type of health facility, 2004-2009

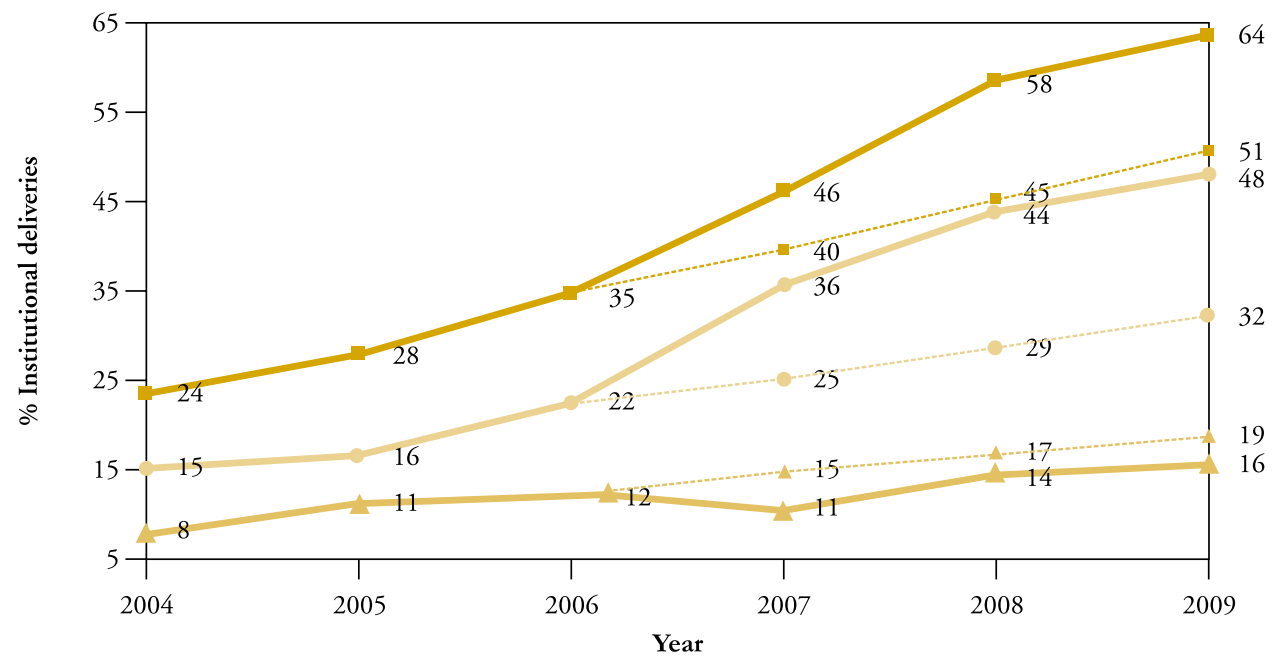

\begin{tabular}{|llll|}
\hline- Combined & Public & Private \\
$\cdots$ & Trend line combined & Trend line public & Trend line private \\
\hline
\end{tabular}




\section{Association between JSY beneficiary status and utilisation of delivery care services}

Figure 5.3 compares the proportions of institutional deliveries for the most recent birth among JSY beneficiaries and non-beneficiaries and shows unquestionably that beneficiaries were more likely than non-beneficiaries to have delivered in a health facility (98\% versus 32\%) (Figure 5.3-A). The majority of beneficiaries had delivered in a CHC or district hospital (79\%); just 15 percent and 2 percent had delivered in a PHC and an accredited private facility, respectively. The corresponding percentages among urban beneficiaries were 97, 2 and 1, respectively (Figure 5.3-B);

Figure 5.3: Association between JSY beneficiary status and utilisation of delivery care services: cross-sectional comparison of women's experiences during the most recent birth, according to residence

\section{A. Combined}

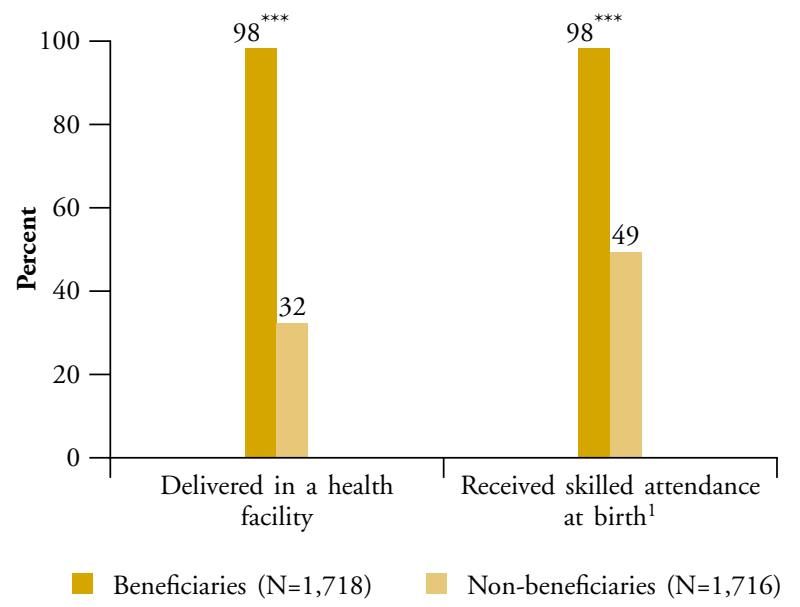

Note: ${ }^{1} 12$ and 4 women in rural and urban areas, respectively, reported that although they had delivered in a health facility, a traditional birth attendant, compounder, person who escorted them to the facility, or no one had attended their delivery. ${ }^{* * *} p \leqslant 0.001$.

\footnotetext{
${ }^{1}$ Eleven women reported that they had delivered in a sub-centre.
}

\section{B. Urban}

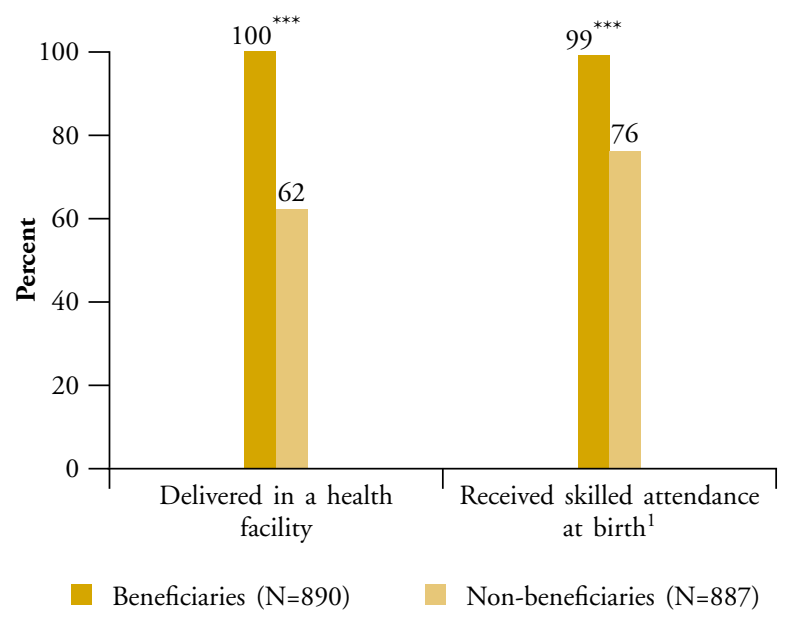

Note: ${ }^{1} 4$ women in urban areas reported that although they had delivered in a health facility, a traditional birth attendant, compounder, person who escorted them to the facility, or no one had attended their delivery. ${ }^{* * *} p \leqslant 0.001$.

\section{Rural}

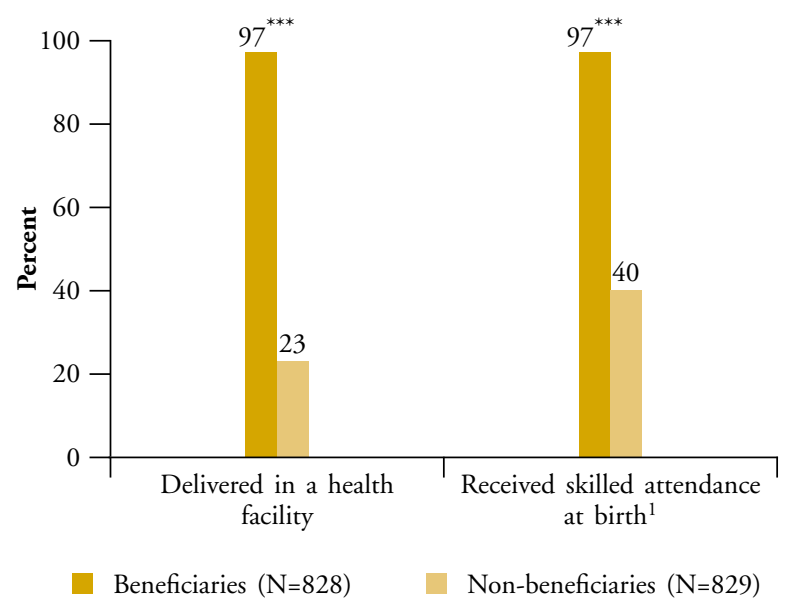

Note: ${ }^{1} 12$ women in rural areas reported that although they had delivered in a health facility, a traditional birth attendant, compounder, person who escorted them to the facility, or no one had attended their delivery. Percentages indicated in the figure are weighted; the number of respondents is unweighted. ${ }^{* * *} p \leqslant 0.001$. 
among rural beneficiaries, they were 72, 19 and 5, respectively (Figure 5.3-C). The majority of non-beneficiaries had delivered at home (66\%) or in a private or NGO-run hospital $(27 \%)$; the corresponding percentages in urban areas were 37 and 55, respectively, and in rural areas, 75 and 19, respectively (not shown in the figure). ${ }^{1}$ Skilled attendance at birth, likewise, was significantly more evident among beneficiaries than non-beneficiaries (98\% versus 49\%) (Figure 5.3-A). Similar patterns were observed among urban and rural women, although the differences were much wider in rural than in urban areas (institutional deliveries: 74 versus 38 percentage points; skilled attendance at birth: 57 versus 23 percentage points) (Figures $5.3-\mathrm{C}$ and B, respectively).

\section{Effect of the JSY on the utilisation of delivery} care services

Table 5.2 presents a comparison of the utilisation of delivery care services before and after the introduction of the JSY by the sub-sample of women who had experienced a birth at both these points in time, categorised into beneficiaries and non-beneficiaries based on whether or not they had availed of JSY benefits for the birth that took place in the one year preceding the interview. Findings indicate a phenomenal increase in the utilisation of safe delivery services. While institutional deliveries increased by 57 points among beneficiaries, post introduction of the JSY; they remained unchanged among non-beneficiaries (a decline of 3 points). The use of skilled attendance at birth, similarly, increased by 43 points among beneficiaries subsequent to the introduction of the JSY, but was unaffected among non-beneficiaries (a decline of 3 points). These patterns persisted in both rural and urban areas; however, the increase observed among rural beneficiaries, post inception of the JSY, was greater than that of their urban counterparts (institutional deliveries: 63 points versus 29 points; skilled attendance at birth: 49 points versus 16 points).

\section{Table 5.2}

Effect of the JSY on the utilisation of delivery care services: panel comparison of women's experiences before and after introduction of the JSY, according to residence

\begin{tabular}{|c|c|c|c|c|c|c|c|c|c|c|c|c|}
\hline \multirow{3}{*}{$\begin{array}{l}\text { Indicators of } \\
\text { utilisation of } \\
\text { delivery care } \\
\text { services }\end{array}$} & \multicolumn{4}{|c|}{$\begin{array}{c}\text { Combined } \\
N=1,207\end{array}$} & \multicolumn{4}{|c|}{$\begin{array}{l}\text { Urban } \\
\mathrm{N}=537\end{array}$} & \multicolumn{4}{|c|}{$\begin{array}{c}\text { Rural } \\
N=670\end{array}$} \\
\hline & \multicolumn{2}{|c|}{$\begin{array}{c}\text { Beneficiaries } \\
\mathrm{N}=606\end{array}$} & \multicolumn{2}{|c|}{$\begin{array}{c}\begin{array}{c}\text { Non- } \\
\text { beneficiaries } \\
\mathrm{N}=601 \\
\end{array} \\
\end{array}$} & \multicolumn{2}{|c|}{$\begin{array}{c}\text { Beneficiaries } \\
\mathrm{N}=\mathbf{2 6 7}\end{array}$} & \multicolumn{2}{|c|}{$\begin{array}{c}\text { Non- } \\
\text { beneficiaries } \\
\mathrm{N}=270 \\
\end{array}$} & \multicolumn{2}{|c|}{$\begin{array}{c}\text { Beneficiaries } \\
\mathrm{N}=339\end{array}$} & \multicolumn{2}{|c|}{ 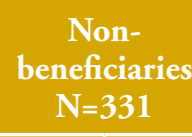 } \\
\hline & $\begin{array}{l}\text { Pre- } \\
\text { JSY }\end{array}$ & $\begin{array}{l}\text { Post- } \\
\text { JSY }\end{array}$ & $\begin{array}{l}\text { Pre- } \\
\text { JSY }\end{array}$ & $\begin{array}{l}\text { Post- } \\
\text { JSY }\end{array}$ & $\begin{array}{l}\text { Pre- } \\
\text { JSY }\end{array}$ & $\begin{array}{l}\text { Post- } \\
\text { JSY }\end{array}$ & $\begin{array}{l}\text { Pre- } \\
\text { JSY }\end{array}$ & $\begin{array}{c}\text { Post- } \\
\text { JSY }\end{array}$ & $\begin{array}{l}\text { Pre- } \\
\text { JSY }\end{array}$ & $\begin{array}{l}\text { Post- } \\
\text { JSY }\end{array}$ & $\begin{array}{l}\text { Pre- } \\
\text { JSY }\end{array}$ & $\begin{array}{l}\text { Post- } \\
\text { JSY }\end{array}$ \\
\hline $\begin{array}{l}\text { Delivered in } \\
\text { a health } \\
\text { facility (\%) }\end{array}$ & 41.1 & $97.6^{* * *}$ & 26.2 & $22.7^{*}$ & 70.5 & $99.4^{* * *}$ & 58.6 & 58.4 & 34.0 & $97.2^{* * *}$ & 18.5 & $14.2^{*}$ \\
\hline $\begin{array}{c}\text { Received skilled } \\
\text { attendance at } \\
\text { birth (\%) }\end{array}$ & 54.6 & $97.3^{* * *}$ & 40.8 & 38.3 & 82.3 & $97.9^{* * *}$ & 70.8 & 69.1 & 47.8 & $97.2^{* * *}$ & 33.6 & 30.9 \\
\hline
\end{tabular}

Note: Percentages indicated in the table are weighted; the number of respondents is unweighted. ${ }^{*} p \leqslant 0.05 ;{ }^{* * *} p \leqslant 0.001$. 


\section{Utilisation of postpartum care services}

Four indicators reflecting key postpartum care services assessed the effect of the JSY on the utilisation of postpartum care services: any postpartum check-up at the health facility or at home received from health care personnel (a doctor, nurse, ANM or LHV) or other communitybased health worker, namely, ASHA or AWW; any postpartum check-up received from health care personnel, any postpartum check-up received from health care personnel within two days of delivery, and postpartum adoption of contraception.

Figure 5.4: Association between JSY beneficiary status and utilisation of postpartum care services: cross-sectional comparison of women's experiences during the most recent birth, according to residence

\section{A. Combined}

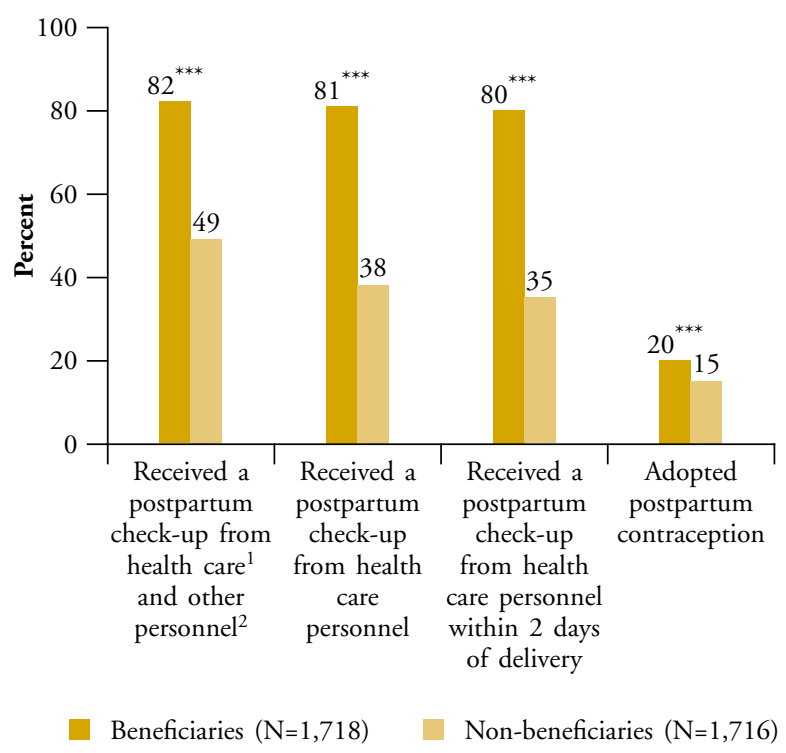

Note: ${ }^{1}$ Includes doctors, nurses, ANMs and LHVs. ${ }^{2}$ Includes ASHAs and $A W W$ s. Percentages indicated in the figure are weighted; the number of respondents is unweighted. ${ }^{* * *} p \leqslant 0.001$.

\section{B. Urban}

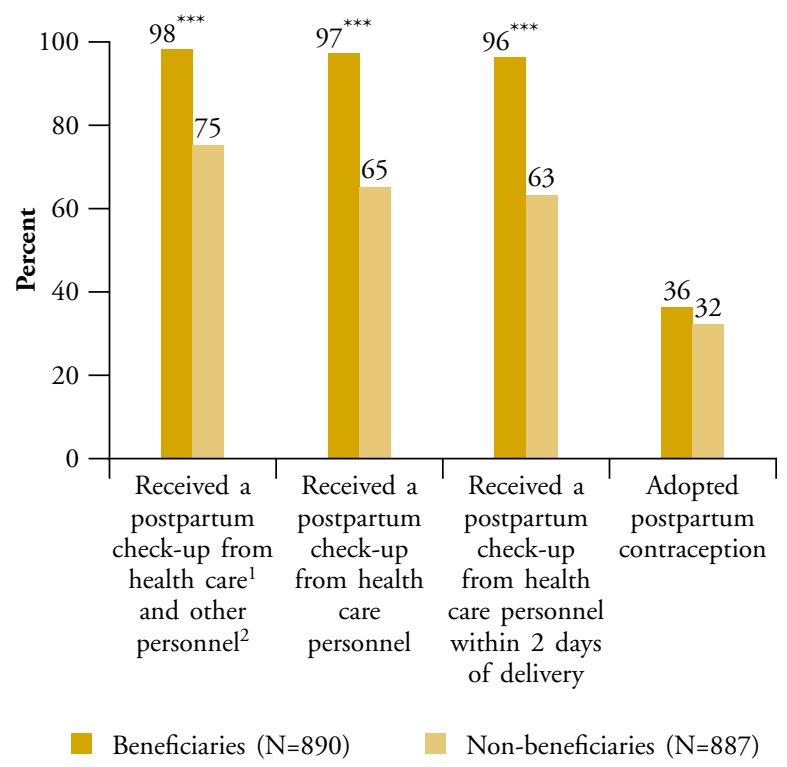

Note: ${ }^{1}$ Includes doctors, nurses, ANMs and LHVs. ${ }^{2}$ Includes ASHAs and AWWs. Percentages indicated in the figure are weighted; the number of respondents is unweighted. ${ }^{* * *} p \leqslant 0.001$.

\section{Rural}

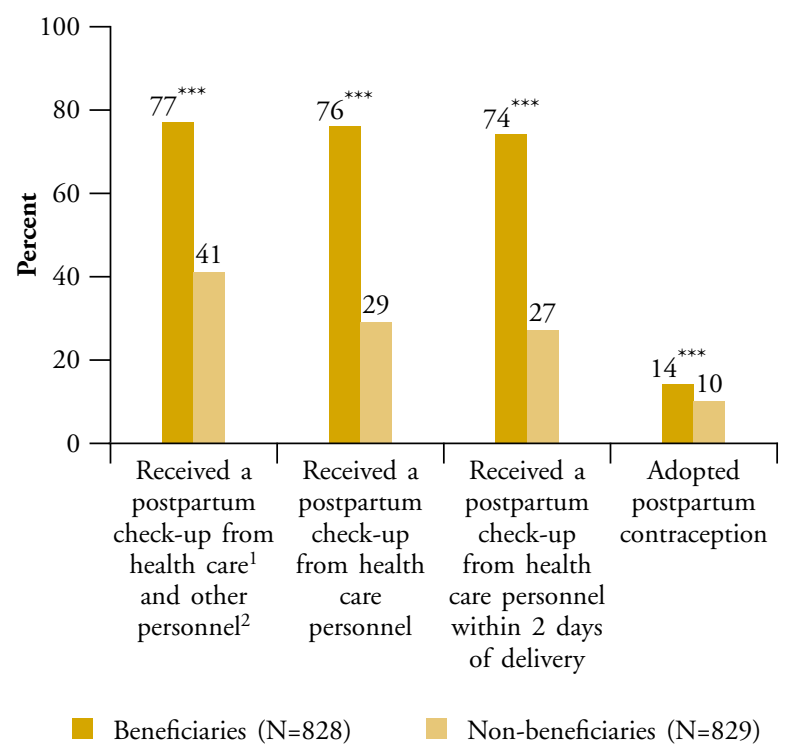

Note: ${ }^{1}$ Includes doctors, nurses, ANMs and LHVs. ${ }^{2}$ Includes ASHAs and $A W W s$. Percentages indicated in the figure are weighted; the number of respondents is unweighted. $\quad{ }^{* * *} p \leqslant 0.001$. 


\section{Association between JSY beneficiary status and utilisation of postpartum care services}

Figure 5.4 presents a comparison of the postpartum care services received during the most recent birth by JSY beneficiaries and non-beneficiaries. Findings indicate impressive differences between the two groups in the utilisation of postpartum services (Table 5.1b, Panel A). Beneficiaries were significantly more likely than non-beneficiaries to have received a postpartum check-up ( $82 \%$ versus $49 \%$ ), a postpartum check-up from health care personnel (81\% versus $38 \%$ ), and a postpartum check-up from health care personnel within two days of delivery (80\% versus $35 \%$ ) (Figure $5.4-\mathrm{A})$. Similar differences were observed in both rural and urban areas, although the differences were wider in rural (36-47 percentage points) (Figure 5.4-C) than in urban (23-33 percentage points) areas (Figure 5.4-B). Likewise, with regard to postpartum adoption of contraception, beneficiaries were significantly more likely than non-beneficiaries to accept contraception (20\% versus $15 \%$ ) (Figure 5.4-A). While a similar pattern was observed in rural areas, no such differences were evident in urban areas (Figures 5.4-C and 5.4-B, respectively).

Multivariate analyses also reaffirm the differences between the two groups (Table 5.3a); beneficiaries were 6-10 times more likely than non-beneficiaries to have received postpartum care services. We note that these findings clearly underscore significant differences in the utilisation of postpartum care services by JSY beneficiaries compared to nonbeneficiaries. The association between JSY status and the utilisation of postpartum care services observed among the rural and urban samples, however, need to be interpreted cautiously as these estimates tend to have huge standard errors and wide confidence intervals, as can be seen in Table 5.3a.

Results of regression analyses also indicate that even after controlling for potentially confounding factors, beneficiaries were 1.4 times as likely as nonbeneficiaries to have adopted contraception following delivery. In rural areas too, beneficiaries were 1.5 times as likely as non-beneficiaries to have adopted postpartum contraception; no such association was observed in urban areas.

\section{Table 5.3a} Association between JSY beneficiary status and utilisation of postpartum care services by women
according to residence: logistic regression results ${ }^{@}$

\begin{tabular}{|c|c|c|c|}
\hline $\begin{array}{l}\text { Indicators of utilisation of postpartum care } \\
\text { services }\end{array}$ & $\begin{array}{l}\text { Combined } \\
\mathbf{N}=3,434\end{array}$ & $\begin{array}{l}\text { Urban } \\
\mathrm{N}=1,777\end{array}$ & $\begin{array}{c}\text { Rural } \\
\mathbf{N}=1,657\end{array}$ \\
\hline $\begin{array}{l}\text { Received any postpartum check-up from } \\
\text { health care }{ }^{1} \text { and other }{ }^{2} \text { personnel }\end{array}$ & $\begin{array}{l}5.16^{* * *} \\
(4.38 \text { to } 6.09)\end{array}$ & $\begin{array}{c}16.37^{* * *} \\
(8.29 \text { to } 32.30)\end{array}$ & $\begin{array}{l}4.71^{* * *} \\
(3.99 \text { to } 5.60)\end{array}$ \\
\hline $\begin{array}{l}\text { Received any postpartum check-up from } \\
\text { health care personnel }\end{array}$ & $\begin{array}{l}8.23^{* * *} \\
(6.96 \text { to } 9.74)\end{array}$ & $\begin{array}{c}20.69^{* * *} \\
(11.16 \text { to } 38.34)\end{array}$ & $\begin{array}{l}7.53^{* * *} \\
(6.30 \text { to } 9.00)\end{array}$ \\
\hline $\begin{array}{l}\text { Received any postpartum check-up from } \\
\text { health care personnel within two days of } \\
\text { delivery }\end{array}$ & $\begin{array}{l}8.27^{* * *} \\
\text { (7.00 to } 9.77)\end{array}$ & $\begin{array}{c}14.39^{* * *} \\
(8.56 \text { to } 24.20)\end{array}$ & $\begin{array}{l}7.73^{* * *} \\
(6.47 \text { to } 9.25)\end{array}$ \\
\hline Postpartum adoption of contraception & $\begin{array}{l}1.40^{* * *} \\
(1.16 \text { to } 1.68)\end{array}$ & $\begin{array}{l}1.21 \\
(0.91 \text { to } 1.62)\end{array}$ & $\begin{array}{l}1.53^{* * *} \\
(1.19 \text { to } 1.96)\end{array}$ \\
\hline
\end{tabular}

Note: ${ }^{\circledR}$ After controlling for rural-urban residence and study district, odds ratios greater than 1 indicate the extent to which JSY beneficiaries were more likely than non-beneficiaries to have received postpartum services; values in parentheses indicate 95\% confidence interval. ${ }^{1}$ Includes doctors, nurses, ANMs and LHVs. ${ }^{2}$ Includes ASHAs and AWWs. ${ }^{* * *} p \leqslant 0.001$. 


\section{Effect of the JSY on the utilisation of postpartum care services}

Table $5.3 \mathrm{~b}$ presents a comparison of the utilisation of postpartum care services before and after the introduction of JSY by the sub-sample of women who had experienced a birth at both these points in time, and by JSY beneficiary status for the birth that took place in the one year preceding the interview. Findings show a considerable increase in the utilisation of postpartum care services for post-JSY births in respect of all indicators for which data are available (panel comparisons for postpartum contraception could not be made as these data were not collected for pre-JSY births) (Table 5.3b, Panel A). Thus, introduction of the JSY resulted in an increase of 32-41 points in the utilisation of postpartum services among beneficiaries; among nonbeneficiaries, it increased by just $1-5$ points. Patterns remained similar when rural and urban samples were analysed separately; however, improvements among beneficiaries were wider in rural than in urban areas on all these indicators subsequent to initiation of the JSY (35-45 points versus 19-25 points).

Results of regression analyses show that even after controlling for potentially confounding factors, the net effect of the JSY remained positive and statistically significant: women receiving a postpartum check-up showed a net increase of 27 percent, attributable to the JSY, and those receiving a postpartum check-up from health care personnel, and from health care personnel within two days of delivery displayed a net increase of 39 percent each, attributable to the JSY. A similar positive net effect was observed in both urban and rural areas (Table 5.3b, Panel B).

\section{Adoption of best practices in newborn care}

Essential practices in three components of newborn care namely, immediate newborn care, breastfeeding and immunisation, were used to assess the effect of the JSY on newborn care practices. Women who reported that they had delivered in transit were excluded from the analyses presented in the subsections below.

\section{Adoption of best practices in immediate care of the newborn}

The indicators of best practices in immediate newborn care that we used were percentages reporting that the newborn was received by the person who attended the delivery rather than being delivered on to the floor, that the cord was cut immediately, that nothing was applied on the cord stump, and that the newborn was immediately wiped dry and wrapped rather than bathed. Additionally, an indicator of comprehensive immediate newborn care, reflecting those who answered in the affirmative for all the four indicators, was calculated.

\section{Association between JSY beneficiary status and the adoption of best practices in immediate newborn care}

Table 5.4a compares the immediate newborn care practices followed as reported by JSY beneficiaries and non-beneficiaries during the most recent birth. We note that a substantial number of women reported that they did not know whether these practices had been followed at the time of the delivery and as such, were excluded from the analysis (290 women did not know whether their newborn 


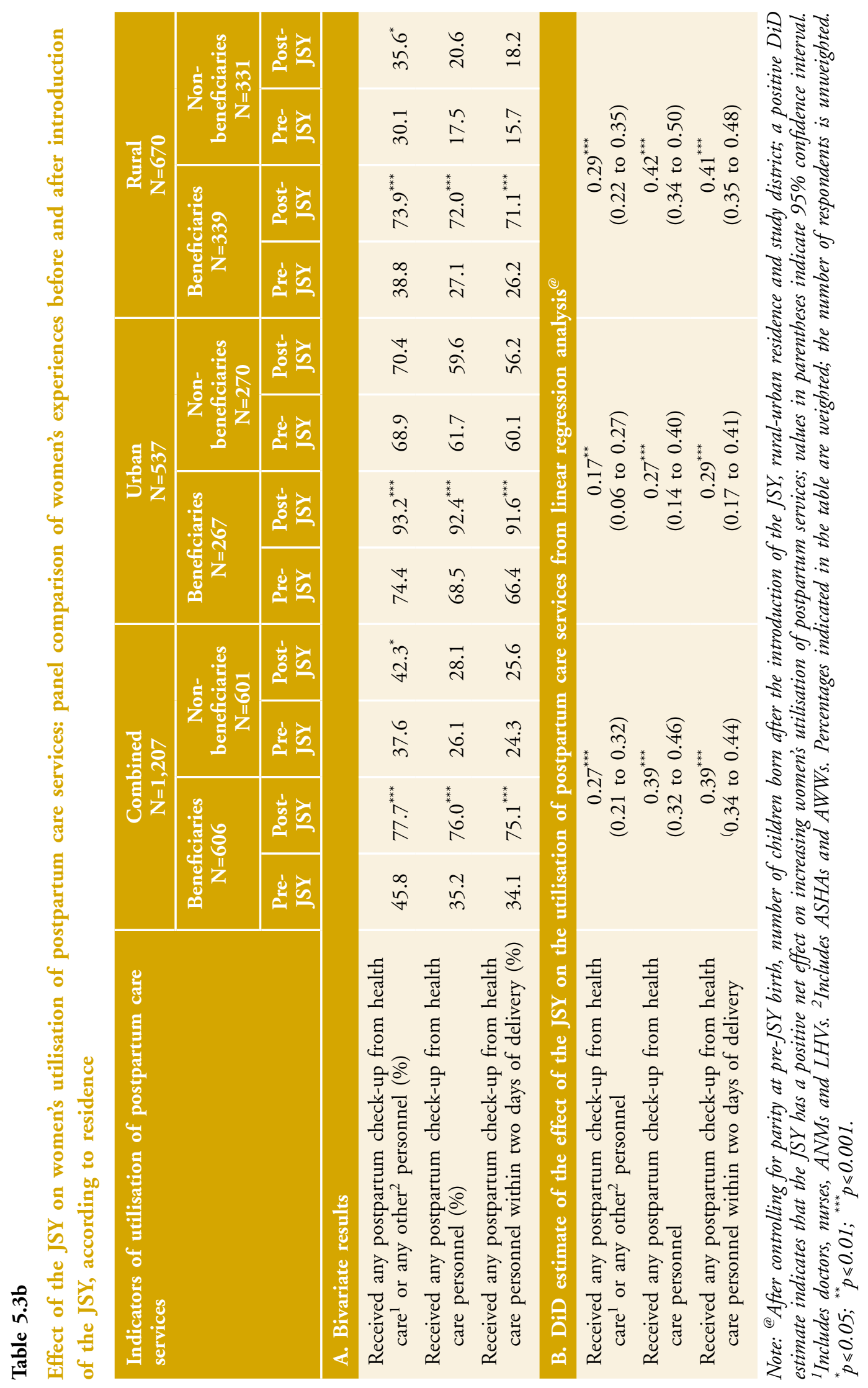


was received by the person attending the delivery, 704 women did not know whether the cord stump was cut without delay, 699 women did not know whether any substance was applied on the cord stump, 388 women did not know whether their newborn was immediately wiped dry and wrapped, and 1160 women did not know whether their newborn had received comprehensive immediate care). The background characteristics of the women who were thus excluded suggest that they were better educated, came from economically better-off households, and were more likely to belong to the Hindu religion and general castes. While this raises the issue of selectivity, we believe that there is no reason to assume that these women would have received services of poorer quality than those received by women included in the analyses, and may have, on the contrary, received better care than those who

\section{Table 5.4a}

Association between JSY beneficiary status and the adoption of best practices in immediate newborn care: cross-sectional comparison of women's experiences during the most recent birth, according to residence

\begin{tabular}{|c|c|c|c|c|c|c|}
\hline \multirow{2}{*}{$\begin{array}{l}\text { Indicators of best } \\
\text { practices in immediate } \\
\text { newborn care }\end{array}$} & \multicolumn{2}{|c|}{$\begin{array}{l}\text { Combined } \\
\mathbf{N}=3,409\end{array}$} & \multicolumn{2}{|c|}{$\begin{array}{c}\text { Urban } \\
\mathbf{N}=1,773\end{array}$} & \multicolumn{2}{|c|}{$\begin{array}{c}\text { Rural } \\
\mathbf{N}=1,636\end{array}$} \\
\hline & $\begin{array}{c}\text { Beneficiaries } \\
\mathrm{N}=1,713\end{array}$ & $\begin{array}{c}\text { Non- } \\
\text { beneficiaries } \\
\mathbf{N}=1,696\end{array}$ & $\begin{array}{c}\text { Beneficiaries } \\
\mathbf{N}=\mathbf{8 9 0}\end{array}$ & $\begin{array}{c}\text { Non- } \\
\text { beneficiaries } \\
\mathbf{N}=\mathbf{8 8 3}\end{array}$ & $\begin{array}{c}\text { Beneficiaries } \\
\mathbf{N}=\mathbf{8 2 3}\end{array}$ & $\begin{array}{l}\text { Non- } \\
\text { beneficiaries } \\
\mathbf{N}=\mathbf{8 1 3}\end{array}$ \\
\hline \multicolumn{7}{|l|}{ A. Bivariate results } \\
\hline $\begin{array}{l}\text { Newborn was received } \\
\text { by person attending } \\
\text { the delivery rather } \\
\text { than delivered on to } \\
\text { the floor }(\%)\end{array}$ & $89.6^{* * *}$ & 76.1 & 94.0 & 90.3 & $88.2^{* * *}$ & 72.0 \\
\hline $\begin{array}{l}\text { Cord was cut } \\
\text { immediately (\%) }\end{array}$ & $55.3^{* * *}$ & 45.6 & 57.9 & 60.3 & $54.5^{* * *}$ & 41.9 \\
\hline $\begin{array}{l}\text { Nothing was applied on } \\
\text { the cord stump (\%) }\end{array}$ & $84.5^{* * *}$ & 64.8 & $88.5^{* * *}$ & 68.8 & $83.3^{* * *}$ & 63.7 \\
\hline $\begin{array}{l}\text { Newborn was wiped } \\
\text { dry and wrapped, } \\
\text { and not bathed } \\
\text { immediately }(\%)\end{array}$ & $83.3^{* * *}$ & 44.5 & $86.8^{* * *}$ & 64.0 & $82.2^{* * *}$ & 39.1 \\
\hline $\begin{array}{l}\text { Newborn received } \\
\text { comprehensive } \\
\text { immediate care (\%) }\end{array}$ & $37.0^{* * *}$ & 12.2 & $42.0^{* * *}$ & 26.6 & $35.7^{* * *}$ & 8.9 \\
\hline \multicolumn{7}{|c|}{ B. Logistic regression results ${ }^{\circledR}$} \\
\hline $\begin{array}{l}\text { Newborn received } \\
\text { comprehensive } \\
\text { immediate care }\end{array}$ & \multicolumn{2}{|c|}{$\begin{array}{c}4.09^{* * *} \\
(3.31 \text { to } 5.04)\end{array}$} & $\begin{array}{r}2.03 \\
(1.38 \text { to }\end{array}$ & $\begin{array}{l}3^{* * *} \\
2.99)\end{array}$ & \multicolumn{2}{|c|}{$\begin{array}{l}5.30^{* * *} \\
(4.10 \text { to } 6.85)\end{array}$} \\
\hline \multicolumn{7}{|c|}{$\begin{array}{l}\text { Note: }{ }^{\circledR} \text { After controlling for rural-urban residence and study district; odds ratios greater than } 1 \text { indicate the extent to which } \\
\text { JSY beneficiaries were more likely than non-beneficiaries to report that their newborn had received comprehensive immediate } \\
\text { care; values in parentheses indicate } 95 \% \text { confidence interval. Percentages indicated in the table are weighted; the number of } \\
\text { respondents is unweighted. The analyses exclude women who had delivered in transit. }{ }^{* * *} p \leqslant 0.001 .\end{array}$} \\
\hline
\end{tabular}


were included. Hence, our estimates can be safely assumed to be reliable or even an underestimate of the effect of the JSY.

Findings highlight notable differences between beneficiaries and non-beneficiaries with regard to all the indicators of immediate newborn care

(Table 5.4a). Beneficiaries were significantly more likely than non-beneficiaries to report that their newborn had received all the above-mentioned best practices in immediate care. Specifically, they were more likely than non-beneficiaries to report that their newborn was received by the person who attended the delivery rather than delivered on to the floor $(90 \%$ versus $76 \%)$, that the cord was cut immediately ( $55 \%$ versus $46 \%$ ), that nothing was applied on the cord stump (85\% versus 65\%), and that their newborn was immediately wiped dry and wrapped rather than bathed $(83 \%$ versus 45\%) (Table 5.4a, Panel A) Finally, 37 percent of beneficiaries compared to 12 percent of nonbeneficiaries reported that all of the above immediate newborn care practices had been followed. This pattern was also evident in the rural sample; in the urban sample, however, it held good for only three of the five indicators. Results of regression analyses indicate that these differences remained significant even after controlling for potentially confounding factors (Table 5.4a, Panel B). Thus, beneficiaries were four times as likely as non-beneficiaries to report that their newborn had received comprehensive immediate care. Moreover, these differences were observed in both urban and rural areas in multivariate analyses (odds ratio of 2.0 and 5.3, respectively).

\section{Effect of the JSY on the adoption of best practices in immediate newborn care}

Table $5.4 \mathrm{~b}$ presents a comparison of best practices in immediate newborn care followed before and after the introduction of the JSY as reported by the sub-sample of women who had experienced a birth at both these points in time, categorised into beneficiaries and non-beneficiaries based on whether or not they had availed of JSY benefits for the birth that took place in the one year preceding the interview. As with the cross-sectional analysis, we note that a substantial number of women reported that they did not know whether these practices had been followed at the time of their delivery and were excluded from the analysis (96 women did not know whether their newborn was received by the person attending the delivery, 245 women did not know whether the cord stump was cut without any delay, 261 women did not know whether any substance was applied on the cord stump, 130 women did not know whether their newborn was immediately wiped dry and wrapped, and 418 women did not know whether their newborn had received comprehensive immediate care). As in the case of the cross-sectional findings, the background characteristics of the women who were thus excluded suggest that they were better educated, came from economically betteroff households, and were more likely to belong to the Hindu religion and general castes. While this raises the issue of selectivity, we believe, as before, that there is no reason to assume that these women would have received services of poorer quality than those received by women included in the analyses, and may have, on the contrary, received better care than those who were included. Hence, our estimates can be safely assumed to be reliable or even an underestimate of the effect of the JSY.

Findings presented in Table 5.4b, Panel A, suggest that the introduction of the JSY contributed to improvements in the adoption of best practices in immediate newborn care. For example, post introduction of the JSY, beneficiaries reported marginal improvements in such practices as the 


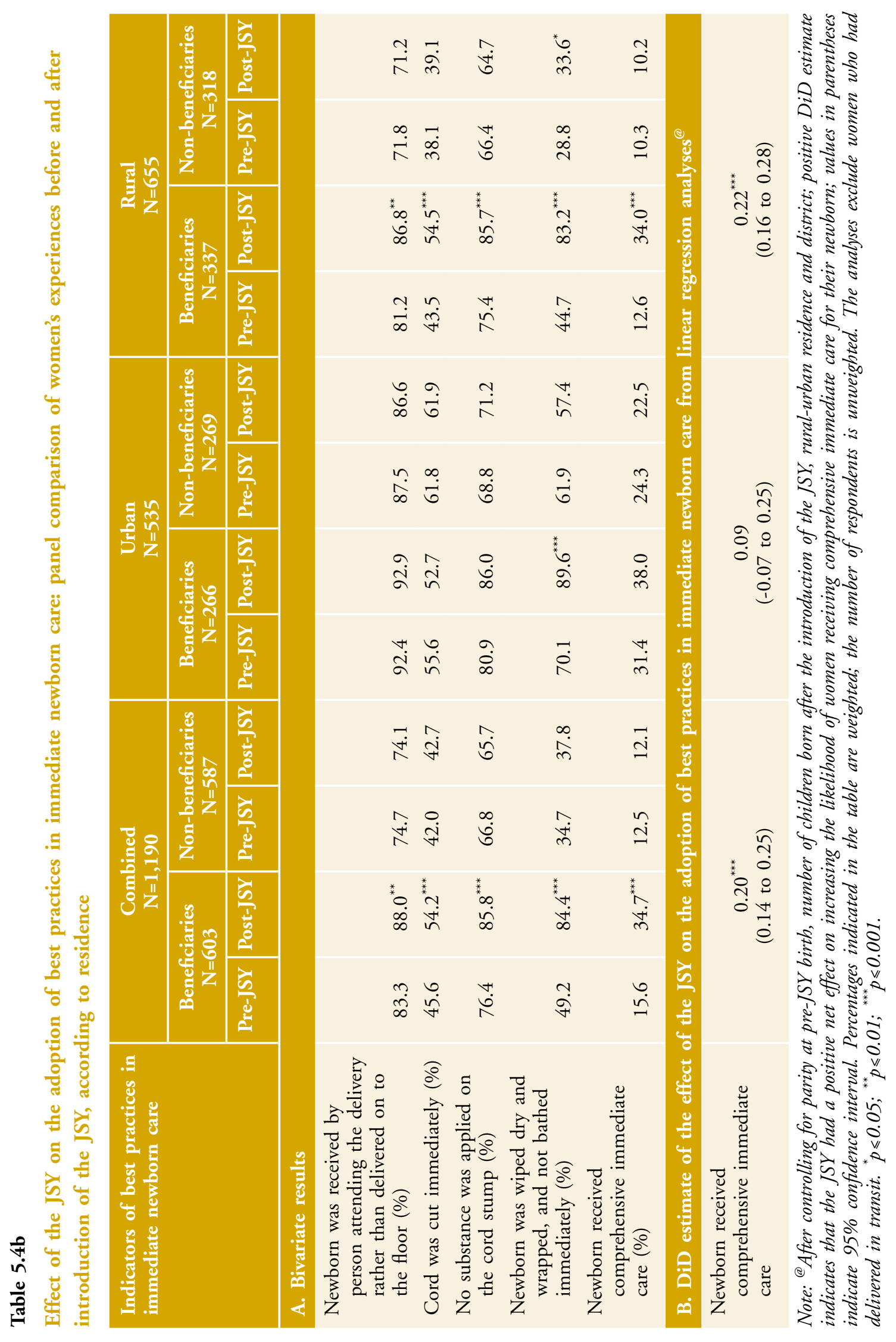


newborn being received by the person who attended the delivery rather than delivered on to the floor, immediate cord-cutting and non-application of any substance on the cord stump (5-9 points), and an even greater improvement in the practice of immediately wiping dry and wrapping the newborn instead of bathing it right away (35 points). Finally, beneficiaries reported a 19-point increase in the adoption of all the four best practices discussed above. In contrast, there was almost no change in these indicators among non-beneficiaries. Separate analyses of rural and urban samples showed a differential impact of the JSY (Table 5.4b, Panel A). In urban areas, bivariate comparisons showed a significant increase in the adoption of one of the four practices considered-that of wiping dry and wrapping the newborn immediately rather than bathing it—among beneficiaries and no significant increase in any of the four practices among nonbeneficiaries, following the introduction of the JSY. In rural areas, in contrast, notable increases of 6-39 points in the adoption of all four practices were observed among beneficiaries compared to almost no change (decline by 1 point to an increase by 5 points) among non-beneficiaries.

Results of regression analyses show that even after controlling for potentially confounding factors, the net effect of the JSY remained positive and statistically significant on newborns who had received comprehensive immediate care (an additional increase by $20 \%$, attributable to the JSY, $\mathrm{CI}=0.14-0.25$ ). A similar positive net effect was observed in rural areas, but not in urban areas (Table 5.4b, Panel B).

\section{Breastfeeding practices}

Best practices in immediate breastfeeding of newborns followed by the respondents were measured by using the following indicators: percentages reporting that the newborn was not given any prelacteal feeds, that the newborn was breastfed immediately, that is, within an hour of delivery, and that the newborn was fed colostrum. A summary indicator of best practices in immediate breastfeeding, reflecting those who answered in the affirmative on all three indicators was also calculated. In addition, an indicator of exclusive breastfeeding was calculated among women whose infant was aged more than six months at the time of the interview.

\section{Association between JSY beneficiary status and adoption of best practices in breastfeeding}

Table 5.5a compares the breastfeeding practices followed by JSY beneficiaries and non-beneficiaries during their most recent birth. Findings show that beneficiaries were significantly more likely than non-beneficiaries to have followed best practices in breastfeeding their newborn (Table 5.5a, Panel A). Specifically, they were more likely to have not given the newborn any prelacteal feeds (56\% versus 26\%), breastfed the newborn immediately (29\% versus $14 \%)$ and fed colostrum to the newborn $(78 \%$ versus $65 \%$ ). They were also more likely to have followed all three best practices (22\% versus $8 \%$ ). Findings, moreover, suggest that among mothers with infants aged more than six months, beneficiaries were slightly more likely than non-beneficiaries to have exclusively breastfed their infant for six months (31\% versus $27 \%$ ). Similar findings were observed in rural areas; in urban areas, differences by beneficiary status assumed statistical significance for only three of the five indicators included in our analysis.

Results of regression analyses indicate that these differences remained significant even after controlling for potentially confounding factors (Table 5.5a, Panel B). Beneficiaries were three times as likely as non-beneficiaries to have followed best practices in immediate breastfeeding of their newborn and 1.3 times as likely as non-beneficiaries to have 


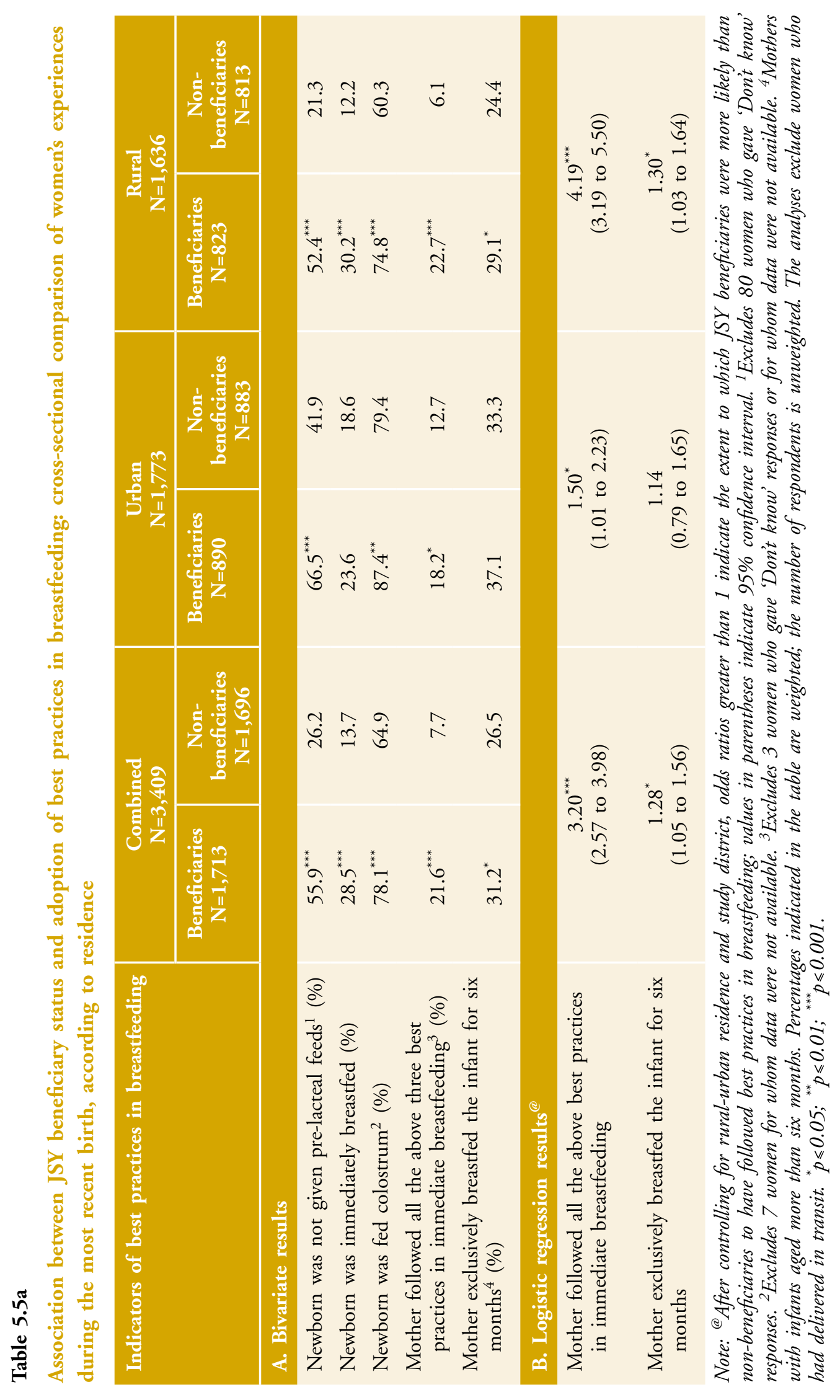




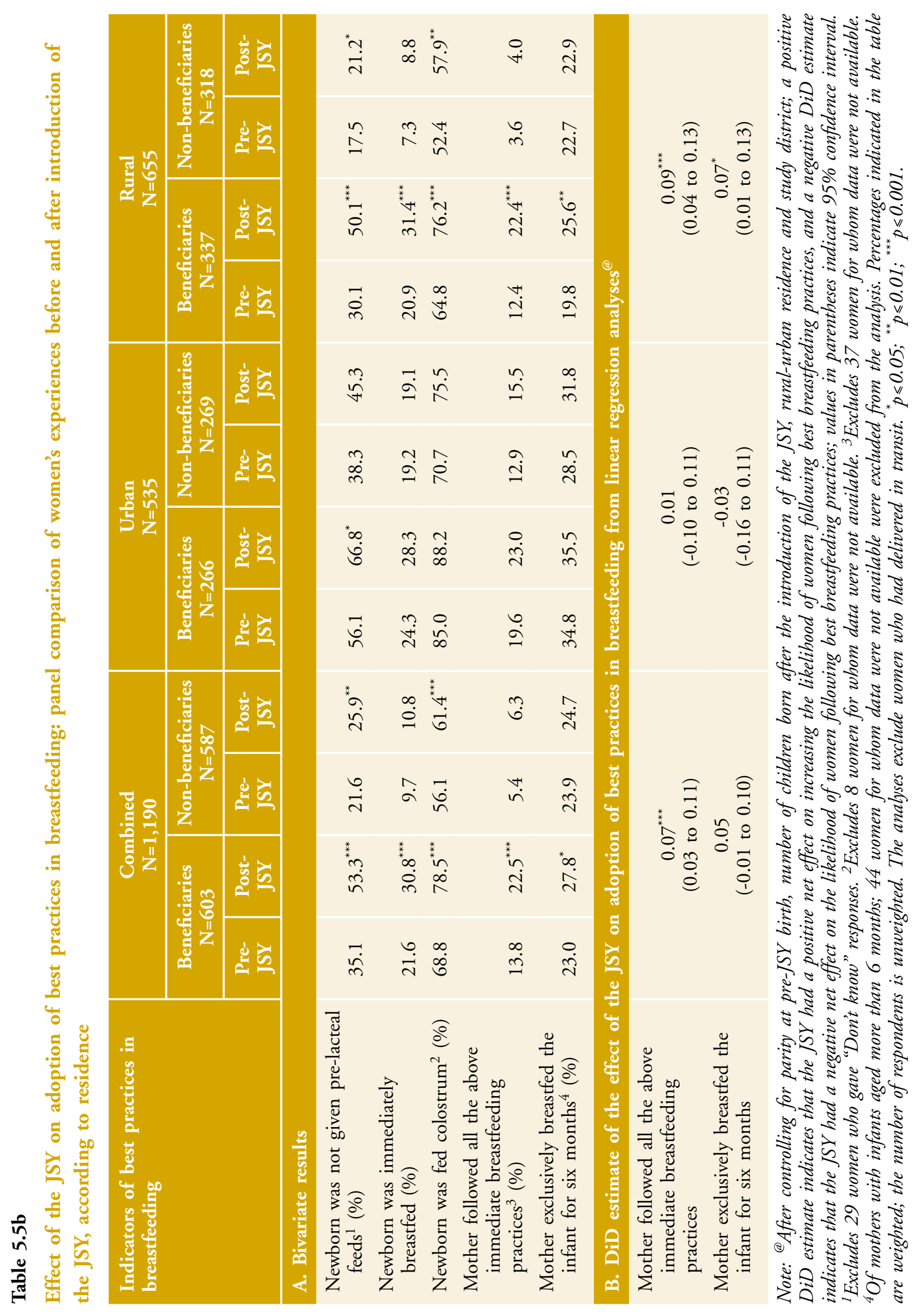


breastfed their infants exclusively for six months. While similar results were obtained with regard to both these indicators in rural areas (odds of 4.2 and 1.3 , respectively), only one indicator-adoption of best practices in immediate breastfeeding_assumed statistical significance in urban areas (odds of 1.5).

\section{Effect of the JSY on adoption of best practices in breastfeeding}

Table 5.5b compares the three indicators of best practices in breastfeeding before and after the introduction of the JSY among the sub-sample of women who had experienced a birth at both points in time, categorised into beneficiaries and non-beneficiaries based on whether or not they had availed of JSY benefits for the birth that took place in the one year preceding the interview. Findings suggest improvements in the adoption of best practices in breastfeeding a newborn, with the introduction of the JSY (Table 5.5b, Panel A). For example, subsequent to the initiation of the scheme, beneficiaries reported significant improvements in the range of 9-18 points in such best practices in breastfeeding their newborn as not giving prelacteal feeds, immediate breastfeeding, and feeding colostrum. Likewise, they reported a 9-point increase in the adoption of all of the three best practices. Among mothers with infants aged more than six months, beneficiaries who exclusively breastfed their infant for six months showed just a 5-point increase. In contrast, non-beneficiaries reported minimal changes in all three indicators ( $0-5$ points).

Separate analyses of rural and urban samples showed a differential impact of the JSY by ruralurban residence (Table 5.5b, Panel A). In urban areas, the adoption of one of the four best practices in breastfeeding considered, namely, not feeding any prelacteals increased significantly among beneficiaries; no change was observed among non-beneficiaries, subsequent to the inception of the JSY. In rural areas, in contrast, notable increases in the adoption of all four best practices were observed: an increase of 6-20 points among beneficiaries compared to no change or a marginal increase (0-6 points) among non-beneficiaries.

Results of regression analyses show that even after controlling for potentially confounding factors, the net effect of the JSY on the adoption of best

\section{Figure 5.5: Association between JSY beneficiary status and full immunisation of infants: cross- sectional comparison of women's experiences during the most recent birth, according to residence}

\section{A. Combined}

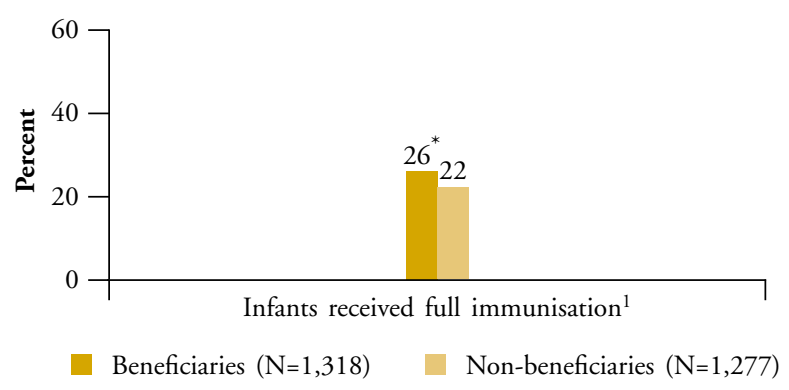

Note: Percentages are based on women whose infant was aged more than 4 months; 115 women for whom data were not available were excluded from the analysis. Percentages indicated in the figure are weighted; while the number of respondents is unweighted. p $\leqslant 0.05$.

\section{B. Urban}

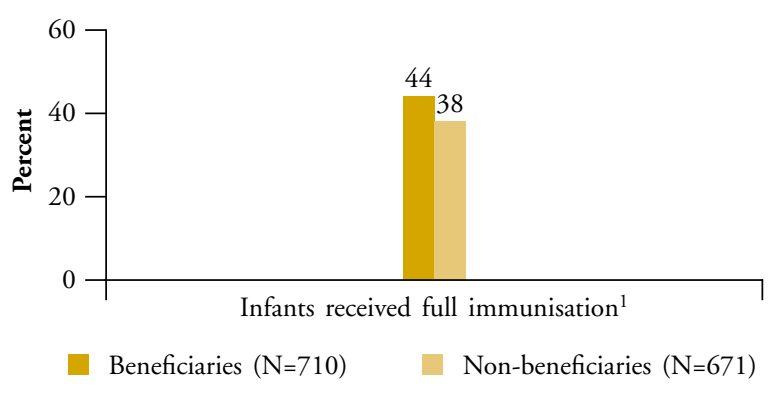

Note: Percentages are based on women whose infant was aged more than 4 months; 115 women for whom data were not available were excluded from the analysis. Percentages indicated in the figure are weighted; while the number of respondents is unweighted. 


\section{Rural}

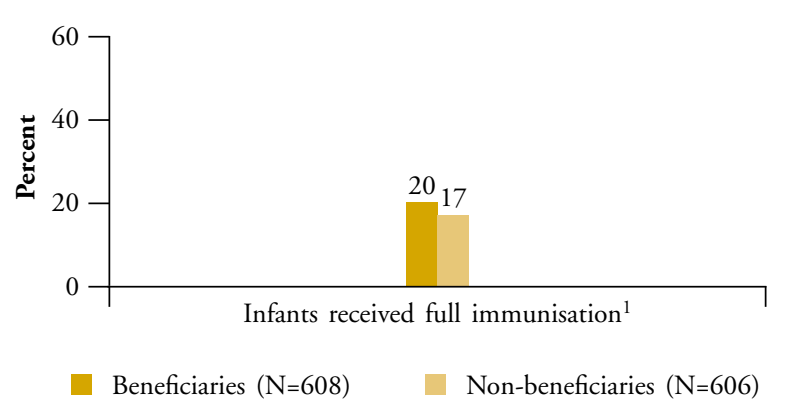

Note: Percentages are based on women whose infant was aged more than 4 months; 115 women for whom data were not available were excluded from the analysis. Percentages indicated in the figure are weighted; while the number of respondents is unweighted.

practices in immediate breastfeeding remained positive and statistically significant (a net increase of $7 \%$ attributable to the JSY). A similar positive net effect was observed in rural areas but not in urban areas (Table 5.5b, Panel B). Findings show no effect with respect to the practice of exclusive breastfeeding for six months for the combined and urban samples; however, a positive net effect was observed for the rural sample.

\section{Immunisation of infants}

An indicator of full immunisation, as defined by the percentage of infants who had received the BCG vaccine, and three doses each of the oral polio and DPT vaccines, was calculated among women whose infant was more than four months old at the time of the interview. We note that this analysis was restricted to women whose infant was more than four months old at the time of the interview so as to ensure equal exposure time for all infants considered in the analysis. We also note that we excluded measles vaccination from the definition of full immunisation for the same reason.
Association between JSY beneficiary status and full immunisation of infants

Figure 5.5 compares percentages of beneficiary and non-beneficiary women whose infant had received full immunisation, among women whose infant was more than four months old at the time of the interview. Findings suggest that beneficiaries were slightly more likely than non-beneficiaries to report that their infant was fully immunised (26\% versus 22\%) (Figure 5.5-A). No such differences were observed when rural and urban samples were analysed separately (Figure 5.5-B and 5.5-C, respectively). Results of regression analyses reiterate these findings: beneficiaries were 1.3 times as likely as non-beneficiaries to report that their infant had received full immunisation even after controlling for rural-urban residence and study district $(\mathrm{CI}=1.03-$ 1.52). No such significant differences were observed when the samples were analysed separately, by residence.

Effect of the JSY on full immunisation of infants

Table 5.6 presents a comparison of experiences related to the full immunisation of infants born before and after the introduction of the JSY in the sub-sample of women who had experienced a birth at both these points in time, categorised into beneficiaries and non-beneficiaries based on whether or not they had availed of JSY benefits for the birth that took place in the one year preceding the interview. For women who had given birth in the year prior to the interview, only those whose infant was more than four months old were considered. Following the introduction of the JSY, 
Table 5.6

Effect of the JSY on full immunisation of infants: panel comparison of women's experiences before and after introduction of the JSY, according to residence

\begin{tabular}{|c|c|c|c|c|c|c|c|c|c|c|c|c|}
\hline \multirow[t]{3}{*}{ Immunisation } & \multicolumn{4}{|c|}{$\begin{array}{c}\text { Combined } \\
\mathbf{N}=913\end{array}$} & \multicolumn{4}{|c|}{$\begin{array}{c}\text { Urban } \\
\mathrm{N}=425\end{array}$} & \multicolumn{4}{|c|}{$\begin{array}{c}\text { Rural } \\
N=488\end{array}$} \\
\hline & \multicolumn{2}{|c|}{$\begin{array}{c}\text { Beneficiaries } \\
\mathrm{N}=463\end{array}$} & \multicolumn{2}{|c|}{$\begin{array}{c}\text { Non- } \\
\text { beneficiaries } \\
\mathrm{N}=450 \\
\end{array}$} & \multicolumn{2}{|c|}{$\begin{array}{c}\text { Beneficiaries } \\
\mathbf{N}=\mathbf{2 1 7}\end{array}$} & \multicolumn{2}{|c|}{$\begin{array}{c}\text { Non- } \\
\text { beneficiaries } \\
\mathbf{N}=\mathbf{2 0 8} \\
\end{array}$} & \multicolumn{2}{|c|}{$\begin{array}{c}\text { Beneficiaries } \\
\mathrm{N}=246\end{array}$} & \multicolumn{2}{|c|}{$\begin{array}{c}\text { Non- } \\
\text { beneficiaries } \\
\mathbf{N}=242 \\
\end{array}$} \\
\hline & $\begin{array}{l}\text { Pre- } \\
\text { JSY }\end{array}$ & $\begin{array}{l}\text { Post- } \\
\text { JSY }\end{array}$ & $\begin{array}{l}\text { Pre- } \\
\text { JSY }\end{array}$ & $\begin{array}{l}\text { Post- } \\
\text { JSY }\end{array}$ & $\begin{array}{l}\text { Pre- } \\
\text { JSY }\end{array}$ & $\begin{array}{l}\text { Post- } \\
\text { JSY }\end{array}$ & $\begin{array}{l}\text { Pre- } \\
\text { JSY }\end{array}$ & $\begin{array}{l}\text { Post- } \\
\text { JSY }\end{array}$ & $\begin{array}{l}\text { Pre- } \\
\text { JSY }\end{array}$ & $\begin{array}{l}\text { Post- } \\
\text { JSY }\end{array}$ & $\begin{array}{l}\text { Pre- } \\
\text { JSY }\end{array}$ & $\begin{array}{l}\text { Post- } \\
\text { JSY }\end{array}$ \\
\hline \multicolumn{13}{|c|}{ A. Bivariate results } \\
\hline $\begin{array}{l}\text { Infants } \\
\text { received full } \\
\text { immunisation } \\
(\%)\end{array}$ & 5.8 & $21.9^{* * *}$ & 8.4 & $18.6^{* * *}$ & 7.6 & $38.1^{* * *}$ & 10.1 & $35.4^{* * *}$ & 5.3 & $17.4^{* * *}$ & 8.0 & $14.3^{* *}$ \\
\hline \multicolumn{13}{|c|}{ B. DiD estimate of the effect of the JSY on full immunisation of infants from linear regression analysis ${ }^{\circledR}$} \\
\hline $\begin{array}{l}\text { Infants } \\
\text { received full } \\
\text { immunisation }\end{array}$ & & $\begin{array}{r}0 \\
(-0.01\end{array}$ & 6 & & & $\begin{array}{r}0 . \\
(-0.09\end{array}$ & 5 & & & $\begin{array}{r}0 . \\
(-0.01\end{array}$ & 6 & \\
\hline
\end{tabular}

Note: ${ }^{\circledR}$ After controlling for parity at pre-JSY birth, number of children born after the introduction of the JSY, rural-urban residence and district; positive DiD estimate indicates that the JSY had a positive net effect on increasing the likelihood of women obtaining full immunisation for their infant; values in parentheses indicate $95 \%$ confidence interval. Percentages are based on women whose infant was aged more than 4 months; 119 women for whom data were not available were excluded from the analysis. Percentages indicated in the table are weighted; the number of respondents is unweighted. ${ }^{* *} p \leqslant$ $0.01 ;{ }^{* * *} p \leqslant 0.001$.

full immunisation of infants increased by 16 points among beneficiaries compared to 10 points among non-beneficiaries. Similar patterns were observed in both urban and rural areas (Table 5.6, Panel A). These differences, however, did not assume statistical significance in the multivariate analysis (Table 5.6, Panel B).

\section{Summary}

Findings presented in this chapter underscore that the JSY has contributed to increasing the utilisation of maternal health services and adoption of best practices in newborn care.

In the area of antenatal services, the JSY has made significant contributions to promoting the use of selected antenatal services such as obtaining three or more antenatal check-ups and iron and folic acid supplements, as confirmed by the positive net association observed in cross-sectional analyses and the positive net effect observed in panel analyses. With regard to receiving an antenatal check-up in the first trimester, findings were mixed: although a positive association was observed in cross-sectional analyses, no significant net effect was observed when we compared women's experiences before and after the introduction of the JSY. Hence, it is difficult to say convincingly that the JSY has contributed to enabling women to receive an early antenatal check-up.

As far as delivery services are concerned, the JSY has unquestionably made a significant contribution to increasing institutional deliveries and skilled attendance at birth. 
Likewise, the JSY has contributed to increasing women's utilisation of postpartum services, particularly in respect of receiving a check-up from health care personnel immediately after delivery, as confirmed by the positive net association observed in cross-sectional analyses and the positive net effect observed in panel analyses. Findings also indicate a positive association between the receipt of JSY benefits and the adoption of postpartum contraception.

Significant improvements in the adoption of newborn-related best practices were also evident. Among women who had given birth prior to and after the JSY had been introduced, those who had received JSY benefits for the most recent birth were more likely than those who had not, to have received comprehensive care for their newborn and followed best practices in immediate breastfeeding (that is, not feeding prelacteals, immediate breastfeeding and feeding colostrum), even after potentially confounding factors had been controlled. However, findings were mixed with regard to exclusive breastfeeding and full immunisation of infants; thus, although a positive net association between the receipt of JSY benefits and exclusive breastfeeding for six months and full immunisation of infants was evident in cross-sectional analyses, no significant net effect was observed when we compared women's experiences before and after the introduction of the JSY. Hence, it is difficult to say convincingly that the JSY has contributed to promoting these practices. These findings suggest that the JSY may not be effective in influencing behaviours that require sustained effort over a long period of time.

Findings, moreover, indicate that the JSY has produced a differential impact in rural and urban areas. Among rural women, the scheme has undoubtedly contributed to the likelihood of their obtaining three or more antenatal check-ups, iron and folic acid supplements, an institutional delivery, skilled attendance at birth, and a postpartum checkup from health care personnel immediately after delivery. It has also contributed to encouraging rural women to obtain comprehensive immediate care for their newborn, to follow correct practices related to immediate breastfeeding of their newborn and exclusive breastfeeding of the infant for six months. In contrast, in urban areas, the contribution of the JSY was limited to women obtaining an institutional delivery, skilled attendance at birth and a postpartum check-up from health care personnel immediately after delivery. These findings may well reflect the differential access to health services that women in rural and urban areas have, with urban women having greater access to a wide array of services than rural women thereby, limiting the effects of the JSY on increasing their utilisation of maternal health services and adoption of best practices in newborn care. 


\section{CHAPTER 6}

\section{Effect of the JSY on the quality of maternal health services}

Several previous evaluations of the JSY have raised concerns about the quality of maternal health services provided at government health facilities in view of the expanded service demand generated by the introduction of the JSY (Das et al., 2011; Devadasan et al., 2008; Iyengar et al 2008; 2009a; 2009b; Sharma, 2008). In order to assess whether the JSY has contributed to improving the quality of maternal health services or otherwise, we included several questions that attempted to capture multiple dimensions of quality of care. Findings presented in this chapter specifically describe the effect of the JSY on the quality of care received during the antenatal, delivery and postpartum periods as well as women's access to health care providers, supplies, and a respectful and clean facility.

As mentioned in Chapter 1, we used panel analysis drawing on the unmatched sample of women who had given birth before and after the JSY was introduced, categorised into beneficiaries and non-beneficiaries, based on whether or not they had received JSY cash assistance for the most recent birth (795 and 857 women, respectively). We compared the quality of care received at pre- and post-JSY births by beneficiaries and non-beneficiaries. Paired t-tests were first used to assess the significance of change over time, if any, in both the groups. We also assessed the net effect using difference-indifference estimation. Since we used the unmatched sample of women in these analyses, we controlled for such covariates as age, education, religion, caste, household economic status, parity at pre-JSY birth, number of children born after the introduction of the JSY, rural-urban residence, and study district. We note that the sub-samples used for the analyses varied by the type of indicators used.

\section{Effect of the JSY on the quality of antenatal care services}

Five components of the quality of antenatal care services received by women were measured: the extent to which women seeking antenatal services had received comprehensive information about pregnancy care, the extent to which women had received comprehensive antenatal services, the nature of client-provider interaction, the technical quality of services, and continuity of services.

Four indicators were used to measure the extent to which information related to pregnancy care was provided to women seeking antenatal services, namely, whether the woman had received information from the health care provider about: (1) the danger signs during pregnancy, delivery or the postpartum period; (2) birth preparedness, that is, making a delivery plan, including preparations for her delivery and the expected date of delivery; (3) the importance of postpartum check-ups; and

(4) newborn care, that is, breastfeeding, care of the newborn or danger signs in the newborn.

The extent to which women seeking antenatal services were provided with comprehensive services 
was quantified by a categorical variable that assessed whether women had received four or more of the following recommended services: weight measurement, height measurement, blood pressure measurement, blood test, urine test, an abdominal examination and an internal examination.

The quality of client-provider interaction was assessed by asking a single question as to whether the health care provider had always treated the respondent with respect.

To measure the technical quality of services, we used a proxy indicator that assessed whether the health care provider had enquired about signs of pregnancy-related complications experienced by the respondent, if any, whenever she had an antenatal check-up. Likewise, to measure the continuity of services, we used a proxy indicator that assessed whether the provider had reminded her about follow-up visits.

In order to compare improvements or otherwise in the quality of antenatal services with the introduction of the JSY, we focus on the experiences of women who had given birth before and after the JSY was introduced, and had received some antenatal services at both these points in time. Among them, we compare the experiences of those who had availed of JSY benefits for the recent birth, with those who had not done so. Findings present a mixed picture about the effect of the JSY on the quality of antenatal services (Table 6.1). Although the percentages of women receiving comprehensive information on pregnancy care remained low, some improvement was observed among those seeking antenatal services. For example, subsequent to the introduction of the JSY, percentages of beneficiary women reporting that they had received information on danger signs during pregnancy, delivery or the postpartum period increased by 8 points compared to a 3-point increase among non-beneficiaries (Table 6.1, Panel A). Differences were narrower, however, with regard to women who had received information on birth preparedness (4 points versus 1 point), the importance of postpartum check-ups (3 points each), and newborn care or complications (8 versus 6 points).

Similarly, some improvement was evident in the provision of comprehensive services; post inception of the JSY, percentages of women who had received four or more services during antenatal visits increased by 17 points among beneficiaries compared to 5 points among non-beneficiaries. Likewise, percentages of women who reported that the health care provider had always reminded them about follow-up visits increased by 7 points among beneficiaries compared to 2 points among non-beneficiaries. Findings were inconsistent with regard to other indicators of quality of services (Table 6.1, Panel A). For example, similar improvements were reported by both beneficiaries and non-beneficiaries in such practices as the health care provider enquiring about pregnancy-related complications experienced by them, if any, at every antenatal visit (increase of 6 percentage points). Almost no change was observed either among beneficiaries or non-beneficiaries reporting that the health care provider had treated them well. Patterns were similar for the most part, when rural and urban samples were analysed separately.

When controlled for potentially confounding factors, changes in only a few indicators assumed statistical significance (Table 6.1, Panel B). For example, the net effect of the JSY remained positive and significant with regard to women receiving information on danger signs during pregnancy, delivery or the postpartum period (an additional increase of 5\%, attributable to the JSY) and women receiving four or more services during antenatal visits (an additional increase of $7 \%$, attributable to the 


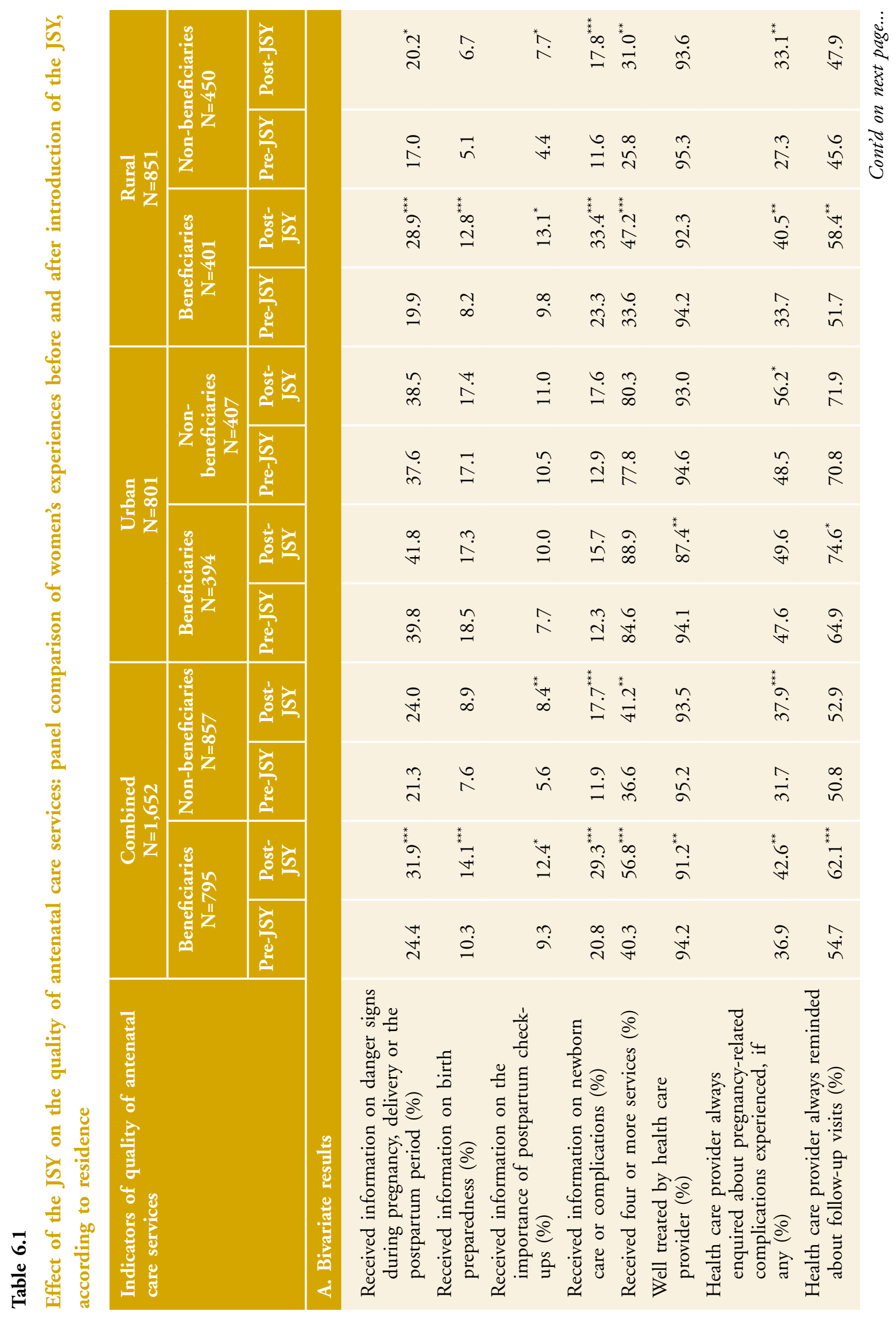




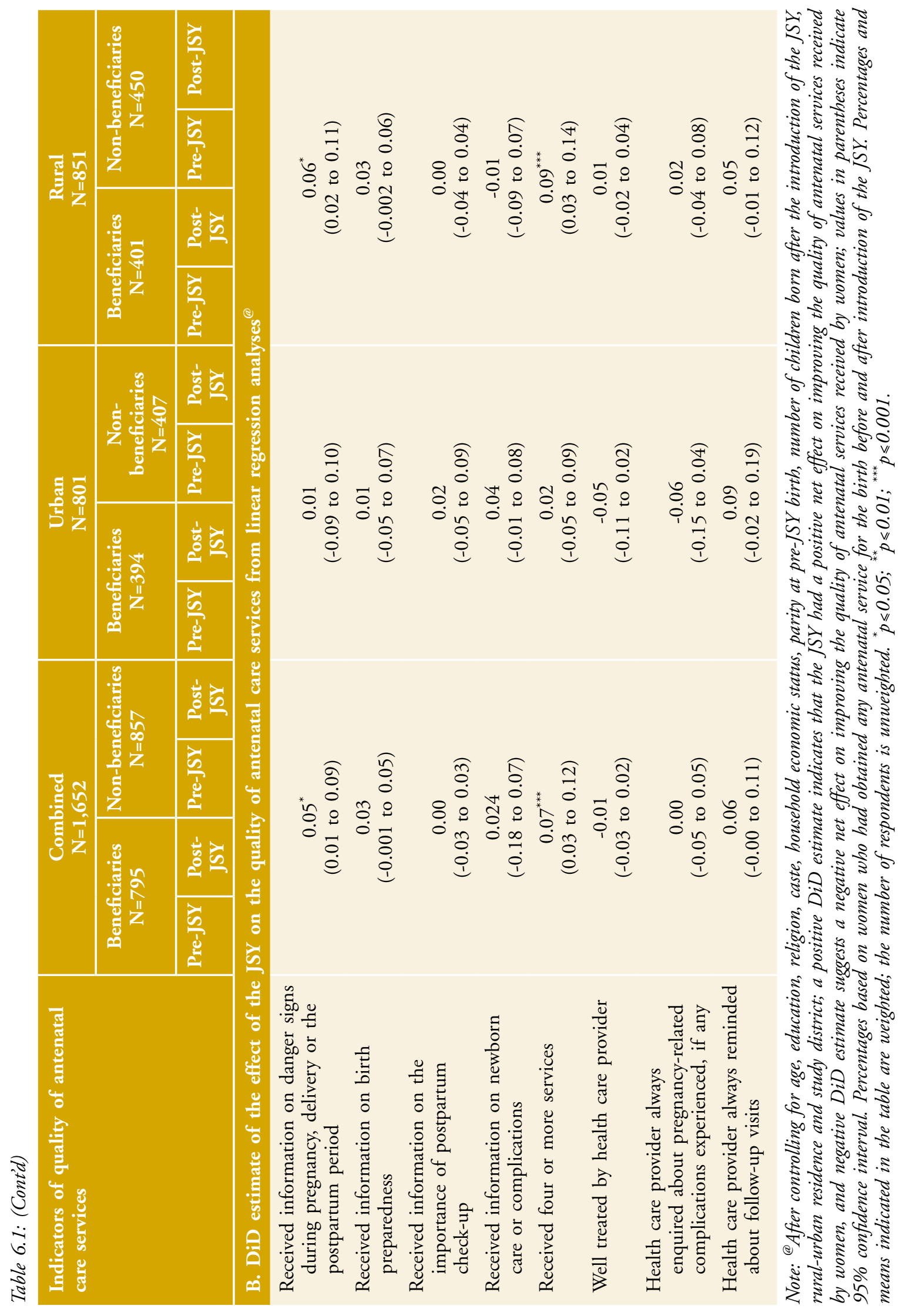


JSY); a similar pattern was observed in rural areas but not in urban areas. No change was observed in terms of other indicators of quality of services, regardless of rural-urban residence.

\section{Effect of the JSY on the quality of delivery care services}

Several questions were posed to women who had delivered in a health facility to assess the quality of delivery care services. These questions related to healthy and harmful practices followed during labour and delivery, the availability of the health care provider and the provider's behaviour toward the client, access to supplies, and the availability of a clean and confidential delivery facility. We note that 95 percent of beneficiaries had delivered in a district hospital, a $\mathrm{CHC}$ or a $\mathrm{PHC}$, and 85 percent of non-beneficiaries had delivered in non-accredited private or NGO facilities. In other words, the findings presented in Tables 6.2 and 6.3 reflect a comparison of the quality of delivery services offered in government and private facilities. We also note that given the small number of women who had given birth at both time points in a similar health facility that is, those who had delivered in a public facility or those who had delivered in a private facility at both time points, findings are presented for the combined sample and not separately for rural and urban samples.

\section{Effects of the JSY on healthy and harmful practices followed during labour and delivery}

Women were questioned about both healthy and harmful practices followed at the health facility where they had delivered in order to assess the quality of labour and delivery services they had received. Specifically, they were asked whether the health care provider had conducted each of the following examinations at the time of admission to the health facility for delivery: abdominal examination, vaginal examination, temperature measurement and pulse measurement. They were also asked whether they had been given an injection after the baby was delivered but before the placenta was expelled (most likely oxytocin, for the management of the third stage of labour) and whether they had been discharged at least 24 hours after the delivery. We note that 159 women, who said that they did not know whether they had been administered an injection between the delivery of the newborn and the placenta, were excluded from the analysis. Except for being better educated, the characteristics of the women who were thus excluded were largely similar to those of the women included in the analysis. While this raises the issue of selectivity, we believe that there is no reason to assume that these women would have received services of poorer quality than those received by women included in our analyses, and may, on the contrary, have received better care than those who were included. Hence, our estimates can be safely assumed to be reliable or even an underestimate of the effect of the JSY.

In order to explore the extent to which healthy delivery practices had been followed before and after the introduction of the JSY, we compared deliveryrelated experiences of the sub-sample of women who had given birth in a similar health facility at both times, and who had and had not received JSY benefits for the birth that took place in the one year preceding the interview. Findings are presented in Table 6.2. Bivariate comparisons did not indicate any difference either among beneficiaries or nonbeneficiaries, in the extent to which women received the recommended examinations on admission to a health facility for delivery, or in the use of oxytocin for the management of the third stage of labour subsequent to the commencement of the JSY (Table 6.2, Panel A). However, a significant improvement 
Table 6.2

Effects of the JSY on healthy and harmfull practices followed during labour and delivery: panel comparison of women's experiences before and after introduction of the JSY

\begin{tabular}{l|l|l|l|l|}
$\begin{array}{l}\text { Indicators of healthy and harmful practices followed } \\
\text { during labour and delivery }\end{array}$ & \multicolumn{2}{|c|}{$\begin{array}{c}\text { Beneficiaries } \\
\text { N=360 }\end{array}$} & \multicolumn{2}{|c|}{$\begin{array}{c}\text { Non-beneficiaries } \\
\text { N=202 }\end{array}$} \\
\cline { 2 - 5 } & Pre-JSY & Post-JSY & Pre-JSY & Post-JSY \\
\hline A. Bivariate results
\end{tabular}

\section{Healthy practices followed during labour and delivery}

Health care provider conducted all four check-ups (\%)

28.1

Health care provider gave an injection after respondent delivered but before the placenta was expelled ${ }^{1}(\%)$

Respondent discharged 24 hours after delivery (\%)

\section{Harmful practices followed during labour and delivery}

Health care provider applied strong fundal pressure before respondent delivered (\%)

50.3

28.1

46.2

51.1

Health care provider gave an intra-muscular injection during labour before the baby was delivered to speed up the delivery/increase pain ${ }^{2}(\%)$

77.6

9.2

59.2

56.5

$65.8^{* * *}$$$
\text { (7). }
$$

B. DiD estimate of the effects of the JSY on healthy and harmful practices followed during labour and

delivery from linear regression analyses ${ }^{\circledR}$

Health care provider conducted all four check-ups

Health care provider gave an injection after respondent delivered but before the placenta was expelled ${ }^{1}$

0.04

$(-0.03$ to 0.10$)$

Respondent discharged 24 hours after delivery ${ }^{3}$

$0.16^{* *}$

$(0.04$ to 0.27$)$

$-0.08$

Health care provider applied strong fundal pressure before respondent delivered

Health care provider gave an intra-muscular injection during labour before the baby was delivered to speed up the delivery/increase pain ${ }^{2}$

Note: ${ }^{\circledR}$ After controlling for age, education, religion, caste, household economic status, parity at pre-JSY birth, number of children born after the introduction of the JSY, rural-urban residence and study district; a positive DiD estimate indicates that the JSY had a positive net effect on improving the quality of labour and delivery services received by women, and a negative DiD estimate suggests a negative net effect on improving the quality of labour and delivery services receive by women; values in parentheses indicate 95\% confidence interval. ${ }^{1}$ Excludes 159 women for whom data were not available. ${ }^{2}$ Excludes 53 women for whom data were not available. ${ }^{3}$ After controlling for type of delivery (normal or complicated, that is, requiring a c-section, episiotomy or blood transfusion), in addition to the standard covariates. Percentages based on women who had delivered in similar health facilities before and after the JSY was introduced, that is public-public

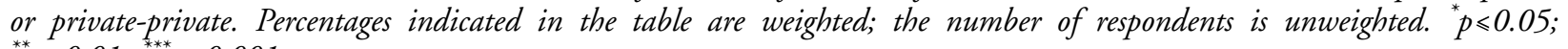
$\stackrel{* *}{p} \leqslant 0.01 ; \stackrel{* * *}{p} \leqslant 0.001$. 
in the practice of discharging women at least 24 hours after delivery was evident among beneficiaries (an increase of 16 points) while non-beneficiaries reported almost no change (a decline of 3 points). Multivariate analyses reiterated these results. When controlled for potentially confounding factors, a positive and significant net effect was observed in the practice of discharging women after at least 24 hours of delivery (an additional increase of $16 \%$, attributable to the JSY) (Table 6.2, Panel B). However, no net effect was observed with respect to conducting essential examinations on admission for delivery or in the use of injections (most likely, oxytocin) for the management of the third stage of labour.

Women were also asked about two harmful practices that are often followed during labour and delivery, namely, whether the health care provider had applied strong fundal pressure before the delivery and whether they had been given an intramuscular injection during labour before the baby was delivered to speed up delivery or increase pain (likely, oxytocin). We note that 53 women who reported that they did not know whether or not such an injection had been administered to them were excluded from the analysis. The characteristics of the women who were thus excluded were similar to those of the women included in the analysis. Bivariate comparisons indicate almost no change in these practices following the introduction of the JSY either among beneficiaries or non-beneficiaries, except that the beneficiaries reported a 6-point decline in the use of injections (most likely, oxytocin) to expedite delivery (Table 6.2, Panel A). When controlled for potentially confounding factors, however, no net effect was observed in the case of both the practices (Table 6.2, Panel B).

\section{Effect of the JSY on access to client-friendly facilities}

We also enquired of women about their access to health care providers, supplies, and a respectful and clean facility. Specifically, we probed whether the service provider was available when the respondent reached the facility for delivery and whether the provider behaved respectfully with the respondent, that is, the provider did not shout at the respondent during labour and delivery. Women were also probed about whether they were asked to arrange for medicines and other supplies or blood from outside the facility. Besides, a number of questions also assessed women's access to a respectful and clean facility - whether the respondent was allotted a bed and was not asked to share it with other women, whether a clean labour room was available and whether visual privacy was ensured. Women who responded affirmatively to these three questions were considered to have access to a respectful and clean delivery facility. Finally, women were asked whether the provider had allowed their escort to remain with them during delivery.

Findings presented in Table 6.3 suggest no change in most indicators pertaining to access to providers, supplies, and a respectful and clean facility subsequent to the inception of the JSY. The only exception observed was with regard to allowing the escort to remain with the respondent during delivery; post introduction of the JSY, beneficiaries reported an increase of 9 points while no significant change was observed among non-beneficiaries (Panel A). These differences remained significant in the multivariate analyses too (Panel B). 


\section{Table 6.3}

Effect of the JSY on access to client-friendly facilities: panel comparison of women's experiences before and after introduction of the JSY

\begin{tabular}{|c|c|c|c|c|}
\hline \multirow[t]{2}{*}{ Indicators of client-friendly facilities } & \multicolumn{2}{|c|}{$\begin{array}{l}\text { Beneficiaries } \\
\mathrm{N}=360\end{array}$} & \multicolumn{2}{|c|}{$\begin{array}{l}\begin{array}{l}\text { Non-beneficiaries } \\
\mathrm{N}=202\end{array} \\
\end{array}$} \\
\hline & Pre-JSY & Post-JSY & Pre-JSY & Post-JSY \\
\hline \multicolumn{5}{|l|}{ A. Bivariate results } \\
\hline $\begin{array}{l}\text { Health care provider was available when respondent reached } \\
\text { the facility }(\%)\end{array}$ & 87.9 & 85.6 & 93.1 & 86.1 \\
\hline $\begin{array}{l}\text { Health care provider behaved well with respondent (that is, } \\
\text { did not shout at her during labour and delivery) }(\%)\end{array}$ & 83.7 & 84.8 & 90.1 & 90.1 \\
\hline $\begin{array}{l}\text { Respondent was asked to arrange medicines and other } \\
\text { supplies or blood }(\%)\end{array}$ & 89.4 & 89.0 & 76.1 & 72.3 \\
\hline $\begin{array}{l}\text { Respondent reported access to a respectful and clean } \\
\text { facility }(\%)\end{array}$ & 54.9 & 53.7 & 79.5 & 85.9 \\
\hline $\begin{array}{l}\text { Escort was allowed to remain with respondent during } \\
\text { delivery }(\%)\end{array}$ & 41.7 & $50.3^{* * *}$ & 28.8 & 25.2 \\
\hline \multicolumn{5}{|c|}{$\begin{array}{l}\text { B. DiD estimate of the effect of the JSY on access to client-friendly facilities from linear regression } \\
\text { analyses }{ }^{\circledR}\end{array}$} \\
\hline $\begin{array}{l}\text { Health care provider was available when respondent reached } \\
\text { the facility }\end{array}$ & \multicolumn{4}{|c|}{$\begin{array}{l}0.05 \\
(-0.05 \text { to } 0.14)\end{array}$} \\
\hline $\begin{array}{l}\text { Health care provider behaved well with respondent (that is, } \\
\text { did not shout at her during labour and delivery) }\end{array}$ & \multicolumn{4}{|c|}{$\begin{array}{c}0.01 \\
(-0.08 \text { to } 0.10)\end{array}$} \\
\hline $\begin{array}{l}\text { Respondent was asked to arrange medicines and other supplies } \\
\text { or blood }^{1}\end{array}$ & \multicolumn{4}{|c|}{$\begin{array}{c}0.02 \\
(-0.07 \text { to } 0.10)\end{array}$} \\
\hline Respondent reported access to a respectful and clean facility ${ }^{1}$ & \multicolumn{4}{|c|}{$\begin{array}{c}-0.09 \\
(-0.21 \text { to } 0.02)\end{array}$} \\
\hline $\begin{array}{l}\text { Escort was allowed to remain with respondent during } \\
\text { delivery }^{1}\end{array}$ & \multicolumn{4}{|c|}{$\begin{array}{c}0.12^{* *} \\
(0.03 \text { to } 0.21)\end{array}$} \\
\hline
\end{tabular}

Note: ${ }^{\circledR}$ After controlling for age, education, religion, caste, household economic status, parity at pre-JSY birth, number of children born after the introduction of the JSY, rural-urban residence and study district; a positive DiD estimate indicates that the JSY had a positive net effect on the availability of client-friendly service facilities and a negative DiD estimate suggests a negative net effect on the availability of client-friendly service facilities; values in parentheses indicate $95 \%$ confidence interval. ${ }^{1}$ After controlling for type of delivery (normal or complicated, that is, requiring a c-section, episiotomy or blood transfusion), in addition to the standard covariates. Percentages based on women who had delivered in similar heath facilities both before and after the JSY was introduced that is, public-public or private-private. Percentages indicated in the table are weighted; the number of respondents is unweighted. ${ }^{* *} p \leqslant 0.01 ;{ }^{* * *} p \leqslant 0.001$.

\section{Effect of the JSY on the quality of postpartum care services}

The quality of postpartum care services was assessed among women who had received at least one postpartum check-up from health care personnel for births that had taken place before and after the introduction of the JSY. Two sets of indicators were used. One of these assessed whether women had received comprehensive check-ups that is, whether each of the following - blood pressure, temperature and vaginal bleeding-had been checked. A second indicator measured the extent to which women had received comprehensive information on self-care and 
newborn care. This indicator summed up women's responses to five questions related to information received from health care providers, at any time, as part of their postpartum check-ups. These questions probed whether women had received information about taking care of themselves and their baby, breastfeeding, immunisation and contraception. The respondent was assigned a score of 1 for each item on which she had received information and 0 otherwise. Scores were summed up to create the index, the value of which ranged from 0 indicating that no information had been received to 5 indicating that full information had been received (Cronbach's alpha=0.84).
In order to explore the effect of the JSY on the quality of postpartum care services, we focus on women who had experienced a birth before as well as after the JSY was introduced, and had received a postpartum check-up at both times. Among these women, we compare the experiences of those who had and had not availed of JSY benefits for the birth that took place in the one year preceding the interview. Findings, presented in Table 6.4, are for the combined sample only because of the small number of women who had received postpartum check-ups at both points in time. Findings, by and large, indicate almost no change in the quality of postpartum services

\section{Table 6.4}

Effect of the JSY on the quality of postpartum care services: panel comparison of women's experiences before and after introduction of the JSY

\begin{tabular}{|c|c|c|c|c|}
\hline \multirow[t]{2}{*}{$\begin{array}{l}\text { Indicators of quality of postpartum care } \\
\text { services }\end{array}$} & \multicolumn{2}{|c|}{$\begin{array}{l}\text { Beneficiaries } \\
\quad \mathrm{N}=414\end{array}$} & \multicolumn{2}{|c|}{$\begin{array}{l}\text { Non-beneficiaries } \\
\mathbf{N}=\mathbf{2 8 0}\end{array}$} \\
\hline & Pre-JSY & Post-JSY & Pre-JSY & Post-JSY \\
\hline \multicolumn{5}{|l|}{ A. Bivariate results } \\
\hline $\begin{array}{l}\text { Comprehensive postpartum check-ups } \\
\text { received (\%) }\end{array}$ & 15.0 & 14.2 & 24.0 & 24.8 \\
\hline $\begin{array}{l}\text { Index of comprehensive postpartum information } \\
\text { received }(0-5)(\%)\end{array}$ & 2.7 & $3.2^{* * *}$ & 2.7 & $3.2^{* * *}$ \\
\hline $\begin{array}{l}\text { Health care provider reminded respondent about } \\
\text { follow-up visits }(\%)\end{array}$ & 39.4 & 37.3 & 44.8 & $54.1^{*}$ \\
\hline \multicolumn{5}{|c|}{$\begin{array}{l}\text { B. DiD estimate of the effect of the JSY on the quality of postpartum care services from linear regression } \\
\text { analyses }{ }^{\circledR}\end{array}$} \\
\hline $\begin{array}{l}\text { DiD estimate for women having received } \\
\text { comprehensive postpartum check-ups }\end{array}$ & \multicolumn{4}{|c|}{$\begin{array}{l}-0.03 \\
(-0.10 \text { to } 0.05)\end{array}$} \\
\hline $\begin{array}{l}\text { Difference in the extent to which comprehensive } \\
\text { postpartum information was received }(0-5) \\
\text { before and after JSY }\end{array}$ & \multicolumn{4}{|c|}{$\begin{array}{c}0.010 \\
(-0.303 \text { to } 0.323)\end{array}$} \\
\hline \multicolumn{5}{|c|}{$\begin{array}{l}\text { Note: }{ }^{\circledR} \text { After controlling for age, education, religion, caste, household economic status, parity at pre-JSY birth, number of } \\
\text { children born after the introduction of the JSY, rural-urban residence and study district; a negative DiD estimate indicates } \\
\text { that the JSY had a negative net effect on the quality of postpartum care services received by women; values in parentheses } \\
\text { indicate } 95 \text { confidence interval. Percentages based on women who had received a postpartum check-up from health care } \\
\text { personnel before and after the introduction of the JSY. Percentages indicated in the table are weighted; the number of } \\
\text { respondents is unweighted. }{ }^{*} p \leqslant 0.05^{* * *} p \leqslant 0.001 \text {. }\end{array}$} \\
\hline
\end{tabular}


received subsequent to the introduction of the JSY. For example, bivariate results show no significant change in the extent of comprehensive check-ups received either by beneficiary or non-beneficiary women from health care personnel. With respect to receiving comprehensive information, findings, by and large, indicate similar rates of improvement among both beneficiaries and non-beneficiaries post introduction of the JSY; the mean score of the index of comprehensive postpartum information received increased from 2.7 to 3.1/3.2 among beneficiaries and non-beneficiaries (Table 6.4, Panel A). Finally, no statistically significant change was observed in percentages of beneficiaries or non-beneficiaries reporting that the provider had reminded them about follow-up visits. Multivariate analyses also confirm the absence of improvements in the quality of postpartum services with the introduction of the JSY, regardless of the indicator (Table 6.4, Panel B).

\section{Summary}

Findings present a mixed picture with respect to the effect of the JSY on the quality of the maternal health services received by women during pregnancy, delivery and the postpartum period. With regard to antenatal services, the introduction of the JSY was associated with improvements in the extent to which women received information on pregnancy-related complications and four or more services at antenatal visits. No change was observed in other indicators such as receiving information on birth preparedness, the importance of postpartum check-ups, newborn care or complications; and the nature of clientprovider interaction that is, whether the health care provider had enquired, during routine check-ups, about any complications that the woman may have experienced and reminded her about follow-up visits.

Findings were mixed with regard to the effect of the JSY on the quality of delivery services as well. A positive net effect was apparent in terms of such practices as discharging women from the facility at least 24 hours following delivery and allowing an escort to stay with them during delivery. However, no change was observed in other practices such as the extent to which the health care provider conducted all the essential examinations on admission for delivery, active management of the third stage of labour, not following harmful practices during labour and delivery, women's easy access to health care providers and the providers' behavior toward women delivering at the health facility, the availability of supplies at the health facility, and women's access to a respectful and clean health facility. Finally, the inception of the JSY did not bring about any change in the quality of postpartum care services received by women. 


\section{CHAPTER 7}

\section{Associations between JSY beneficiary status and women's experiences of maternal and newborn complications}

This chapter presents findings with regard to the associations between women's experiences of the JSY and the complications experienced by them during pregnancy, delivery and the postpartum period as well as those experienced by their newborns. We note that the information presented here is based on women's self-reports and should be interpreted with caution. As mentioned in Chapter 1, the analyses presented in this chapter draw on the unmatched sample of women who had and had not availed of JSY benefits for the most recent birth that is, in the one year preceding the interview (2,232 and 2,479 women, respectively). Percentages of outcome variables obtained for beneficiary and non-beneficiary groups were compared to assess the associations, and t-tests were conducted to test for significance. Additionally, we used regression analysis to control for potentially confounding factors.

\section{Associations between JSY beneficiary status and women's experiences of pregnancy-related complications}

Table 7.1 presents women's reports of severe complications experienced during pregnancy, labour and delivery, and the postpartum period. Severe complications of pregnancy included symptoms of preeclampsia after 20 weeks of gestation, defined as the experience of both blurred vision and severe headache or high blood pressure (if the woman had got her blood pressure checked); fits; vaginal bleeding after 20 weeks of gestation; high fever with severe chills or loss of consciousness; symptoms of jaundice, defined as the experience of both change in the colour of eyes to yellow and change in the colour of urine to dark yellow; and symptoms of severe anaemia, defined as the experience of all of the following symptoms namely, pale eyes, pallid face, pale palms, breathlessness following light work, and breathlessness on lying on one's back. Severe complications during labour and delivery were defined as labour lasting for more than 12 hours, fits during labour and abnormal presentation of the foetus. Severe complications during the postpartum period included bleeding that required the woman to change the cloth used to contain the blood every hour or more often; symptoms of sepsis, defined as the experience of high fever with foul-smelling discharge within 72 hours of delivery; and fits.

A comparison of the experiences of JSY beneficiaries and non-beneficiaries indicate that beneficiaries were slightly less likely than non-beneficiaries to report one or more severe complications during pregnancy, particularly in rural areas (Table 7.1, Panel A). However, no such differences were observed in terms of prevalence of reported complications during labour and delivery, and during the postpartum period, regardless of rural-urban residence. However, beneficiaries were slightly more likely than non-beneficiaries to have sought treatment (70\% versus 64\%); a similar 


\section{Table 7.1}

Associations between JSY beneficiary status and pregnancy-related complications: cross-sectional comparison of women's experiences during the most recent birth, according the residence

\begin{tabular}{|c|c|c|c|c|c|c|}
\hline \multirow[t]{2}{*}{$\begin{array}{l}\text { Pregnancy-related } \\
\text { complications }\end{array}$} & \multicolumn{2}{|c|}{$\begin{array}{c}\text { Combined } \\
\mathrm{N}=4,711 \\
\end{array}$} & \multicolumn{2}{|c|}{$\begin{array}{c}\text { Urban } \\
\mathrm{N}=2,354\end{array}$} & \multicolumn{2}{|c|}{$\begin{array}{c}\text { Rural } \\
\mathbf{N}=\mathbf{2 , 3 5 7}\end{array}$} \\
\hline & $\begin{array}{c}\text { Beneficiaries } \\
\mathrm{N}=\mathbf{2 , 2 3 2}\end{array}$ & $\begin{array}{c}\text { Non- } \\
\text { beneficiaries } \\
\mathbf{N}=2,479\end{array}$ & $\begin{array}{c}\text { Beneficiaries } \\
\mathbf{N}=1,170\end{array}$ & $\begin{array}{c}\text { Non- } \\
\text { beneficiaries } \\
\mathbf{N}=\mathbf{1 , 1 8 4}\end{array}$ & $\begin{array}{c}\text { Beneficiaries } \\
\mathrm{N}=1,062\end{array}$ & $\begin{array}{c}\text { Non- } \\
\text { beneficiaries } \\
\mathrm{N}=\mathbf{1 , 2 9 5}\end{array}$ \\
\hline
\end{tabular}

A. Bivariate results

One or more severe complications during pregnancy (\%)

One or more severe complications during labour and delivery (\%)

One or more severe complications during the postpartum period (\%)

Of those who experienced any complication, \% who sought treatment

\section{B. Logistic regression results ${ }^{(1)}$}

One or more severe complications during pregnancy
0.89

(0.79-1.01)

1.18

(0.88-1.59)

0.97

(0.81-1.17)

$1.33^{* *}$

$(1.09-1.63)$
1.18

(0.90-1.54)

1.45

(0.64-3.30)

1.53

(0.98-2.37)

1.32

$(0.82-2.12)$
$0.83^{*}$

(0.72-0.96)

1.06

(0.77-1.47)

0.83

(0.67-1.03)

$1.36^{* *}$

Note: ${ }^{\circledR}$ After controlling for age, education, religion, caste, household economic status, parity, rural-urban residence and study district; odds ratios greater than 1 indicate the extent to which JSY beneficiaries were more likely than non-beneficiaries to have experienced complications and to have sought treatment for these complications, and odds ratios less than 1 indicate the extent to which beneficiaries were less likely than non-beneficiaries to have experienced complications and to have sought treatment for these complications; values in parentheses indicate 95\% confidence interval. The analyses excludes 59 women who were awaiting the JSY cash benefit. Percentages indicated in the table are weighted; the number of respondents is unweighted. ${ }^{*} p \leqslant 0.05 ; \stackrel{*}{p} \leqslant 0.01$. 
pattern was observed in rural areas but not in urban areas. Multivariate analyses also suggest that differences between beneficiaries and nonbeneficiaries were narrow for the most part. Some exceptions are, however, notable. When controlled for potentially confounding factors, rural beneficiaries were again less likely than rural non-beneficiaries to report experiences of one or more complications during pregnancy (odds ratio of 0.83) (Table 7.1, Panel B). Moreover, of those who had suffered complications, beneficiaries were 1.3-1.4 times more likely than non-beneficiaries to have sought treatment for their condition.

\section{Associations between JSY beneficiary status and women's experiences of complications in the newborn}

Complications in newborns were assessed by asking women whether their newborn had experienced such conditions as absence of breathing, fast breathing, fever, stiffness of body, infection of the umbilical cord and diarrhoea in the first few weeks of birth.

\section{Table 7.2}

Associations between JSY beneficiary status and complications in the newborn: cross-sectional comparison of women's experiences during the most recent birth, according to residence

\begin{tabular}{|c|c|c|c|c|c|c|}
\hline \multirow[t]{2}{*}{ Newborn complications } & \multicolumn{2}{|c|}{$\begin{array}{l}\text { Combined } \\
\mathrm{N}=4,711\end{array}$} & \multicolumn{2}{|c|}{$\begin{array}{c}\text { Urban } \\
\mathbf{N}=2,354\end{array}$} & \multicolumn{2}{|c|}{$\begin{array}{c}\text { Rural } \\
\mathbf{N}=\mathbf{2 , 3 5 7}\end{array}$} \\
\hline & $\begin{array}{c}\text { Beneficiaries } \\
\mathbf{N}=\mathbf{2 , 2 3 2}\end{array}$ & $\begin{array}{c}\text { Non- } \\
\text { beneficiaries } \\
\mathbf{N}=\mathbf{2}, 479\end{array}$ & $\begin{array}{c}\text { Beneficiaries } \\
N=1,170\end{array}$ & $\begin{array}{c}\text { Non- } \\
\text { beneficiaries } \\
\mathbf{N}=\mathbf{1 , 1 8 4}\end{array}$ & $\begin{array}{c}\text { Beneficiaries } \\
\mathbf{N}=1,062\end{array}$ & $\begin{array}{c}\text { Non- } \\
\text { beneficiaries } \\
\mathbf{N}=\mathbf{1 , 2 9 5}\end{array}$ \\
\hline
\end{tabular}

\section{One or more complications experienced by newborns (\%)} 50.6 51.3 50.2 47.0 50.7

Among newborns who experienced complications, \% who were treated $88.9^{* *}$ 85.0 94.6 93.2 $86.9^{*}$ 83.1

\section{B. Logistic regression results}

One or more complications experienced by newborns

0.95

(0.84-1.07)

1.26

(0.98-1.63)
1.16

(0.91-1.49)

1.28

(0.61-2.67)
$0.87^{*}$

(0.76-1.00)

who experienced

complications, \% who were treated

Note: ${ }^{\circledR}$ After controlling for age, education, religion, caste, household economic status, parity, rural-urban residence and study district; odds ratios greater than 1 indicate the extent to which JSY beneficiaries were more likely than non-beneficiaries to report that their newborn had experienced complications and that they had sought treatment for these complications, and odds ratios less than 1 indicate the extent to which beneficiaries were less likely than non-beneficiaries to report that their newborn had experienced complications and that they had sought treatment for these complications; values in parentheses indicate 95\% confidence interval. Percentages indicated in the table are weighted; the number of respondents is unweighted. $\stackrel{*}{p} \leqslant 0.05 ;{ }^{* *} p \leqslant 0.01$. 
Findings, presented in Table 7.2 Panel A, show that differences by JSY beneficiary status were evident only for the rural sample, and that too, with respect to seeking treatment for the complication/s experienced; among mothers who reported that their newborn had experienced one or more complications, beneficiaries were slightly more likely than non-beneficiaries to have sought treatment.

Multivariate analyses, however, reveal a somewhat different picture. Findings show that in rural areas, beneficiaries were less likely than non-beneficiaries to report that their newborn had experienced any complication (odds of 0.87) (Table 7.2, Panel B). However, the differences between the two groups in terms of treatment-seeking were not statistically significant.
Summary

Findings show some differences between JSY

beneficiaries and non-beneficiaries in terms of the maternal and newborn complications experienced by women at the time of their most recent delivery and their treatment-seeking patterns, particularly in rural areas. In rural areas, beneficiaries were less likely than non-beneficiaries to report that they had experienced one or more complications during pregnancy and that their newborn had experienced any complication. They were, moreover, more likely to have sought treatment for pregnancy-related complications. Differences were insignificant in terms of complications experienced during labour and delivery, and the postpartum period. 


\section{CHAPTER 8}

\section{Summary and recommendations}

This chapter summarises the major findings of the study and highlights key programme

recommendations for improving the reach and effects of the JSY.

\section{Summary}

Awareness of the JSY, although universal, remains superficial

Findings highlight that awareness of the JSY is almost universal. Family members, friends and neighbours were the leading sources of information about the JSY, regardless of the place of residence. Although almost all women were aware of the JSY, fewer were correctly informed about the conditions for benefiting from the scheme, including the type of facility where they could deliver in order to qualify for JSY benefits or about its entitlements such as a specified amount of cash and the assistance of ASHAs. For example, not a single woman was aware that a woman delivering at home is eligible for JSY benefits if she is aged 19 and above, belongs to a BPL household and is having her first or second delivery. Moreover, just two-thirds of urban women and one-third of rural women knew that they were entitled to receive Rs.1,000 and Rs.1,400, respectively, and hardly any women-less than 1 percent-knew that they were entitled to receive support from ASHAs during pregnancy, delivery and the postpartum period.

\section{Awareness of the ASHA and schemes other than the JSY intended to promote safe motherhood remains limited}

Awareness of the ASHA was also limited; fewer than one-half of women had heard of the ASHA. Among those who reported awareness, the most commonly known responsibilities of the ASHA included facilitating three antenatal check-ups, counselling about institutional delivery and escorting women to a health facility for delivery.

Awareness of schemes other than the JSY intended to promote safe motherhood such as the 108 ambulance service and the special nutritional supplementation scheme was also limited; fewer than one-half of women were aware of the ambulance service, and just one-quarter were aware of the special nutritional supplementation scheme.

\section{The reach of the JSY remains limited and inequitable}

Although all women in the state were eligible, fewer than half had benefited from the JSY. Findings, moreover, suggest that the reach of the JSY remains inequitable; the most vulnerable were less likely than others to have availed of the JSY. Thus, women living in rural areas; those at high risk of maternal complications, that is, very young mothers or highparity mothers; and those belonging to socially and economically excluded groups, for example, Muslim 
women, illiterate women and poor women were less likely than others to have benefitted from the scheme.

Findings, moreover, indicate that most of the women who had received cash assistance had obtained the full amount. Almost one-half of beneficiaries had received the cash amount within a week of delivery, although one in seven had not received it until between one and three months of delivery. Further, for the majority of beneficiaries, the amount received was as much as or more than the expenses incurred during delivery. Fewer than one-tenth of women also reported paying a bribe or making an unauthorised payment to the ASHA or a health care provider in order to get their monetary entitlement.

Women who had not availed of the JSY cash assistance mentioned primarily such reasons as perceived poor quality of delivery services at public sector health facilities, the preference of women themselves or their family members for a home delivery, constraints faced at the family level to go to a health facility for delivery, lack of awareness of the scheme or of the importance of institutional deliveries and concerns about the administration of the scheme.

\section{The reach of the ASHA and schemes other than the JSY, intended to promote safe motherhood, is even more limited}

Few women obtained non-monetary entitlements, for example, support from ASHAs or benefits of other schemes such as the 108 ambulance service and the special nutritional supplementation scheme. Just onequarter of all women had received assistance from the ASHA during pregnancy and even fewer, during delivery and the postpartum period. Likewise, just 5 percent of women had used the 108 ambulance service to go to a health facility for delivery, and hardly any had received a voucher for special nutritional supplements in the form of five kilograms of ghee.

\section{Awareness of best practices in maternal and newborn care is greater among JSY beneficiaries than non-beneficiaries}

Findings underscore that JSY beneficiaries were better informed than non-beneficiaries about best practices related to the care of women during pregnancy, delivery and the postpartum period, as also to newborn care. For example, beneficiaries were more likely to report comprehensive awareness of antenatal care practices, awareness of at least one essential preparation to be made for a safe delivery and awareness of the importance of regular postpartum check-ups. They were also more likely to display comprehensive awareness of best practices related to the immediate care of the newborn, and awareness of best practices in breastfeeding and the immunisation schedule for infants. Additionally, compared to non-beneficiaries, they were better informed about the complications of pregnancy, delivery and the postpartum period. No differences were observed in their awareness of selected complications in the newborn.

Findings also highlight rural-urban differentials in the association between women's awareness of best practices in maternal and newborn care and JSY beneficiary status. Rural beneficiaries scored better than non-beneficiaries on almost all indicators of awareness; however, in urban areas, notable differences were observed with respect to just two indicators, namely, comprehensive awareness of correct breastfeeding practices and awareness of the immunisation schedule. These findings likely reflect the differential access to information that women in rural and urban areas have, with urban women 
having greater access to a wide array of sources of information than rural women, thus limiting the effect of the JSY on improving women's awareness of best practices in maternal and newborn care in urban areas.

\section{Awareness of best practices in maternal and newborn care among women, in general, remains poor}

Although the JSY has contributed to improving women's awareness of best practices in maternal and newborn care, we note that levels of awareness remain low. For example, of the JSY beneficiaries, just 30 percent reported comprehensive awareness of antenatal care practices (that is, awareness of the importance of having regular check-ups, three or more check-ups and the first check-up in the first trimester), 40 percent knew about birth preparedness and 35 percent knew about the importance of routine postpartum check-ups. Awareness of best practices in newborn care, likewise, remains limited even among JSY beneficiaries. For example, just 16 percent of the beneficiaries had comprehensive awareness of best practices in immediate newborn care (that is, awareness of the importance of wiping dry and wrapping and not bathing the newborn immediately after birth and not applying any substance on the cord stump), and just 25 percent had comprehensive awareness of correct breastfeeding practices (that is, awareness of the importance of immediate breastfeeding, feeding colostrum and exclusive breastfeeding for six months).

\section{Utilisation of maternal health services and} adoption of best practices in newborn care have increased with the introduction of the JSY, especially in rural areas

Findings underscore the contribution of the JSY to increasing the utilisation of maternal health services and the adoption of best practices in newborn care.

In the area of antenatal services, the JSY has promoted such practices as getting three or more antenatal check-ups, and iron and folic acid supplements, as confirmed by the positive net association observed in both cross-sectional and panel analyses. With regard to getting an antenatal check-up in the first trimester, findings were mixed; although a positive association was observed in the cross-sectional analysis, no significant net effect was observed when we compared women's experiences before and after the inception of the JSY. Hence, it is difficult to say convincingly that the JSY has contributed to enabling women to receive an early antenatal check-up.

As far as delivery services are concerned, the JSY has without doubt enhanced institutional deliveries and skilled attendance at birth.

Likewise, the JSY has contributed to increasing the utilisation of postpartum services by women, particularly in terms of receiving a check-up from health care personnel immediately after delivery, as confirmed by the positive net association observed in both cross-sectional and panel analyses. Findings also indicate a positive association between JSY experience and the acceptance of postpartum contraception.

Significant improvements in the adoption of best practices in newborn care were also evident. Among women who had given birth both prior to the introduction of the JSY and in the recent past, JSY beneficiaries were significantly more likely than nonbeneficiaries to have received comprehensive care for their newborn and to have followed best practices in immediate breastfeeding (that is, not feeding prelacteals, breastfeeding within an hour of delivery and feeding colostrum), as confirmed by the positive net association observed in cross-sectional and panel analyses. However, findings were mixed with regard 
to exclusive breastfeeding and full immunisation of infants; thus, although a positive net association between JSY experience and exclusive breastfeeding and full immunisation of infants was evident in cross-sectional analyses, no significant net effect was observed when we compared women's experiences before and after the introduction of the JSY. Hence, it is difficult to say convincingly that the JSY has contributed to promoting these practices. These findings suggest that the JSY may not be effective in influencing behaviours that require sustained efforts over long periods of time such as those involving prolonged breastfeeding and complying with the full immunisation schedule.

Findings, moreover, indicate a differential impact of the JSY programme in rural and urban areas. The JSY had a far more significant and consistent positive effect on the utilisation of maternal health services and the adoption of best practices in newborn care by rural than urban women. It has enabled rural women to obtain three or more antenatal check-ups, iron and folic acid supplements, an institutional delivery, skilled attendance at birth and postpartum check-ups from health care personnel immediately after delivery besides encouraging them to obtain comprehensive immediate care for their newborn, to follow best practices in immediate breastfeeding and exclusive breastfeeding of the infant for six months. In contrast, in urban areas, the contribution of the JSY was far more limited in that it enabled women to obtain an institutional delivery, skilled attendance at birth, and a postpartum check-up from health care personnel immediately after delivery. These urban-rural differences may reflect the differential access of rural and urban women to maternal and newborn health services, with urban women having greater access to a wide array of services than rural women, thus limiting the effects of the JSY on increasing women's utilisation of maternal health services and adoption of best practices in newborn care.

Low utilisation of maternal health services and limited adoption of best practices in newborn care, in general, remain a major concern

Notwithstanding the fact that the JSY has led to an increase in the utilisation of maternal health services and adoption of best practices in newborn care, the levels remain far from satisfactory. For example, only 59 percent of JSY beneficiaries had their first antenatal check-up in the first trimester and 79 percent had three or more antenatal checkups. Moreover, despite having delivered in a health facility, only 80 percent of beneficiary women had received a postpartum check-up within two days of delivery and only 20 percent had adopted postpartum contraception. The adoption of best practices in newborn care, similarly, remains limited even among beneficiaries; for example, only 29 percent had breastfed their newborn within an hour of delivery, 78 percent had fed colostrum and 56 percent reported that they did not give any prelacteal feeds to the newborn.

\section{The quality of maternal health services, by and large, remains unchanged and poor}

Findings present a mixed picture with respect to the effect of the JSY on the quality of maternal health services received by women during pregnancy, delivery and the postpartum period. With regard to antenatal services, subsequent to the introduction of the JSY, improvements were observed in the percentages of women who received information related to pregnancy-related complications and four or more services during antenatal visits. No change was observed in the other indicators such as percentages of women who received information on birth preparedness, the importance of postpartum 
check-ups, and newborn care or complications. Likewise, the nature of the health care provider's interactions with women-percentages of women reporting that the provider had asked them during routine check-ups whether they had experienced any complications, and reminded them about follow-up visits—remained unchanged.

Findings were mixed with regard to the effect of the JSY on the quality of delivery services as well. A positive net effect was apparent in terms of such practices as discharging women from the facility at least 24 hours following delivery and allowing an escort to stay with the woman during delivery. However, no change was observed in several other indicators, including the extent to which the recommended examinations were conducted by the service provider when women were admitted for delivery, active management of the third stage of labour, non-use of harmful delivery practices, women's easy access to health care providers and the providers' behaviour toward women delivering at the health facility, availability of supplies at the health facility, and women's access to a respectful and clean health facility. Finally, no change was evident in the quality of postpartum services received by women subsequent to the introduction of the JSY.

Above all, findings underscore that the quality of services received by women during pregnancy, delivery and the postpartum period remains unacceptably poor. For example even among JSY beneficiaries, few women had received, in the course of antenatal services, comprehensive information about complications that may occur during pregnancy as well as about birth preparedness. Despite clear guidelines for pregnancy care and the management of common obstetric complications by medical officers and ANMs (MOHFW, 2005), our study shows that evidence-based best practices in labour and delivery were rarely followed in the study settings. Such harmful practices as applying strong fundal pressure before delivery and the use of injections (most likely, oxytocin) to speed up delivery continue to characterise delivery care at the facility level. Limited access to medicines and other supplies as well as to a respectful and clean facility for delivery remain other major concerns.

\section{Maternal and newborn complications are slightly lower among JSY beneficiaries than non-beneficiaries, especially in rural areas}

Findings show some differences between JSY beneficiaries and non-beneficiaries in terms of experiences of maternal and newborn complications and treatment-seeking patterns, particularly in rural areas. Beneficiaries were less likely than nonbeneficiaries to report that they had experienced one or more complications during pregnancy and that their newborn had experienced one or more complications. They were, moreover, more likely to have sought treatment for pregnancy-related complications. Differences were insignificant in terms of complications experienced during labour and delivery, and the postpartum period.

\section{Recommendations}

The findings of our study reiterate the need for programmatic attention to ensure the reach of the JSY to the most vulnerable and to improve the quality of maternal and newborn health services. They suggest a number of priority areas for action.

Strengthen efforts to better inform women, their family and the community, in general, about the JSY and other schemes intended to promote safe motherhood

Findings that women's awareness of the JSY, although universal, remains superficial, and their 
awareness of the ASHA and other schemes for promoting safe motherhood remains limited, call for programmes to better inform women, their family and the community, in general, about the salient features of these schemes. Given that family members and members of the social network were the major sources of information, communitylevel campaigns highlighting women's entitlements under these schemes need to be initiated. At the same time, ASHAs and other health care providers entrusted with the responsibility of enabling women to take advantage of these schemes need to be oriented about the importance of imparting detailed information about these schemes to women and their family.

\section{Address the barriers faced by the most vulnerable in benefiting from the JSY}

Findings that the most vulnerable women-socioeconomically as well as in terms of being at risk of experiencing maternal complications-were less likely than others to have availed of the JSY, emphasise the need for targeted efforts to address the concerns that these groups have in accessing the scheme. As evident from the findings, moreover, programmes are needed that address women's concerns about the poor quality of services, their lack of awareness about their entitlements, their apprehensions about the administration of the JSY, and their cultural preferences and constraints.

\section{Make efforts to improve the administration of the JSY and other safe motherhood schemes}

Although the majority of women who had availed of JSY benefits were satisfied with the scheme, some concerns remain. For example, one in seven beneficiary women did not receive the cash benefit until between one and three months of delivery and one in seven women had to pay a bribe or make an unauthorised payment to obtain it. Likewise, just one-quarter or fewer women had been assisted by ASHAs during pregnancy, delivery and the postpartum period. Clearly, efforts to improve the administration of the JSY and other safe motherhood schemes are needed.

\section{Address barriers, including lack of in-depth awareness among women, to adopting best practices in maternal and newborn care}

Findings that the adoption of best practices in maternal and newborn care by women, in general, is far from satisfactory emphasise the need for efforts to better understand the barriers, other than systemic issues, that women and their family experience, and to devise innovative approaches that enable them to overcome these barriers. Findings indicate that limited awareness of best practices in maternal and newborn care in the study settings is a key barrier. Programmes are needed that raise awareness among women and their family members about the importance of ensuring comprehensive care during pregnancy, making delivery-related preparations, ensuring appropriate care during the postpartum period and adopting best practices in newborn care. These efforts must also raise women's awareness of the danger signs that may occur during pregnancy, delivery and the postpartum period and appropriate facilities where treatment can be sought. Other barriers are less well-studied and need to be better understood, for example, family and community attitudes to adopting new behaviours, women's ability to override the perceptions of other family members in order to adopt best practices, and lack of involvement of men in the health care of their spouse and newborn. 


\section{Improve the quality of services}

Findings underscore that perceived poor quality of services in public sector health facilities has deterred many women from accepting the benefits offered by the JSY. Findings, moreover, indicate that those who had availed of maternal health services continue to receive poor quality care, notwithstanding the fact that the introduction of the JSY has not compromised the quality of care. From the perspectives of increasing the uptake of government schemes intended to improve maternal and child health by women and of making motherhood safe for them, efforts are needed to improve the quality of maternal and newborn health services. Further, actions are needed that enable health care providers to render maternal health care services in friendly and non-threatening ways. Actions are also needed to mobilise communities to undertake social auditing to improve the quality of services provided, and to create among women and their family members a sense of entitlement to health care and other services.

In conclusion, while the JSY has contributed significantly to increasing the utilisation of maternal health services and the adoption of best practices in newborn care, efforts are needed now to improve the quality of care and access to maternal and newborn health care services for the most vulnerable groups of women, concerns that require programmatic attention as the demand for services is enhanced. 


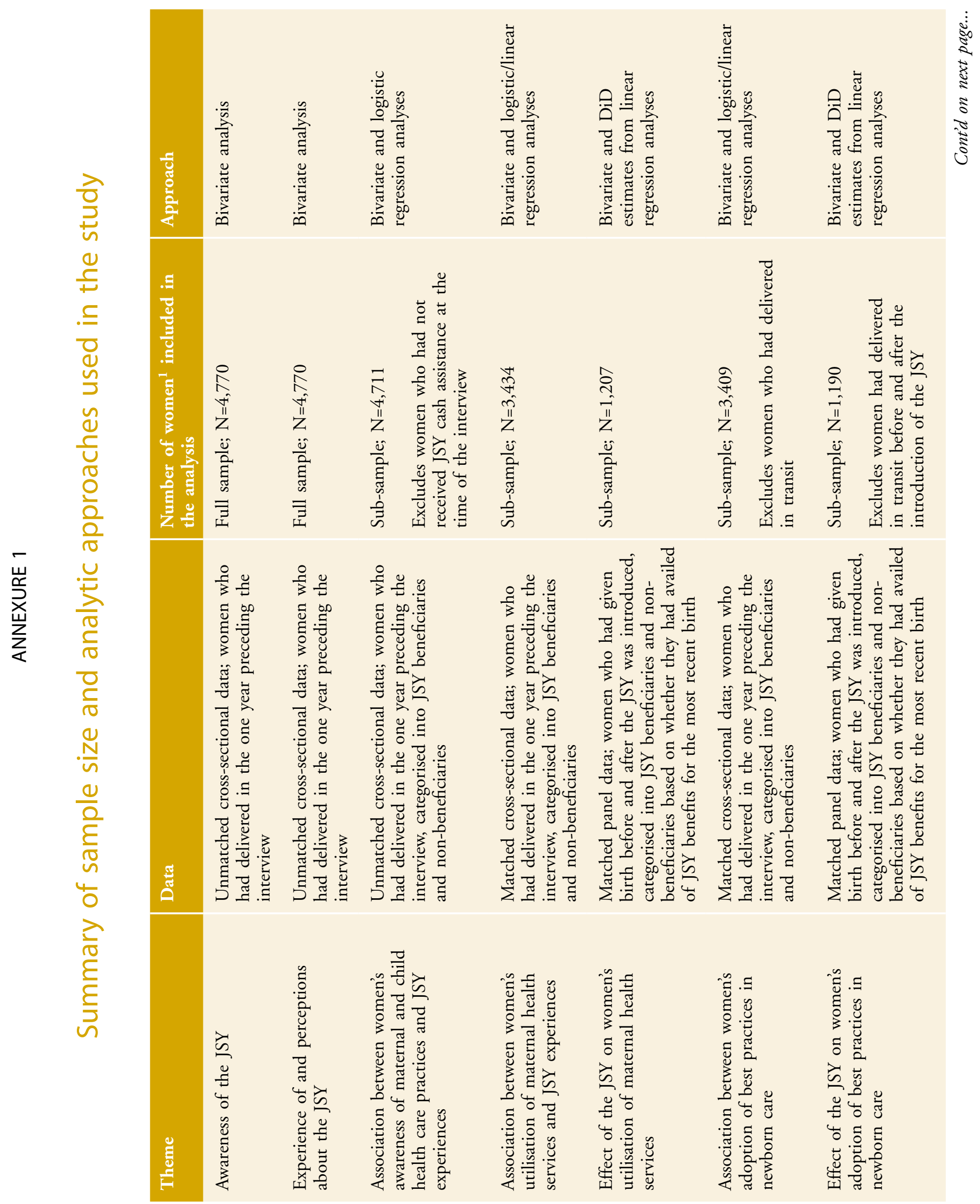




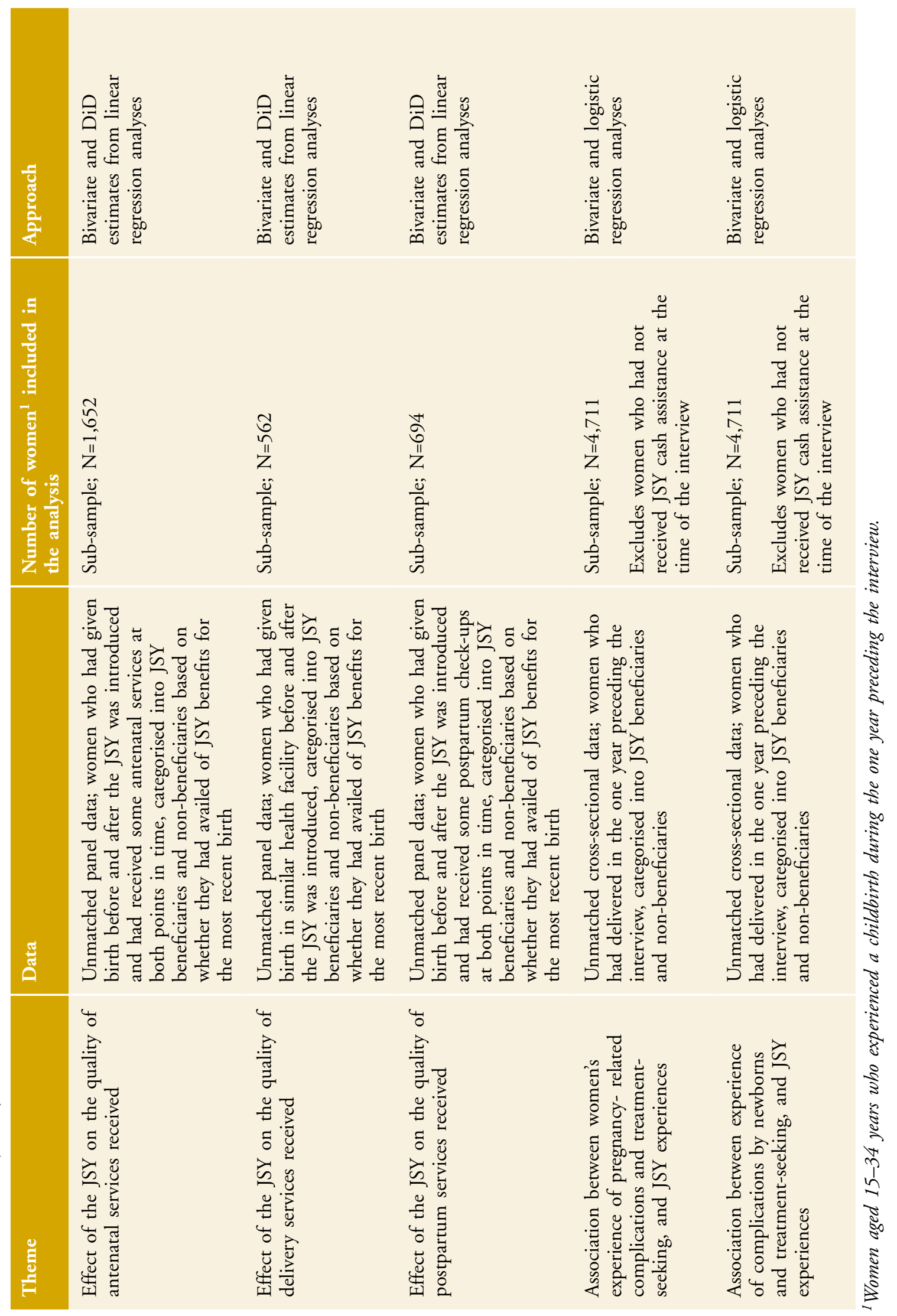




\section{ANNEXURE 2}

\section{Percentage distribution of the matched sample of JSY beneficiaries and non-beneficiaries by selected background characteristics}

\begin{tabular}{|c|c|c|}
\hline Characteristics & $\begin{array}{l}\text { Beneficiaries } \\
(\mathrm{N}=1718)\end{array}$ & $\begin{array}{c}\text { Non-beneficiaries } \\
(\mathbf{N}=1716)\end{array}$ \\
\hline \multicolumn{3}{|l|}{ Age } \\
\hline$<18$ & 2.0 & 2.8 \\
\hline $18-19$ & 12.4 & 11.8 \\
\hline $20-24$ & 50.2 & 49.3 \\
\hline $25-29$ & 25.8 & 27.7 \\
\hline $30-34$ & 9.6 & 8.4 \\
\hline \multicolumn{3}{|l|}{ Religion } \\
\hline Hindu & 82.6 & 82.3 \\
\hline Muslim & 16.5 & 16.4 \\
\hline Other $^{1}$ & 0.9 & 1.3 \\
\hline \multicolumn{3}{|l|}{ Caste } \\
\hline Scheduled castes & 26.6 & 25.9 \\
\hline Scheduled tribes & 7.8 & 8.2 \\
\hline Other backward castes & 46.3 & 45.7 \\
\hline General castes & 19.1 & 19.8 \\
\hline \multicolumn{3}{|l|}{ Education } \\
\hline None & 44.9 & 49.0 \\
\hline $1-7$ years & 29.0 & 27.8 \\
\hline $8-11$ years & 19.0 & 14.8 \\
\hline 12 and above & 7.0 & 8.4 \\
\hline \multicolumn{3}{|l|}{ Parity } \\
\hline 1 & 31.5 & 29.8 \\
\hline $2-3$ & 47.9 & 49.3 \\
\hline $4+$ & 20.6 & 20.9 \\
\hline \multicolumn{3}{|l|}{ Wealth quintile } \\
\hline First quintile & 17.1 & 18.9 \\
\hline Second quintile & 19.0 & 20.7 \\
\hline Third quintile & 21.5 & 19.1 \\
\hline Fourth quintile & 22.2 & 20.0 \\
\hline Fifth quintile & 20.2 & 21.3 \\
\hline Total & 100.0 & 100.0 \\
\hline
\end{tabular}

${ }^{1}$ Other includes Christians, Sikhs and Jains. 


\section{ANNEXURE 3}

\section{Calculation of the wealth index}

Household economic status was measured using a wealth index composed of household asset data on ownership of selected durable goods, including means of transportation, as well as data on access to a number of amenities. The wealth index was constructed by allocating the following scores to a household's reported assets or amenities:

Type of house: 4 for pucca; 2 for semi-pucca; 0 for kachcha

Agricultural land owned: 2 for yes; 0 for no

Access to toilet facility: 4 for own flush toilet; 2 for shared flush toilet; 1 for shared or pit toilet; 0 for no facility

Source of lighting: 2 for electricity; 1 for kerosene, gas, or oil; 0 for other source of lighting

Fuel for cooking: 2 for electricity, liquid petroleum gas, or biogas; 1 for coal/charcoal / kerosene/wood/crop residue/dung cakes; 0 for other fuels

Source of drinking water: 2 for own piped water, hand pump, well; 1 for public piped water, hand pump, well; 0 for other water sources

Ownership of house: 2 for yes; 0 for no

Ownership of different durable goods: 4 each for car or tractor; 3 each for motor cycle, scooter, land line/ mobile, refrigerator, colour television, computer/laptop; 2 each for bicycle, electric fan, radio/transistor, sewing machine, black and white television, water pump, animal drawn cart or thresher; 1 for a watch/clock

The index score, so constructed, ranged from 0 to 58. Households were then ranked according to the index score. This ranked sample was divided into quintiles, that is, five groups, each containing an equal number of households with the first quintile representing households of the lowest (poorest) wealth status and the fifth quintile representing households with the highest (wealthiest) status. 


\section{References}

Ashenfelter, O. 1978. "Estimating the Effect of Training Programs on Earnings," Review of Economics and Statistics 60(1):47-57.

Ashenfelter, O and D. Card. 1985. "Using the Longitudinal Structure of Earnings to Estimate the Effect of Training Programs," Reviews of Economics and Statistics 67(4):648-660.

Barnes, L. 2007. "Women's experience of childbirth in rural Jharkhand," Economic and Political Weekly 42(48):62-70.

Buckley, J and Y. Shang. 2003. "Estimating policy and program effects with observational data: the "differences-in-differences" estimator," Practical Assessment, Research \& Evaluation 8(24). Accessed on 10 June, 2011 at http://PAREonline.net/getvn.asp?v=8\&n=24.

Centre for Operations Research and Training (CORT). 2007a. Assessment of Janani Suraksha Yojana in Assam. Vadodara: CORT.

Centre for Operations Research and Training (CORT). 2007b. Assessment of Janani Suraksha Yojana in Himachal Pradesh. Vadodara: CORT.

Centre for Operations Research and Training (CORT). 2007c. Assessment of ASHA and Janani Suraksha Yojana in Madhya Pradesh. Vadodara: CORT; New Delhi: UNICEF.

Centre for Operations Research and Training (CORT). 2007d. Assessment of ASHA and Janani Suraksha Yojana in Orissa. Vadodara: CORT; New Delhi: UNICEF.

Centre for Operations Research and Training (CORT). 2007e. Assessment of ASHA and Janani Suraksha Yojana in Rajasthan. Vadodara: CORT; New Delhi: UNICEF.

Centre for Operations Research and Training (CORT). 2007f. Assessment of Janani Suraksha Yojana in West Bengal. Vadodara: CORT.

Centre for Operations Research and Training (CORT). 2008a. Assessment of Janani Avam Bal Suraksha Yojana in Bihar. Vadodara: CORT; New Delhi: UNICEF.

Centre for Operations Research and Training (CORT). 2008b. Assessment of Janani Suraksha Yojana in Uttar Pradesh. Vadodara: CORT; New Delhi: UNICEF.

D’Agostino, Jr. and B. Ralph. 1998. "Propensity score methods for bias reduction in the comparison of a treatment to a non-randomized control group," Statistics in Medicine, 17(19):2265-2281.

Das A., D. Rao and A. Hagopian. 2011. "India’s Janani Suraksha Yojana: further review needed," The Lancet 377:295-6.

Devadasan, N., M. A. Eliasa, D. John et al. 2008. "A conditional cash assistance programme for promoting institutional deliveries among the poor in India: process evaluation results," Studies in Health Services Organisation \& Policy, 24:257-74. 
International Institute for Population Sciences (IIPS) and Macro International. 2007. National Family Health Survey (NFHS-3), 2005-06: India, Volume 1. Mumbai: IIPS.

International Institute for Population Sciences (IIPS) and Macro International. 2008. National Family Health Survey (NFHS-3), India, 2005-06: Rajasthan. Mumbai: IIPS.

International Institute for Population Sciences (IIPS). 2010. District Level Household and Facility Survey (DLHS-3), 2007-08: India. Mumbai: IIPS.

Iyengar, S.D., K. Iyengar, J.C. Martines et al. 2008. "Childbirth practices in rural Rajasthan, India: implications for neonatal health and survival," Journal of Perinatology, 28:S23-S30.

Iyengar, S.D., K. Iyengar, V. Suhalka et al. 2009a. "Comparison of domiciliary and institutional delivery-care practices in rural Rajasthan, India," Journal of Health, Population and Nutrition, 27(2):303-312.

Iyengar, S.D., K. Iyengar and V. Gupta. 2009b. "Maternal health: a case study of Rajasthan," Journal of Health, Population and Nutrition, 27(2):271-292.

Lim, S.S., L. Dandona, J.A. Hoisington et al. 2010. "India's Janani Suraksha Yojana, a conditional cash transfer programme to increase births in health facilities: An impact evaluation," The Lancet, 375(9730):1939-2050.

Malini, S., R.M. Tripathi, P. Khattar et al. 2008. "A rapid appraisal on functioning of Janani Suraksha Yojana in South Orissa," Health and Population: Perspectives and Issues, 31(2):126-131.

Ministry of Health and Family Welfare (MOHFW). 2005. National Rural Health Mission (2005-2012). Mission Document. New Delhi: MOHFW, Government of India. Accessed on 22 September, 2010 at http://www. mohfw.nic.in/NRHM/Documents/Mission_Document.pdf.

Ministry of Health and Family Welfare (MOHFW). 2006. Janani Suraksha Yojana: Features and Frequently Asked Questions and Answers. New Delhi: MOHFW, Government of India. Accessed on 21 September, 2010 at http://mohfw.nic.in/dofwwebsite/JSY_features_FAQ_Nov_2006.htm.

Ministry of Health and Family Welfare (MOHFW). 2010. National Rural Health Mission, State Wise Progress as on 30.09.2010. New Delhi: MOHFW, Government of India.

Ministry of Health and Family Welfare (MOHFW). n.d. ASHA—Accredited Social Health Activist. New Delhi: MOHFW, Government of India. Accessed on 18 January, 2011 at http://www.mohfw.nic.in/NRHM/asha. htm\#abt.

Office of Registrar General, India. 2011. Special bulletin on maternal mortality in India 2007-09, Sample Registration System. New Delhi: Office of the Registrar General, India.

Office of the Registrar General and Census Commissioner, India. 2011. Provisional Population Totals, Paper 1 of 2011: Census of India 2011, Series I-India. New Delhi: Office of the Registrar General, India.

Robinson, N. 2007. Visiting Madhya Pradesh: A report on implementation of the National Maternity Benefit Scheme and JSY in four districts of Madhya Pradesh. New Delhi: Jawaharlal Nehru University and Bhopal, Vikas Samvad. Accessed on 21 September, 2010 at http://www.righttofoodindia.org/data/nmbs_mp.pdf.

Rosenbaum, P.R. and D.B. Rubin. 1985. "Constructing a Control Group Using Multivariate Matched Sampling Methods that Incorporate the Propensity Score,” The American Statistician, 39(1):33-38.

Santhya K.G. 2011. Implementing the JSY Programme: Perspectives and experiences of ASHA's in Rajasthan. (forthcoming report). 
Sharma, R. 2008. Janani Suraksha Yojana: A study of the implementation status in selected districts of Rajasthan. Udaipur: Population Research Centre, Mohanlal Sukhadia University.

United Nations Children Fund (UNICEF). 2010. Coverage Evaluation Survey 2009. UNICEF: New Delhi.

United Nations Population Fund. 2009. Concurrent Assessment of Janani Suraksha Yojana (JSY) Scheme in Selected States of India, 2008. Accessed on 22 September, 2010 at http://www.mohfw.nic.in/NRHM/Documents/ JSY_Study_UNFPA.pdf. 


\section{Members of the study team}

Investigators
Babita Bansod
Geeta Gupta
Priya Gupta
Ravi Jain
Binit Jha
Dlilshad Khan
Najma Khan
Nikhat Khan
Manisha Kaushal
Irshad Mohammad
Neha Panday
Prem Kanwar Rathore
Premlata Rathore
B.Srihari
Rituraj Solanki
Mukesh Vijay
Pushplata Yadav
Radha Yadav
Rukmani Yadav
Sheela Yadav

Geeta Gupta

Priya Gupta

1 Jain

Dlilshad Khan

Najma Khan

Nikhat Khan

Irshad Mohammad

Neha Panday

Premlata Rathore

\section{House Listers}

Rakesh Kumar

Hrishikesh Pandey

Brahama Nand Sarswati

Ashish Sharma

Madhvendra Singh Sinsinwar

Anil Kumar Sinha

Jai Shankar Tiwari

\section{Translation}

Monika Bindra

(Late) Rajesh Kumar

\section{Editor}

Jyoti Moodbidri

\section{Coding}

Komal Saxena

\section{Administration}

M A Jose 


\section{Authors}

K G Santhya, Associate II, Population Council, New Delhi

Shireen J Jejeebhoy, Senior Associate, Population Council, New Delhi

Rajib Acharya, Associate I, Population Council, New Delhi

A. J. Francis Zavier, Programme Officer, Population Council, New Delhi 


(1) Population Council

Zone 5-A, Ground Floor India Habitat Centre

Lodi Road

New Delhi 110 003, India 